Portland State University

PDXScholar

Fall 10-27-2016

\title{
Systems Thinking in the Forest Service: a Framework to Guide Practical Application for Social-Ecological Management in the Enterprise Program
}

Megan Kathleen Kmon

Portland State University

Follow this and additional works at: https://pdxscholar.library.pdx.edu/open_access_etds

Part of the Forest Management Commons

Let us know how access to this document benefits you.

\section{Recommended Citation}

Kmon, Megan Kathleen, "Systems Thinking in the Forest Service: a Framework to Guide Practical Application for Social-Ecological Management in the Enterprise Program" (2016). Dissertations and Theses. Paper 3312.

https://doi.org/10.15760/etd.3292

This Thesis is brought to you for free and open access. It has been accepted for inclusion in Dissertations and Theses by an authorized administrator of PDXScholar. Please contact us if we can make this document more accessible: pdxscholar@pdx.edu. 
Systems Thinking in the Forest Service:

A Framework to Guide Practical Application for Social-Ecological Management

in the Enterprise Program

by

Megan Kathleen Kmon

A thesis submitted in partial fulfillment of the requirements for the degree of

\author{
Master of Science \\ in \\ Systems Science
}

Thesis Committee:

Wayne Wakeland, Chair

Martin Reynolds

Joe Fusion

Portland State University

2016 


\begin{abstract}
The U.S. Forest Service (USFS) Enterprise Program (EP), which provides fee-forservice consulting services to the USFS, is interested in integrating systems thinking into its service offerings. Despite there being several excellent sources on the range and diversity of systems thinking, no single framework exists that thoroughly yet concisely outlines what systems thinking is along with its deep history, theoretical tenets, and soft and hard approaches. This thesis is an attempt to create such a framework, aimed specifically at practical application in a land management agency, through literature synthesis injected with original analysis. The usefulness of the framework is then tested using three case studies within the EP and the agency as a whole.

The framework highlights several important aspects of systems thinking, both generally and related specifically to social-ecological management. First, systems thinking is the transdisciplinary study of complex phenomena from a holistic, rather than reductionist, perspective. The world can be viewed as a massive set of embedded systems - elements with relations that lead to nonlinear behavior - making the role of the observer essential in identifying scales of interest and interactions amongst them. Second, the deep history of holistic thinking suggests that its modern scientific study could benefit from exploring the East's long-standing cultural and spiritual approaches to holism through cognitive unity and oneness with mankind and nature. Third, categorizations of systems approaches as "soft" versus "hard" are helpful but can distract us from the ultimate goal of systems thinking, which is to understand the various tools in the systems thinking toolbox so as to apply them critically and creatively to make a meaningful difference in the world. Fourth, I see the soft systems approaches as having a distinct systems thinking orientation and the hard systems
\end{abstract}


approaches as overlapping substantially with operations research, the close cousin of systems thinking. Fifth, I identify a spectrum of complexity, contending that systems thinking tends to be concerned with what I call subjectively and computationally complex systems, as well as complex adaptive systems, leaving simple systems for other approaches. Finally, I contend that it is the soft systems approaches and the two theoretical pillars of hierarchy theory and cooperation theory that will aid wicked social-ecological problem solving the most.

The framework is applied to three case studies. Examination of the EP reorganization using a hard systems approach revealed two critical high-level functions that were absent in the current structure, paving the way for new designs that could take those functions into account. Analysis of an initiative to increase citizen recreation on USFS lands showed that a systems approach had been improperly applied and how the application of a soft approach at the onset could have systematically framed the problem and offered unique normative insights for giving voice to relevant non-agency stakeholders as well as nature and future generations. And viewing the perennial problem of wildfire management through the lens of cooperation theory revealed how USFS leadership could take a more active role in promoting the long-term outlook, durable relationships, and reciprocal behaviors that are required for cooperative improvement to take place.

As environmental narratives worsen and the need for transitioning towards sustainable ways of living heightens, systems thinking offers ever-increasing value to resource managers for its ability to deal with the many perspectives and normative content that underlie wicked problems and to help to illuminate potential consequences of system interventions given the interplay of complex structural dynamics across space and time. 


\section{Acknowledgements}

To my mother and uncle, first and foremost. Mother, you have always been my biggest fan in every adventure of my life, and this was no exception. I couldn't have done this without your emotional support through all the ups and downs. Uncle Steven, it was you who introduced me to systems thinking! You were there by my side - from the first emails in Montana - with your consummate patience, wisdom, and mind-boggling intellect. You challenged me to think critically and ecologically. I will be forever grateful for your enormous contribution to my evolution as a "scholarly systems squirrel."

Uncle Paul, you were my entry point into nature as a child. It was those perfectly sweet experiences on your farm - that I will forever hold as some of my dearest - that planted the "environmental" seed in me.

Michael, you were my entry point into nature as an adult. I evolved, and came to want to do this work, because of experiences we had together in the outdoors, because of knowledge you imparted on me. You gave to me oh so many things, it makes me wonder how they could belong to me.

Wayne, I owe you a huge debt of gratitude for single-handedly keeping alive one of the few remaining systems programs. I can't imagine having studied environmental management through anything other than a systems lens, in any place other than Portland.

Stan, you have been my champion and gateway to realizing my professional dream. I will be eternally thankful you came into my life.

And finally, a huge thanks to my committee members for your expertise and time commitment. 


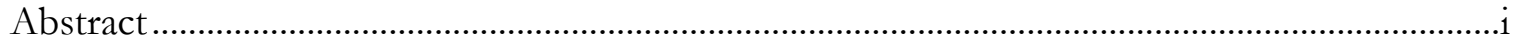

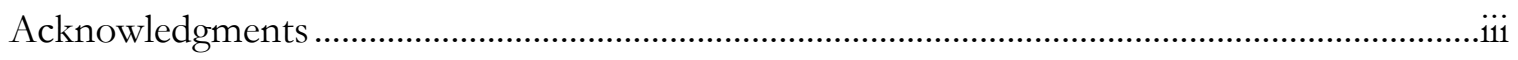

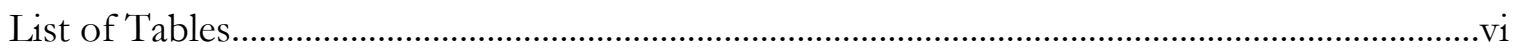

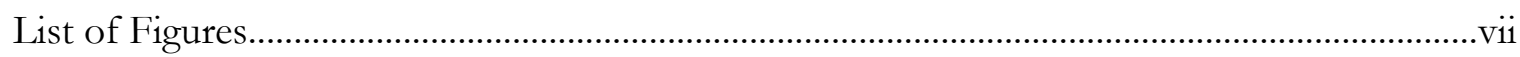

\section{Chapter 1}

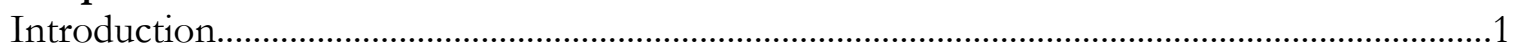

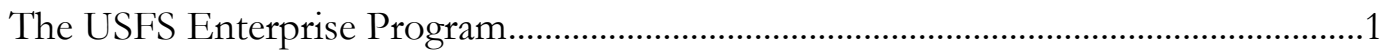

Wicked Environmental Problems and the Need for a New Approach ............................1

Research Gaps and Questions ..........................................................................................

\section{Chapter 2}

What is Systems Thinking?......

Important Relationships: Systems Thinking Vis-à-Vis Soft and Hard Approaches,

Operations Research, and Types of Complexity ...............................................................

Soft and Hard Approaches ...............................................................................

Systems Thinking and Operations Research ...................................................11

Types of Complexity ...........................................................................................13

A Systems Thinking Framework for Social-Ecological Management............................14

\section{Chapter 3}

The History of Holistic Thinking …….......................................................................................

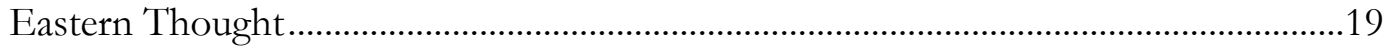

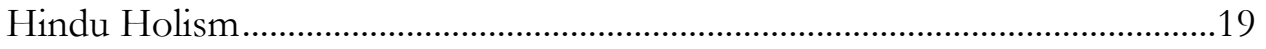

Chinese Holism ....................................................................................................22

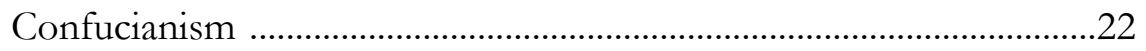

Taoism......................................................................................22

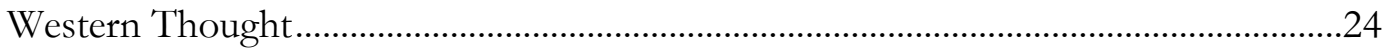

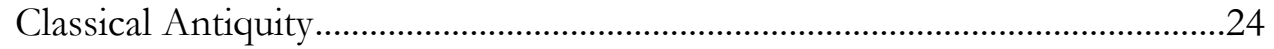

Late Antiquity and the Renaissance ………….....................................................25

Modern Holistic Pragmatism ............................................................................27

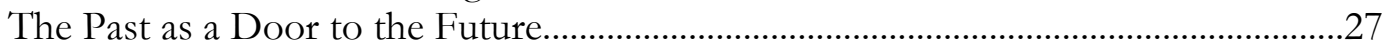

\section{Chapter 4}

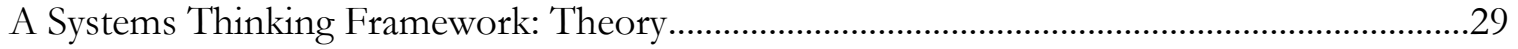

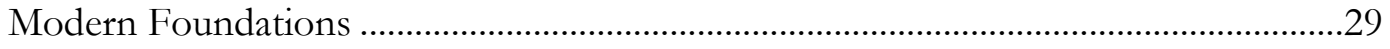

Founding Fathers and Primary Contributors ........................................................ 30

Systems Theories: Abstract Conceptualizations of Complexity.....................................33

Dissipative Structures, or the Thermodynamics of Open Systems...................34

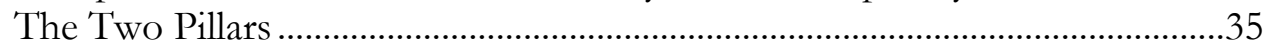

Hierarchy Theory ………………………….........................................36 


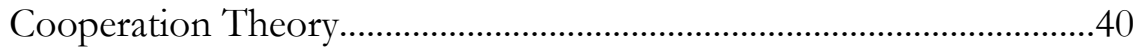

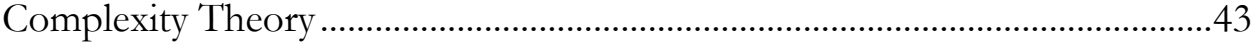

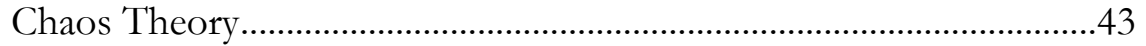

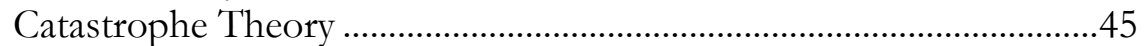

Punctuated Equilibrium ......................................................................4

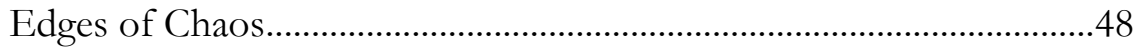

Complex Adaptive Systems .....................................................................49

Panarchy, or the Theory of Adaptive Change .....................................................50

\section{Chapter 5}

A Systems Thinking Framework: Soft Approaches....................................................................55

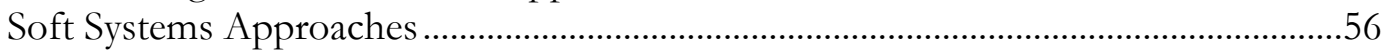

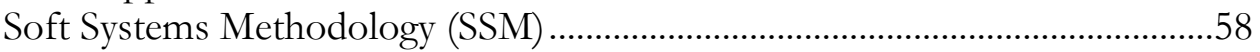

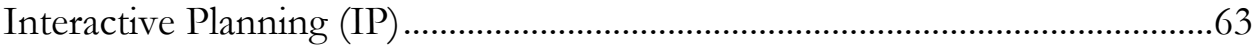

Strategic Assumption Surfacing and Testing (SAST) ........................................68

Strategic Options Development and Analysis (SODA)..................................72

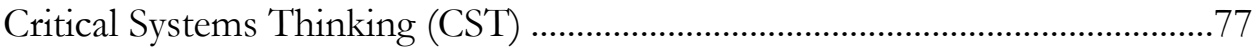

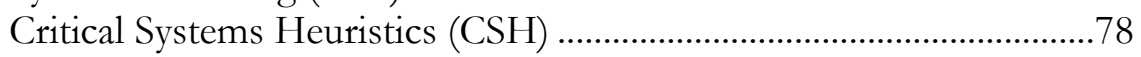

Total Systems Intervention (TSI) and Critical Systems

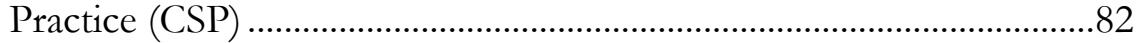

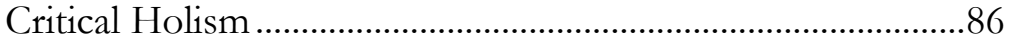

\section{Chapter 6}

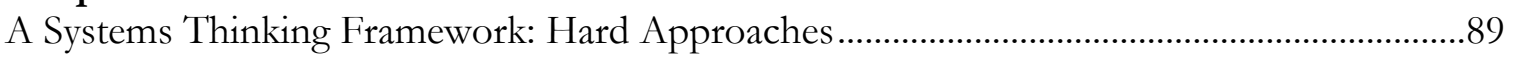

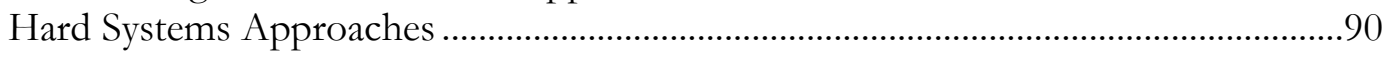

Viable System Model (VSM) ...............................................................................90

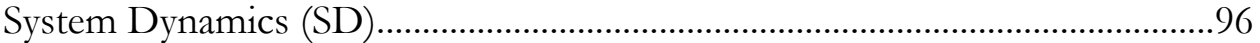

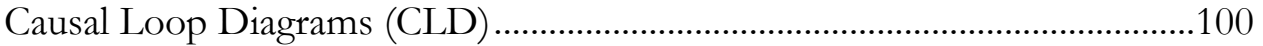

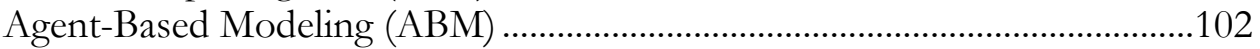

Artificial Intelligence (AI) Models................................................................105

\section{Chapter 7}

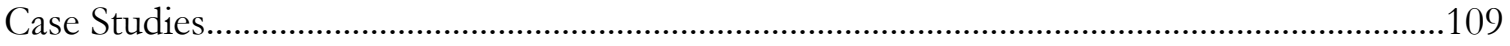

Case Study 1: The Enterprise Program Reorganization...................................................109

Case Study 2: The Recreation Diagnostic..................................................................118

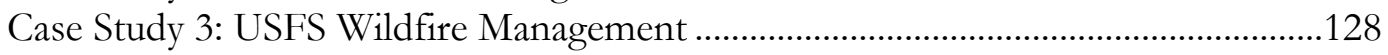

\section{Chapter 8}

Conclusion 


\section{List of Tables}

Table 2.4. Key features of the theoretical, soft, and hard "tools in the systems thinking toolbox".....

Table 4.2. Primary contributors to the systems programme with an eye towards legacy of impact and relevance to SES

Table 7.4. CSH ideal mapping of the role of recreation in the USFS......................................124 


\section{List of Figures}

Figure 2.1. Soft and hard systems thinking approaches .............................................................11

Figure 2.2. Relationship between systems thinking and OR ....................................................12

Figure 2.3. High level overview of the systems thinking framework .........................................15

Figure 4.1. Relationships between the systems theories relevant to SES ....................................30

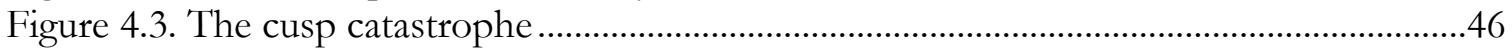

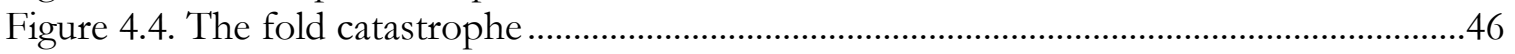

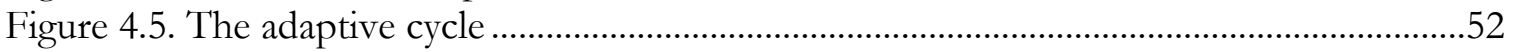

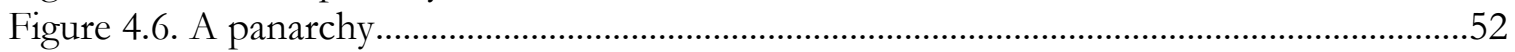

Figure 6.1. System dynamics diagram of population dynamics.................................................99

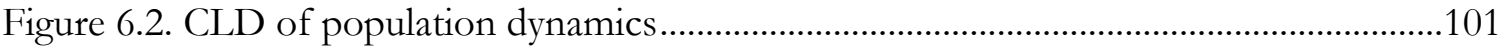

Figure 6.3. Example of an ABM user interface in NetLogo ......................................................103

Figure 7.1. A Viable System Model of the Enterprise Program ................................................117

Figure 7.2. Pseudo-CLD of the role of recreation in the USFS ................................................119

Figure 7.3. Translation of the pseudo-CLD into a linear progression of paradigms...............121 


\section{Chapter 1}

Introduction

"Sanity in the face of complexity requires that we find simple, basic fall-back positions that make sense of the world." - Garrett Hardin in Living Within Limits

\section{The USFS Enterprise Program}

Established in 1998, the USFS EP acts as an internal consulting arm to the Forest Service. A variety of functional units that operate like small businesses offer a wide range of services to the agency, from forest planning to culture and heritage. The program offers the USFS both expertise and workforce scalability, giving managers the flexibility to augment their staffs at a competitive price from "Enterprisers" with agency and resource management experience.

The EP arose out of the Clinton-Gore era National Partnership for Reinventing Government, which sought to make the federal government less expensive and more efficient. The Program receives no appropriated funding and instead operates on free-market principles using a fee-for-service, full-cost recovery business model.

The EP has grown significantly since its inception and is currently undergoing a reorganization to become more collaborative, adaptable, and efficient. As part of this evolution, there is interest amongst Enterprise leadership to develop and integrate systems thinking more fully into its work. Thus, the reorganization offers a ripe opportunity to explore what a rich systems thinking service offering might look like and how it could add value to the "new" Enterprise.

\section{Wicked Environmental Problems and the Need for a New Approach}

Present and future generations are faced with the enormously daunting task of transitioning towards more sustainable ways of living while at the same time confronting 
climate change, growing populations, mounting resource scarcities, diminishing returns on investments (particularly in the area of energy), degraded ecosystem functioning from pollution and biodiversity loss, and increasing demands for the "good life" - all on a highly interconnected global scale within a political-economic framework that places little to no value on the future. The USFS is caught squarely in the middle of this daunting transition with its vital role of stewarding roughly one-tenth of our nation's lands.

Environmental philosopher Bryan G. Norton (2015) aptly characterizes what this presents for environmental managers: a wicked mess, as it were. Contrasted against benign problems, which are clearly defined and have a single, correct solution, wicked problems are difficult to formulate and solve due to conflicting perspectives, uncertainty, and complexity of scale and interrelation (Rittel and Webber 1973). Systems thinker Russell Ackoff (1999) describes such a set of interacting problems as "messes" - overlapping problems that ought to be approached by understanding interactions amongst the parts rather than the parts themselves. Wicked problems share 10 central characteristics (Rittell and Webber 1973), which Norton lumps into four themes.

1. No definitive formulation

2. No stopping rule

3. Solutions are not true/false or good/bad

4. No immediate or ultimate test of a solution

5. Every solution counts significantly

6. No enumerable set of potential solutions; no well-described set of permissible operations

7. Uniqueness 
8. Symptom of another problem

9. Resolution is dependent upon the explanation

10. Planners are responsible for the consequences of their actions and must answer to a pluralist public

Norton's (2015) thematic clustering of these 10 characteristics:

1. Problems of problem formulation

2. Solutions can't be computed

3. Nonrepeatability (solutions are unique, not one-size-fits-all)

4. Temporal open-endedness (there is no discrete point in time in which the problem is fully resolved)

Further compounding the messiness of wicked problems in relation to sustainability is their inherent nonlinearity. Nonlinear phenomena can be distinguished from linear processes by their disproportionate cause-effect relationships in which the magnitude of the effect does not match the magnitude of the cause. Whereas previous approaches to managing the environment viewed it as static and unchanging - an external variable to be manipulated to bring about maximum desired human benefit - it is now widely recognized that the environment cannot be viewed in isolation from the human enterprise. Humans both impact and are impacted by the environment; the environment impacts and is impacted by humans, the most influential species on the planet. In this way, environmental management comes to be viewed more accurately as managing a greater social-ecological system (SES). The SES conception recognizes a coupling between society and the environments we inhabit, with the feedbacks involved in the coupling often resulting in nonlinear behavior. Not only are feedbacks present in SES, but so are other characteristics 
common to nonlinear phenomena: heterogeneity, emergence, thresholds, surprises, legacy effects, and time lags (Liu et al. 2007).

An emerging paradigm shift has been taking place in response to the recognition of the prevalence of wicked problems and nonlinearity in SES. Along with USFS EP leadership, academics and other resource managers are beginning to turn away from the reductionist-equilibrium paradigm towards more systems-oriented approaches (Folke et al. 2002, Liu et al. 2007, Liu et al. 2015, Norton 2015).

\section{Research Gaps \& Questions}

As the challenges of transitioning to sustainable ways of living demand systemsoriented ways to confront wicked social-ecological problems, and as systems thinking garners increasing attention from the environmental community, a comprehensive systems thinking framework geared towards practical application is much needed.

There are several excellent sources on the range and diversity of systems thinking, but no single framework comprehensively captures its long-standing evolution along with its breadth of theoretical and soft and hard approaches from a practitioner perspective. Reynolds and Holwell's (2010) book is an oustanding practitioner's guide, offering an orientation to systems thinking, several perspectives on its modern trajectory and major contributors, along with five systems approaches for interventions in real world problem situations. However, it lacks a pre-modern treatment of holism and is limited to only five systems approaches, two hard and three soft. Jackson's (2003) similarly expansive book covers most of the soft systems approaches, though it is lacking in its coverage of hard approaches and historical perspective. Williams and Imam's (2006) anthology of systems concepts for evaluation covers many, but not all, of the systems thinking approaches, and 
omits theoretical and deep historical coverage. Mobus and Kalton’s (2015) ambitious introductory baccalaureate-level textbook is sweeping in its range, yet lacks deep historical perspective, is highly abstract in its organization and topical coverage, and does not cover soft systems approaches. Flood and Carson (2010) offer yet another sweeping treatment of the systems field, but, like Mobus and Kalton's book, is cantankerous in its organization and gives only partial treatment to the soft and hard approaches. Kornstein's (1996) dissertation covers soft and hard systems thinking, but omits one of the soft approaches and shares a different conception of what is considered to be hard systems thinking. Cabrera et al. (2008, 2015) make helpful strides in making sense of systems thinking, particularly with their proposal of universal DSRP rules (distinctions, systems, relationships, perspective), but lack comprehensive theoretical and soft and hard coverage, as does Midgely and colleagues' (2013) framework for evaluating systemic problem structuring methods. Furtado and Sakowski (2015) stand out as producing the only synthesis of systems science theoretical underpinnings.

The goal of this thesis to produce a concise yet thorough framework, aimed specifically at practical application in a land management agency, that outlines the basics of systems thinking and its breadth of theoretical and soft and hard contributions while also paying homage to the centuries of holistic thinking upon which the modern scientific transdiscipline rests. The framework has both original and synthetic characteristics: it synthesizes key pieces of the aforementioned texts as well as other literature; draws upon my own organizational and topical conception of systems thinking; and traces the historical development of systems thinking and holism back to Eastern thought and Antiquity. The usefulness of the framework is then tested through a series of case studies in the USFS EP. 


\section{$\underline{\text { Research Questions }}$}

1. Given shortcomings in the systems thinking literature, what would a systems thinking framework for practical application within a land management agency look like?

2. How can such a framework be applied to specific wicked problem situations within the USFS and EP specifically?

Methods

1. Literature review and synthesis injected with original thought

2. Application of the framework to three USFS and EP problem situations:
a. The EP reorganization
b. A pilot initiative aimed at increasing citizen use of USFS lands
c. An analysis of wildfire management

\section{$\underline{\text { Hypotheses }}$}

1. The framework will be the first of its kind to synthesize, in one place, the basics of systems thinking, its deep history, SES-related systems theories, and soft and hard systems approaches, encapsulating the comprehensive breadth and diversity of systems thinking.

2. Application of the framework to real world USFS and EP wicked problem situations will demonstrate how the "tools in the systems thinking toolbox" can be used creatively and critically in varied contexts and challenges to bring about improvement. 


\section{Chapter 2}

\section{What Is Systems Thinking? \\ "Tat Tvam Asi- Thou art that." - Upanishads}

Systems thinking is, at its simplistic core, about holism and scale. Systems can be seen as consisting of elements that are related to each other, with the elements containing their own sub-systems and the system itself representing an element within a larger suprasystem. In this way, the world can be seen as a massive set of embedded systems. Systems thinking recognizes these interconnections and their consequences across different scales of space and time given the value-laden decisions we make or consider. Systems thinking is also about critical plurality. I suggest that there is no prescriptive formula to follow if one wishes to think in systems. Systems thinking offers a rich, diverse toolbox of theory and soft and hard approaches that can be applied in a number of different ways depending on a particular problem situation. It is up to us to be critical and creative about how we draw from the plurality of tools and apply them.

I suggest that systems thinking can be broadly characterized as possessing the following attributes:

- Holism. The study of systems is the study of integrated wholes. Systemsness recognizes that microscopic (local) interactions amongst parts can give rise to macroscopic phenomena that cannot always be explained by the nature of the parts themselves. While systems thinking does not deny the usefulness of Cartesian reductionism and the extraordinary scientific gains the paradigm has brought since the Scientific Revolution, it is a reaction against the idea that it is only through reductionism that science can advance. 
- Hierarchical scalarity. The world can be viewed as a massive set of embedded systems, or systems within systems within systems, whose boundaries cross with other systems across various scales of space and time. It is this hierarchical, cross-scalar nature of systems that makes understanding and intervening in them so elusive.

- Nonlinearity. The interconnected, cross-scalar nature of systems usually involves feedbacks, a circularity of compounding consequences amongst elements in a system that results in disproportionate cause-effect relationships, such as exponential growth, exponential decline, goal-seeking behavior, oscillation, chaotic dynamics, and catastrophic dynamics.

- Human construction. Conceptions of systems are human attempts to develop mental models that make sense of the complexities of the world. They represent our perceptions of a particular phenomena rather than an objective system that exists “out there.” We develop mental models of systems within the context of specific problem situations.

- Change-orientation. In practical application, systems thinking is employed in wicked problem situations for the sole intent of bringing about change and improvement.

- Transdisciplinarity. Through its exploration of holism, systems thinking seeks to explain phenomena that occur across all scientific disciplines and walks of life. Hence, systems thinking is not simply interdisciplinary (working across disciplines) - it can transcend them. 


\section{Important Relationships: Systems Thinking Vis-à-Vis Soft and Hard Approaches, Operations Research, and Types of Complexity}

\section{$\underline{\text { Soft and Hard Approaches }}$}

Historically, different approaches to systems thinking have been categorized as "soft" and "hard." A new "critical" category has also recently been suggested. Debates about such categorizations have been ongoing for decades and still remain contentious. Here, I propose that, while the soft-hard distinction is indeed useful and can be a helpful starting point for making sense of the many systems thinking tools - particularly for people new to systems thinking - we should caution against allowing such distinctions from distracting us from understanding all the systems tools and how they can be used.

Recognizing similarities and differences between the systems thinking approaches is extremely helpful from both an application and an organization standpoint. There are major differences between, say, Soft Systems Methodology and System Dynamics - understanding these differences can help guide practitioners towards general types of tools that are most well suited for their needs. Such general categories of approaches are also helpful in organizing frameworks such as this, as they give some semblance of structure to what would otherwise be one large heap of tools. This is particularly valuable in orienting people who are not already familiar with systems thinking. However, the ways in which we label or categorize the spectrum of "tools in the toolbox" can distract us from the ultimate goal of systems thinking, which is to understand all the tools and how they can be used creatively and critically - including using both soft and hard approaches together in complementary ways - to make a meaningful difference in the world. While important, discussions about which systems approaches are soft and which are hard can quickly become derailing, thus, I caution against allowing such dialogues from occupying the central focus of our efforts. 
With this in mind, I suggest a single, basic criterion for differentiating between the many systems approaches: soft systems approaches tend to deal with the numerous "soft" dimensions of messy problems (e.g. what are the various perspectives that shape a problem?, how should those perspectives be included and assessed?, how is the design of the system (i.e. elements and their interrelations) shaped by varying perspectives?, and how are interventions identified and assessed within this formulation of the system?), while hard systems approaches tend to make concrete, through mathematical exactness, the elements involved in a system, their interrelations, and the resulting system behavior. As such, soft approaches tend to be qualitative in nature while hard approaches tend to be quantitative. Both sets of approaches also include some tools that are more methodological in nature and other tools that more closely resemble a method. Methodologies are general research strategies or design processes that specify a theoretical underpinning, phases for conducting research, and techniques or methods for carrying it out, whereas methods are instruments or tools that define specific modes of data collection and arriving at a result. That being said, there is strong overlap between some of the soft and hard approaches. Specifically, the Viable System Model (VSM) and Causal Loop Diagrams (CLD) strongly share both soft and hard qualities. While I identify them as such in the figure below, I later include them in the chapter on hard systems approaches for the sake of ease and for the reasons provided therein related to their dominant characteristics. 


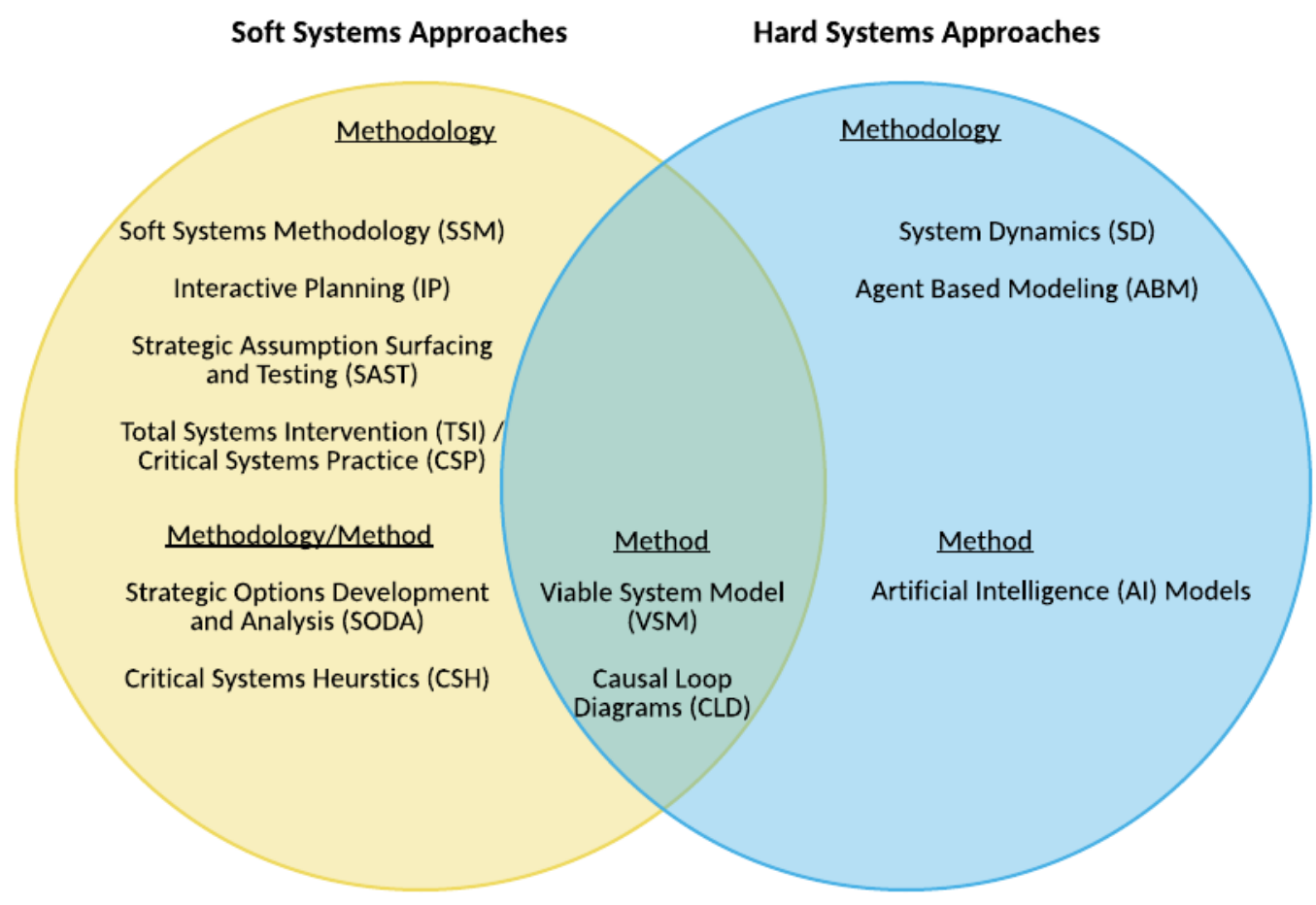

Figure 2.1. Soft and hard systems thinking approaches

\section{Systems Thinking and Operations Research}

Systems thinking is related to operations research (OR), systems analysis (SA), and systems engineering (SE) (Jackson 2003). All four were born out of the logistical and resource management problems of World War II, but OR, SA, and SE (hereafter referred to as simply OR) evolved divergently from the systems programme to embody several shared characteristics: 1) the application of science to real world, complex problems via the conduit of a customer, whether it be the military, government, or a large organization, 2) the near exclusive use of mathematically based models to serve as a laboratory device, and, most importantly, 3) a reliance on clearly defined goals and objectives against which optimal solutions are sought (Flood and Carson 2010, Jackson 2003). This characterization leads some scholars and practitioners to identify OR synonymously with systems thinking, others 
to squarely differentiate between the two, and still others to lump OR with hard systems thinking (Jackson 2003, Reynolds and Holwell 2010) while relegating all "soft" matters to soft systems thinking.

I agree with the latter conception that views soft systems approaches as uniquely associated with systems thinking and hard systems approaches as overlapping substantially with OR. Though both approaches can act in service of a client, they divert sharply when weighed against the remaining two characteristics of OR. Soft systems approaches were born precisely out of a reaction against the limitations of OR, which was not equipped to deal with the many "soft" dimensions of wicked problems, e.g. how to reconcile multiple perspectives as well as the normative, value-laden aspects of problem situations. The very nature of this work stands in contrast to the clear-cut objectives and optimization that define OR. Hard systems approaches, on the other hand, tend to align very much with these aspects.

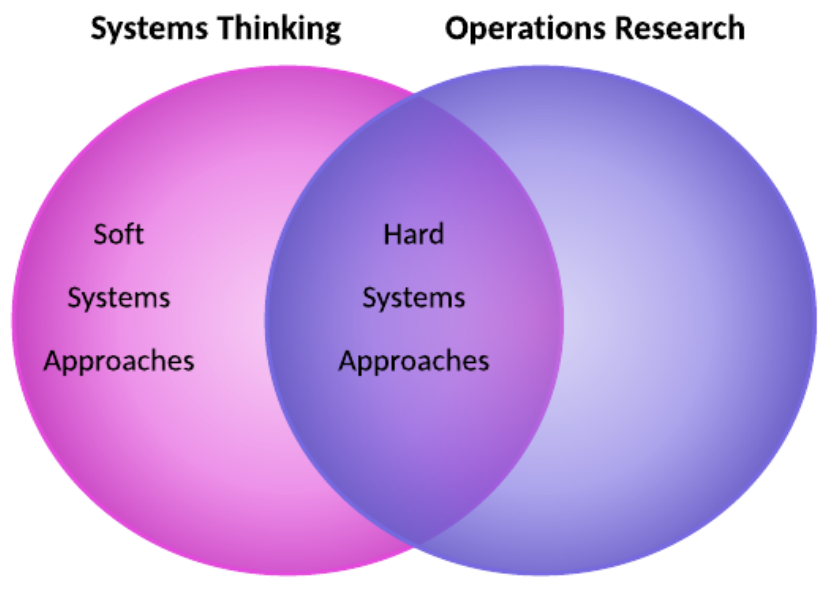

Figure 2.2. Relationship between systems thinking and OR 


\section{Types of Complexity}

The relationship between systems thinking and OR surfaces important distinctions amongst the various types of complex phenomena. While admittedly the degree of a system's complexity lies to a certain extent in the eye of the observer, I set forth that, as a helpful but malleable starting point, the systems universe can nonetheless be seen as generally containing simple systems, complex systems, and complex adaptive systems. A chair, for example, can be viewed, relatively, as a simple system. It contains elements (parts) that are related in such a way as to generate something greater than the sum of the parts - a chair. Generally speaking, however, there is nothing quite confounding or complicated about the relationships between these elements. Pollution in a waterbody or the composition and management of a forest stand, on the other hand, can be thought of as complex systems. Both contain many elements that are related in quite complex ways. Organizations are another type of complex system. The difference between the polluted waterbody and the organization can be described loosely in terms of what I call computational versus subjective complexity. Computationally complex systems can be modeled mathematically in a computer model or simulation, lending, possibly, to various types of optimization (that is, one particular variable in an objective function can be selected and the system can be optimized in favor of maximizing or minimizing that variable). Subjectively complex systems, on the other hand, are difficult to characterize mathematically because of the many subjective ways in which the system can be viewed and since murky relationships between people and entities can often defy mathematical characterization. Finally, complex adaptive systems are complex systems that have both emergent and evolutionary components. That is, larger patterns emerge out of the interplay between localized interactions and evolutionary 
processes. Living systems and the biosphere are prime examples. I suggest that systems thinking tends to be concerned with complex systems and complex adaptive systems, leaving simple systems for other approaches.

\section{A Systems Thinking Framework for Social-Ecological Management}

Having discussed my perspective on three important relational aspects of systems thinking, we can now turn to the framework itself. Viewing a framework as the basic structure of a thing, I offer a systems thinking framework shaped by five areas:

- The general attributes of systems thinking

- The deep history of systems, or holistic, thinking, which serves as the developmental basis upon which the modern transdiscipline rests and which can inform current areas of research

- SES-related systems theories, which serve primarily as abstract conceptualizations of complex phenomena

- The soft systems approaches

- The hard systems approaches

As illustrated in Figure 2.3, the attributes of systems thinking along with its deep history comprise what I call the foundation of systems thinking, with its SES-related theories and soft and hard approaches constituting the many "tools in the systems thinking toolbox" that allow us to apply systems thinking. I offer no prescriptive way in which the framework should be used, instead emphasizing creativity and criticality in application. 


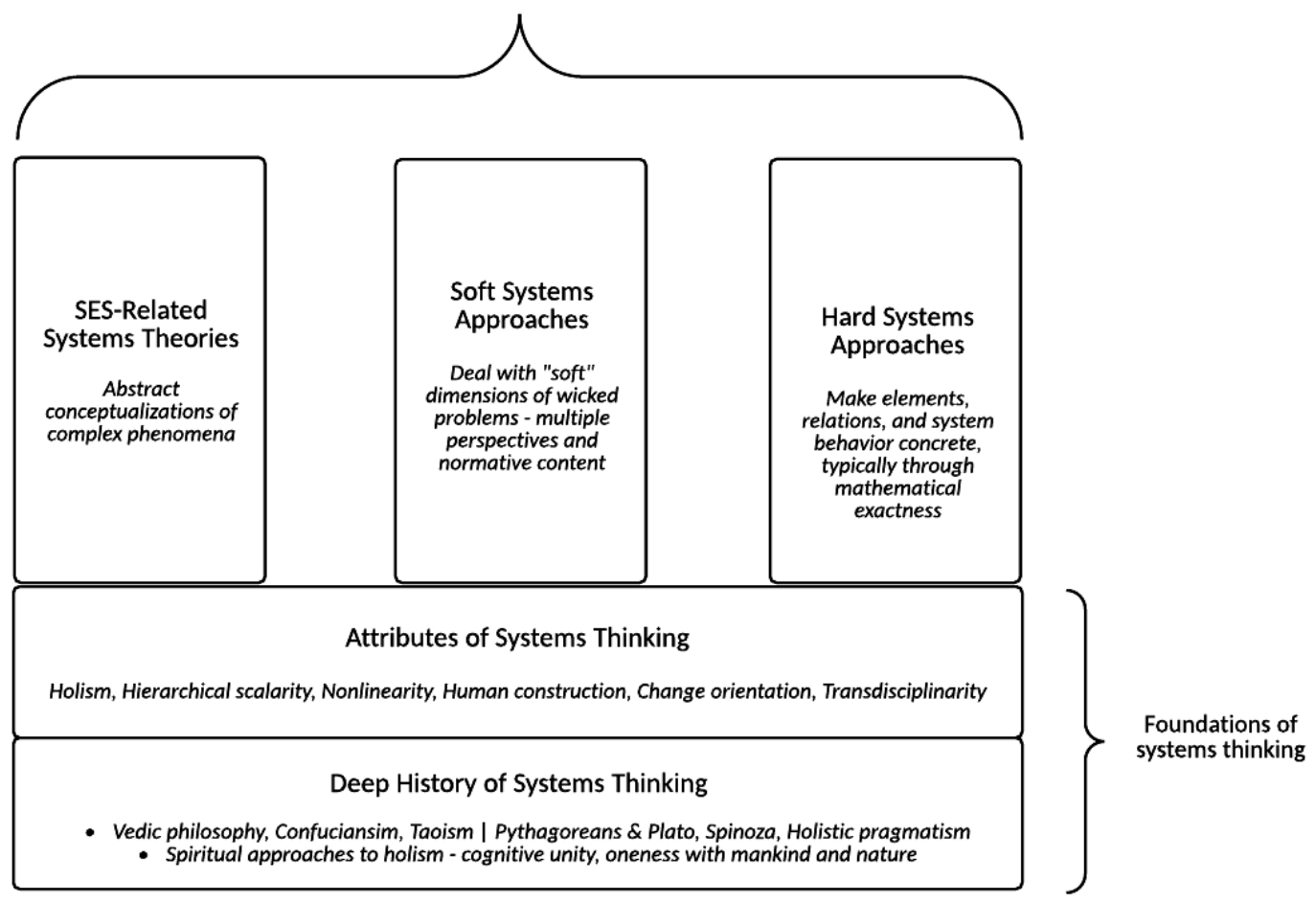

Figure 2.3. High level overview of the systems thinking framework

The table below expands upon this high-level illustration of the framework by capturing key features and uses of its SES-related theories and soft and hard approaches.

\begin{tabular}{|c|c|}
\hline Theory & Basic Premises and Implications \\
\hline $\begin{array}{l}\text { Dissipative Structures / } \\
\text { Thermodynamics of } \\
\text { Open Systems }\end{array}$ & $\begin{array}{l}\text { - Open systems seem to defy the } 2^{\text {nd }} \text { Law of Thermodynamics by minimizing } \\
\text { rather than maximizing entropy (i.e. they don't reach static equilibrium) } \\
\text { - The } 2^{\text {nd }} \text { Law rewritten - open systems maintain dynamic equilibrium } \\
\text { through entropy fluxes with their environments by forming self-organized } \\
\text { hierarchical structures that dissipate excess energy }\end{array}$ \\
\hline Hierarchy Theory & $\begin{array}{l}\text { - Most complex systems are hierarchies: small, fast-changing systems } \\
\text { embedded within larger, slow-moving systems } \\
\text { - High level constraint, which can change, is crucial for system integrity } \\
\text { - It is important to be explicit about which hierarchical levels will be impacted } \\
\text { in which ways by our actions }\end{array}$ \\
\hline Cooperation Theory & $\begin{array}{l}\text { - The extent to which we cooperate is dependent upon the temporal scale } \\
\text { (long or short-term) we employ } \\
\text { - Persistent, face-to-face interactions are critical for cooperation to emerge } \\
\text { - There is no single best strategy for cooperation; a good strategy is } \\
\text { responsive, nice, reciprocal, and looks to the distant future }\end{array}$ \\
\hline Chaos Theory & $\begin{array}{l}\text { - Many phenomena that were previously thought to be stochastic (random) } \\
\text { are actually chaotic }\end{array}$ \\
\hline
\end{tabular}




\begin{tabular}{|c|c|}
\hline & $\begin{array}{l}\text { - Chaotic phenomena are deterministic but not predictable } \\
\text { - Chaotic dynamics are pervasive in SES } \\
\text { - Buffers/resilience are good ways to accommodate the unpredictability of } \\
\text { chaos }\end{array}$ \\
\hline Catastrophe Theory & $\begin{array}{l}\text { - Purports to describe all discontinuously changing phenomena } \\
\text { - The common fold and cusp catastrophes describe sudden, discontinuous } \\
\text { jumps between two different system states } \\
\text { - Catastrophic regime shifts - some undesirable and irreversible - can happen } \\
\text { in SES } \\
\text { - Buffers/resilience are good ways to prevent such regime shifts }\end{array}$ \\
\hline $\begin{array}{l}\text { Punctuated } \\
\text { Equilibrium }\end{array}$ & $\begin{array}{l}\text { - Change is often rapid and episodic rather than slow and incremental } \\
\text { - Resilience is key to coping with episodic change, which is inevitable }\end{array}$ \\
\hline Edges of Chaos & $\begin{array}{l}\text { - The transition phase between the extremes of order and chaos is where } \\
\text { maximum adaptability and computational power are thought to lie } \\
\text { - This sweet spot could be important to unlocking potential and development }\end{array}$ \\
\hline $\begin{array}{l}\text { Complex Adaptive } \\
\text { Systems (CAS) }\end{array}$ & $\begin{array}{l}\text { - Macroscopic patterns emerge out of the interplay between microscopic } \\
\text { interactions and evolutionary processes } \\
\text { - Still a nascent theory } \\
\text { - SES are CAS }\end{array}$ \\
\hline $\begin{array}{l}\text { Panarchy / Theory of } \\
\text { Adaptive Change }\end{array}$ & $\begin{array}{l}\text { - Ecosystems are more accurately viewed as nested adaptively changing } \\
\text { - Pystems (a panarchy) rather than simply resilient } \\
\text { levels } \\
\text { - Can be used as a metaphor or tested empirically } \\
\text { - Has profound implications for catastrophic change and SES management }\end{array}$ \\
\hline $\begin{array}{l}\text { Soft Systems } \\
\text { Approach }\end{array}$ & Core Ideas and Broad Applications \\
\hline $\begin{array}{l}\text { Soft Systems } \\
\text { Methodology (SSM) }\end{array}$ & $\begin{array}{l}\text { Core Ideas } \\
\text { - Uses rich pictures to formulate the problem and explicate perspectives on } \\
\text { improvement } \\
\text { - Organizations don't make rational decisions - they navigate a host of soft } \\
\text { issues } \\
\text { Broad Applications } \\
\text { - Problem formulation } \\
\text { - Identifying possible interventions and their implications by analyzing } \\
\text { multiple perspectives }\end{array}$ \\
\hline $\begin{array}{l}\text { Interacting Planning } \\
\text { (IP) }\end{array}$ & $\begin{array}{l}\text { Core Ideas } \\
\text { - Identifies an ideal state, then works to get there by closing the gaps between } \\
\text { the current state and the ideal } \\
\text { - Objectivity is value-laden and should be derived from many perspectives } \\
\text { Broad Applications } \\
\text { - Problem formulation } \\
\text { - Identifying an ideal end state and how to get there }\end{array}$ \\
\hline $\begin{array}{l}\text { Strategic Assumption } \\
\text { Surfacing and Testing } \\
\text { (SAST) }\end{array}$ & $\begin{array}{l}\text { Core Ideas } \\
\text { - Surfaces various assumptions about a problem and dialectically works } \\
\text { through them } \\
\text { - Problem formulation is just as important as problem solving } \\
\text { Broad Applications } \\
\text { - Problem formulation }\end{array}$ \\
\hline $\begin{array}{l}\text { Strategic Options } \\
\text { Development and } \\
\text { Analysis (SODA) }\end{array}$ & $\begin{array}{l}\text { Core Ideas } \\
\text { - Aggregates individual mental models into a collective model that is used to } \\
\text { identify options for improvement } \\
\text { - Cognitive mapping } \\
\text { Broad Applications } \\
\text { - Problem formulation, identifying interventions, developing strategies, }\end{array}$ \\
\hline
\end{tabular}




\begin{tabular}{|c|c|}
\hline & facilitating negotiations \\
\hline $\begin{array}{l}\text { Critical Systems } \\
\text { Heuristics (CSH) }\end{array}$ & $\begin{array}{l}\text { Core Ideas } \\
\text { Boundary critique: identifies perceptions of values, facts, and system } \\
\text { boundaries - and their interrelated implications - through a series of } 12 \\
\text { questions } \\
\text { - Two-dimensional (normative-instrumental) rationality } \\
\text { Broad Applications } \\
\text { - Stakeholder identification, problem formulation, identifying and evaluating } \\
\text { interventions, ethical implications }\end{array}$ \\
\hline $\begin{array}{l}\text { Total Systems } \\
\text { Intervention (TSI) / } \\
\text { Critical Systems } \\
\text { Practice (CSP) }\end{array}$ & $\begin{array}{l}\text { Core Ideas } \\
\text { - A meta-framework for methodology choice selection } \\
\text { - Methodological pluralism and complementarism } \\
\text { Bethodology selection }\end{array}$ \\
\hline $\begin{array}{l}\text { Hard Systems } \\
\text { Approach }\end{array}$ & Core Ideas and Broad Applications \\
\hline $\begin{array}{l}\text { Viable System Model } \\
\text { (VSM) }\end{array}$ & $\begin{array}{l}\text { Core Ideas } \\
\text { - Models a system's } 5 \text { sub-systems and its environment to assess its viability, } \\
\text { or ability to adapt } \\
\text { - Cybernetics and requisite variety } \\
\text { Broad Applications } \\
\text { - Top-down system design } \\
\text { - Interventions based on system design }\end{array}$ \\
\hline $\begin{array}{l}\text { Causal Loop Diagrams } \\
\text { (CLD) }\end{array}$ & $\begin{array}{l}\text { Core Ideas } \\
\text { - Shows causal connections between elements in a system and the resulting } \\
\text { feedbacks } \\
\text { Broad Applications } \\
\text { - Explicating individual and shared mental models of a system } \\
\text { - Top-down system design } \\
\text { Interventions based on system design }\end{array}$ \\
\hline System Dynamics (SD) & $\begin{array}{l}\text { Core Ideas } \\
\text { - Shows and mathematically defines causal connections between stocks, } \\
\text { - Alows, and variables in a system } \\
\text { Broad Applications } \\
\text { - Explicating individual and shared mental models of a system } \\
\text { - Top-down system design } \\
\text { - Interventions based on system design }\end{array}$ \\
\hline $\begin{array}{l}\text { Agent-Based Modeling } \\
\text { (ABM) }\end{array}$ & $\begin{array}{l}\text { Core Ideas } \\
\text { - Models the interaction of autonomous entities with their environment } \\
\text { - Aodels macroscopic emergence from localized interactions } \\
\text { Broad Applications } \\
\text { - Explicating individual and shared mental models of a system } \\
\text { - Bottom-up system design } \\
\text { - Interventions based on system design }\end{array}$ \\
\hline $\begin{array}{l}\text { Artificial Intelligence } \\
\text { (AI) Models }\end{array}$ & $\begin{array}{l}\text { - Core Ideas } \\
\text { Attempts to incorporate features of human intelligence into computer } \\
\text { models } \\
\text { Broad Applications } \\
\text { - Environmental science models } \\
\text { Are often components of decision support systems (DSS) in SES } \\
\text { management }\end{array}$ \\
\hline
\end{tabular}

Table 2.4. Key features of the theoretical, soft, and hard "tools in the systems thinking toolbox" 
Though this framework aims to provide the background and tools to rigorously apply systems thinking, it is not to say that one is "doing" systems thinking only if one employs the theories and/or soft and hard approaches that are recognized here or within other conceptions of systems thinking. Examining interconnections, root causes, and crossscalar implications is undoubtedly systems thinking, whether or not one employs theory or a particular systems approach. Thinking creatively in a holistic way should always be encouraged - and can lead to useful insights - so long as one is transparent about the processes and approaches one uses. 


\section{Chapter 3}

The History of Holistic Thinking

"Everything of importance has been said before by someone who did not discover it." - Alfred North Whitehead in The Organization of Thought

Systems thinking is but a contemporary expression of the notion of wholeness that has been recognized since the dawn of civilization (Bertalanffy 1972). Let us begin, then, at the very beginning, not only a very good place to start on our journey into systems thinking, but a place which we ought to begin if we are to give due intellectual credit to, and fully appreciate the richness of, the centuries-long development of a way of thinking that we now recognize to be so vital to our continued existence.

\section{Eastern Thought}

Holism is often thought of as the fundamental cultural characterization of East Asia (Lim et al. 2011). Viewing everything in the universe as an integrated whole, holism can be traced back to ancient Hindu and Chinese texts that serve as the philosophical basis for entire ways of life that have persisted for millennia (Kim et al. 2010, Lim et al. 2011, Miller 2008, Tucker 1991).

\section{Hindu Holism}

Vedic philosophy is possibly one of the oldest and most profound holistic philosophies ever produced (Kineman and Anand 2015). Indeed, Aldus Huxley - grandson of Thomas Huxley, "Darwin's Bulldog" - referred to it as "The Perennial Philosophy" (Kineman and Anand 2015, Kineman and Kumar 2007). The Vedas - translated roughly to "total knowledge" - are a massive collection of ancient texts (Boyer 2011) that the Upanishads set out to explain (Kineman and Kumar 2007). 
Despite Vedic philosophy having been known to the world for a long time, its reliability has been plagued by not having an identifiable society from which it emanated (Kineman and Anand 2015). Recently, however, archaeological excavations have revealed that the Indus-Saraswati civilization - located in a basin between India and Pakistan - that thrived seemingly peacefully for upwards of 5,000 years - from 7,000-5,000 B.C. until around 1,900 B.C. - is likely responsible for producing the texts of this most remarkable ancient philosophy (Kineman and Anand 2015). The Saraswati River, described in the Vedas but never known to modern man, has been unearthed from the depths of the Thar Desert under which it was buried following a period of global climate change, leaving the IndusSaraswati people to disperse throughout the region and beyond (Kineman and Anand 2015).

Vedic philosophy fundamentally sets forth the non-dualism of a greater whole achieved through unity, which serves as a transcendent organizing principle (Kineman and Anand 2015, Boyer 2011). It says that the whole dwells within the parts and that the parts constitute the whole (Boyer 2011, Kineman and Anand 2015), captured by the well-known phrase from the Upanishads "Tat Tvam Asi," or "Thou Art That" (Kineman and Anand 2015). The Madhu Vidya from the Upanishads - meaning "honey doctrine," "nectar," or “divine essence," - describes the Oneness of Atman (inner reality, or true inner self) and Brahman (ultimate or universal reality) (Kineman and Anand 2015, Kineman and Kumar 2007). The illusion of separateness between the self and everything else is rejected (Kineman and Anand 2015). Holism pervades everything in the universe, existing in the same form at every level within the whole (Kineman and Anand 2015). Wholeness is achieved through the unification of materiality and spirituality in a higher consciousness; it is a reciprocal relationship between discrete materiality and the non-discrete potentiality of the mind; and it 
is both natural and divine, viewing the divine as being in and enlightening all of us rather than being a separate, unknowable force that saves us from ourselves (Kineman and Anand 2015).

After the dispersal of the Indus-Saraswati civilization, the dualism of Abrahamic religions that rose in the West and the Middle East grew dominant (Kineman and Anand 2015). Vedic philosophy's beautifully developed explications of holism were lost to the West's lower, brutish forms of "mystical” and "dark' magical arts" (Kineman and Anand 2015). As far back as the Hellenistic period, the Greek philosopher Plotinus travelled to the Far East in an attempt to re-establish links with philosophical holism (Kineman and Anand 2015). Gregory Bateson, an influential systems thinker, had profound problems with nondualism (Kineman and Anand 2015). He travelled extensively to India in the 1970s and 80s in an attempt to link Vedic philosophy with modern science (Kineman and Kumar 2007). Indeed, many famous quantum physicists were well versed in Vedic philosophy, which deeply influenced their work (Kineman and Anand 2015). In recent decades, a Vedic scholar has been developing practical applications of the philosophy whereby higher states of consciousness are sought in order to achieve the Oneness of being that is necessary to transcend the fragmented nature of normal waking consciousness (Boyer 2011). Indeed, other scientists are exploring similar techniques using psychedelics (Carhart-Harris et al. 2014). This "fourth state of consciousness" was described in Vedic texts as necessary for human development (Boyer 2011). 


\section{Chinese Holism}

\section{Confucianism}

Confucianism is based on relational identity brought about through self-cultivation to achieve societal harmony (Ho 1995). Rather than having a monistic, universal identity, individuals are viewed in relation to the other person or group with whom they are interacting in any particular situation. Confucianism has Five Cardinal Relationships: those between ruler and minister, father and son, husband and wife, and between brothers and friends (Ho 1995). There is an eternal circularity throughout these hierarchical levels of society. Heightened individual development, achieved through self-cultivation, allows for harmony with the family unit, which then leads to harmony in society; likewise, the actions of a just ruler or government will reverberate down into the lower levels of society, creating a dynamic cosmic harmony (Tao and Brennan 2003, Tucker 1991). Self-cultivation is focused primarily on propriety - proper rules of conduct - and sincerity - a commitment to goodness (Ho 1995). Indeed, such extensive interconnections foster a sense of relativism, embodied by the pervasiveness of a microcosm-macrocosm dyad in Eastern thinking, in which individuals view themselves and others based on the relationship between the part and the whole in any given situation (Kim et al. 2010, Lim et al. 2011, Tucker 1991). Furthermore, Confucianism's holism calls for an integrated balance of “religious reverence, ethical practice, scholarly investigation, and political participation" (Tucker 1991).

\section{Taoism}

Taoism, described by Ho (1995) as the Chinese counterculture, is the pursuit of harmony through the interplay of opposites, namely yin and yang and matter and energy. It is based on the Tao Te Ching, legendarily written by Chou Dynasty imperial archives curator 
Lao Tzu several thousand years ago (Rhee 1997). Like other Eastern philosophies, Taoism is based fundamentally on unity, interrelations, and dynamic change (Rhee 1997).

Indescribable through language, Tao is an essence of continual flow and change that underscores all phenomena (Ho 1995, Rhee 1997). It can only work for those who embrace it, bringing harmony, power, expansion of the mind, loss of fear, and an ability to better face the unknown and easily adapt to changing environments (Rhee 1997). Accepting Tao comes in the form of an immediate, intuitive awareness, and happens only once we have let go of the distinctions between self and non-self (Rhee 1997). Tao is the all-pervading, allembracing mother of the world that unites infinite potentialities (Rhee 1997).

True to its embodiment of contradictions (Ho 1995), Tao harmonizes the very opposing forces that it created. It is said that in the beginning, Tao produced the One, the Two, and the Three (Rhee 1997). The One is spatial-temporal reality; the Two is the opposing forces of yin and yang; and the Three is the physical laws that govern the interaction between matter and energy. All things in the universe spring from the One, Two, and Three and exist as a dynamic interplay between their opposing forces (Rhee 1997).

Unlike Confucianism's emphasis on holistic societal relations, Taoism does not view individuals in relations to others, but rather as unencumbered free agents who should pursue selflessness and the harmony with nature and the cosmos that alignment with Tao brings (Ho 1995). After all, the way of nature is viewed in Taoism as the ideal path to follow - the path of least resistance (Rhee 1997). 


\section{Western Thought}

\section{$\underline{\text { Classical Antiquity }}$}

The word holism can be traced to the Greek word "holon," which refers to a universe made up of integrated wholes that cannot be reduced to its parts (Miller 2008). Similarly, the Greek word for system - which meant to unite, combine, connect, or interweave - appeared in writings spanning a number of disciplines, including geometry, philosophy, music, and medicine (Karcanias and Vasileiadou 2007). The Pythagorean Kallicratides was perhaps the first to explicitly define the word in his work On the Happiness of Family (Karcanias and Vasileiadou 2007):

- "Any system consists of contrary and dissimilar elements, which unite under one optimum and return to the common purpose"

- A system exists as a subsystem of a larger entity and is characterized by elements, a governing rule, a desired common purpose, and is embedded in an environment

Hippocrates (ca. 460-377 BC), considered the "Father of Modern Medicine," viewed the body as a general system in which organs fit harmoniously. He approached diagnostics in the same way, hinting at control and feedback, and relied on the same macrocosmmicrocosm dyad that existed in Eastern thought (Karcanias and Vasileiadou 2007, Kim et al. 2010, Tucker 1991), asserting that imitation happens in both directions.

Whether or not Aristotle's work embraced holism is ambiguous. He is famous for the statement "the whole is more than the sum of the parts" (Bertalanffy 1972) and introduced the notion of complexity and hierarchy in relation to logic (Karcanias and Vasileiadou 2007). Like Hippocrates, he viewed the parts of the human body as part of an 
integrated whole, and even extended that notion of holism to examine how people relate to broader society (Jackson 2003). However, Aristotle seemed to give primacy to the materiality of matter over its organizing principles and interrelations (Zwick 2014). He also posited a top-down structure of causation with God at the top and materiality at the bottom, with no dynamic interactions between the top and bottom levels and those in between (Kineman and Anand 2015).

It is with the Pythagoreans and Plato that holistic, systems thinking truly blossomed during the Hellenistic period. The Pythagorean school that existed during the $5^{\text {th }}$ and $6^{\text {th }}$ centuries B.C. relied on the concept of "cosmos" - an organic whole - and harmony based on numbers that served as the basis for an aesthetic doctrine (Berghaus 1992). They viewed the mathematical interrelations amongst material things as primal (Zwick 2014). Plato was the most influential student of the Pythagorean school, and though Pythagorean philosophy had already filtered into mainstream Hellenistic philosophical thought, it was further transmitted through Plato's academy (Berghaus 1992). Like Greek philosophy in general, which was viewed as a holistic practice rather than simply an intellectual exercise, Platonic dialogues were spiritual practices that demanded self-inquiry and transformation (Miller 2008).

Late Antiquity and the Renaissance

Early Christianity's attempt to reconcile Church doctrine with philosophy resulted in a syncretism of Pythagorean and Platonic thought, which was still heavily incorporated up through the Middle Ages (Berghaus 1992). Petrarch - often called the "Father of Humanism" and credited for initiating the $14^{\text {th }}$ century Renaissance ("Petrarch" 2015) revived a direct interpretation of Platonic thought which Marsilio Ficino and Pico della 
Mirandola then further developed into a philosophy of unity and harmony that became the aesthetic and artistic basis of much of the Italian Renaissance (Berghaus 1992). Nicholas of Cusa then linked Medieval mysticism to the beginnings of modern science with the notion of opposition amongst the parts within a whole (Bertalanffy 1972).

The onset of the Scientific Revolution in the $16^{\text {th }}$ and $17^{\text {th }}$ centuries witnessed the interesting set of complementary yet divergent philosophies of Descartes and Spinoza. Though Descartes became famous for the lasting groundwork he laid on reductionism (breaking problems into as many separate, simple elements as possible) - many ideas of which Spinoza shared - Spinoza simultaneously paved a radical path that some today claim is not only underappreciated, but the basis for systems thinking (Hansson 2012, Jonas 1965). Unlike Descartes, Spinoza postulated a non-dualism of only one "substance" - God's essence (Bennett 2001, Esfeld 1999, Jonas 1965, Melamed 2013, Stock 2000). This substance is infinite, indivisible, and accessible to all. From it, all things are born. Specifically, the two "attributes" of "extension" and "thought" are constituents of the one substance, from which finite, physical "modes" are manifested (Jonas 1965, Stock 2000). Spinoza also contributed to the development of the concept of conatus through the idea of a reciprocal interrelationship between the part and the whole (Hansson 2012, Jonas 1965). He implicitly viewed "modes" as developing and reaching their potential thorough a sort of dualism: being autonomous, determined agents that at the same time are open to inputs from their environments (Jonas 1965).

Two hundred years after Spinoza, Hegelian and Marxist dialecticism, which attempted to approach reality through the exploration of its opposites (Bertalanffy 1972, 
Jackson 2003), brought us even closer a re-emergence of holism vis-à-vis the pragmatism of the early $20^{\text {th }}$ century.

\section{Modern Holistic Pragmatism}

Originated by Charles Pierce and developed later by William James and John Dewey, pragmatism was a reaction against 1) Cartesian rationalism, which set forth that the truths of science can be established by pure reason and pure mathematics, 2) views that privileged $a$ priori knowledge (i.e. knowledge that is independent of experience), 3) the idea that logical and mathematical principles are immutable (i.e. cannot be abandoned in the face of experience), and 4) the tendency amongst positivists to treat ontology, religion, and ethics as separate from science (Norton 2005, White 2002). Morton White (2002) argues that pragmatism, particularly as it was later developed later by W.V. Quine and Pierre Duhem (who was influenced by $19^{\text {th }}$ century organicism), is holistic for four reasons. First, it empirically tests conjunctions of statements or whole bodies of ideas - rather than individual, isolated statements or ideas - against experience. Second, it contains heterogeneous statements about logic, physics, epistemology, and morality. Third, it is a philosophy of culture that can be applied to the study of religion, history, art, law, politics, and morality. And finally, by way of the above, it eviscerates sharp distinctions between $a$ priori and a posteriori (justification based on experience or empiricism) and the analytic (true by virtue of meaning) and synthetic (true by virtue of relation to the world).

\section{The Past as a Door to the Future}

Examining the deep historical traditions of systems thinking serves two primary purposes. First, is enriches our contextual understanding while at the same time giving credit to previous intellectual developments upon which ours stand. Second, it can offer 
perspective and creative entry points into the subject matter. It is important to recognize that, despite being one of the oldest ways of thinking about the world, our awareness of holism has ebbed and flowed across space and time, continually being diminished in favor of more mystical or reductionist approaches. The holism of the Indus-Sawarswati civilization lost its momentum and prominence just as it was flourishing in certain sectors of Greek philosophy. Holism barely managed to stay alive through the Middle Ages, only to be overshadowed by the emergence of positivistic reductionism during the Scientific Revolution. Holism is just now, within the last half-century, returning to modern science in the West, all the while it has been alive in Confucianism, Taoism, and Vedic philosophy for thousands of years. The challenge today is to keep holism alive - at a time when we desperately need it - in ways that are meaningful and as diverse as systems thinking itself.

To that end, I suggest that, in its newfound exploration of holism, modern science could benefit from building upon Eastern developments in holistic thinking that have evolved over thousands of years. Eastern holism seems to be organized primarily around the spiritual and cultural constructs of unity and oneness - unity of mind and oneness with other people and nature. There is exciting potential in exploring the ways in which Eastern philosophical traditions go about achieving that unity, for example, pursuing different states of consciousness to achieve cognitive unity in the Vedic tradition, or self-cultivation to achieve individual and societal harmony in Confucianism, or letting go of the notion of self and rejecting societal expectations in Taoism to follow nature's path and embrace the cosmic Tao. As Morton White argues of holistic pragmatism, we need not separate science from other human affairs such as spirituality or religion. Perhaps the spirituality of holism holds a key to opening new doors in the development of humanity and our pursuit of sustainability. 


\section{Chapter 4}

A Systems Thinking Framework: Theory

"For some, the development of systems thinking is crucial for the survival of humanity." - John Sterman in Business Dynamics: Systems Thinking and Modeling for a Complex World

\section{Modern Foundations}

The holistic conception that has remained alive since the Vedas and Pythagoreans took permanent hold in modern science with Ludwig von Bertalanffy's General Systems Theory (GST) and W. Ross Ashby's cybernetics in the mid $20^{\text {th }}$ century. Considered the fathers of modern systems thinking, Bertalanffy and Ashby laid the foundation for what would become the two dominant strands of the systems programme, what I will call the analytical and computational strands. The analytical strand has been based upon traditional approaches to science, that is, theory and/or process development based upon the scientific method, using mathematical proofs for methodological rigor where appropriate.

Mathematics, however, soon became a limiting factor. It was not keeping pace with new frontiers that were moving towards exploration of complex phenomena from a nonreductionist perspective. Differential equations, the primary mathematical tool available to characterize change, were insufficient. The computational strand was born in response to this limitation, using computer simulations in an attempt to achieve mathematical exactness. Most of the theories covered here fall under the analytical strand (see Figure 4.1). Similarly, the soft systems approaches tend to be associated with the analytical strand while the hard systems approaches tend to be associated with the computational strand. 


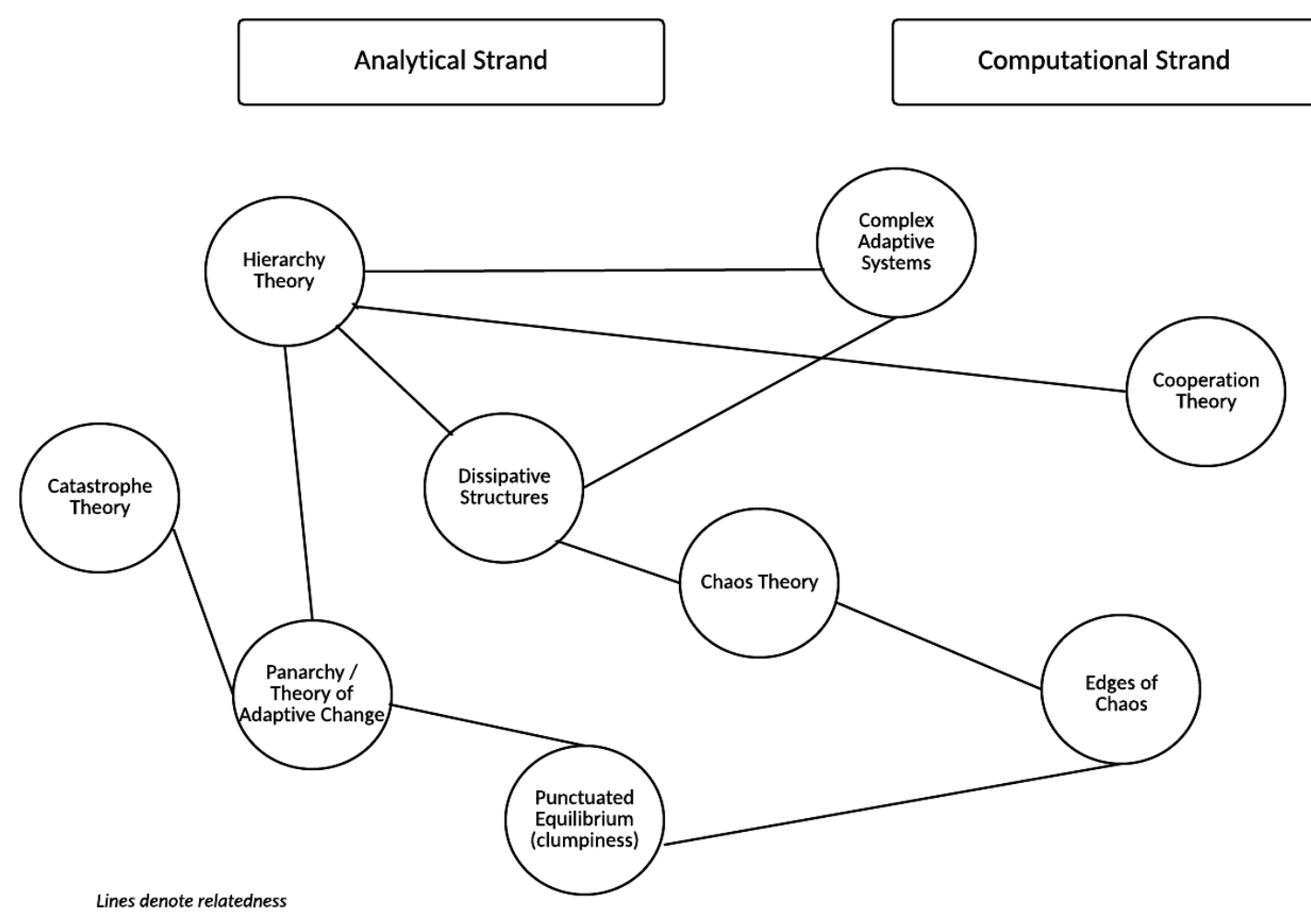

Figure 4.1 Relationships between the systems theories relevant to SES

\section{Founding Fathers and Primary Contributors}

Bertalanffy's expansion of the organismic conception in early $20^{\text {th }}$ century biology can be seen as a Kuhnian paradigm shift that departed significantly from Cartesian reductionism (Bertalanffy 1972). He used the term GST in a broad sense to represent the scientific exploration of wholeness. He saw GST as a regulatory device (Bertalanffy 1950) with the potential to unify science through interdisciplinary concepts, models, and principles (Bertalanffy 1972). He believed it would explore isomorphic laws such as exponential, logistic, and Pareto's laws, and involve a kind of "generalized kinetics and dynamics" exemplified by Prigogine's thermodynamics of open systems (Bertalanffy 1950). While the goal was to expand logico-mathematics to the complex realm, he cautioned against allowing 
a lack of mathematical exactness to impede the exploration of real world, complex problems (Bertalanffy 1972).

Around the same time, psychiatrist W. Ross Ashby was continuing the work of Norbert Wiener on cybernetics. Originally defined by Wiener as the science of control and communication in the animal and machine, Ashby described cybernetics as a theory of machine systems that are open to energy but closed to information and control (Ashby 1956), that is, systems that are dynamic but whose interaction rules remain unchanged (Umpleby 2009). The Law of Requisite Variety - Asbhy's most widely known contribution established the notion of constraint, a hallmark of systems thinking. It stated that selection (options available for action) is limited by the amount of information available, requiring that any regulator in a system must possess the same or greater variety than that of the system it is regulating (Umpleby 2009). Ashby's conception of two feedback loops that govern the evolution of behavior in a changing environment was a precursor to later notions of double loop learning developed by Chris Argyris (Umpleby 2009). In arguing for a richer concept of change, Ashby developed ideas on different system states, sets of transitions between states, and basins of attraction (Ashby 1956). This was exemplified by his electromechanical protobrain that detected levels of stability, leading the way for future work on artificial intelligence (Pickering 2002).

Countless thinkers have followed in the footsteps of Bertalanffy and Ashby to develop the systems programme into what it is today. Figure 4.2 shows a list of the programme's primary contributors, with an eye towards legacy of impact and relevance to SES, divided by which strand their primary contribution(s) fall within (Castellani and Hafferty 2009, Reynolds and Holwell 2010). 


\begin{tabular}{|c|c|}
\hline \multicolumn{2}{|c|}{ Analytical Strand } \\
\hline Kenneth Boulding (1910-1993) & GST co-originator, evolutionary economics \\
\hline Claude Shannon (1916-2001) & Information theory, entropy as a metric \\
\hline Murray Gell-Mann (1929-present) & Measures of complexity \\
\hline Ilya Prigogine (1917-2003) & Thermodynamics of open systems \\
\hline Edward Lorenz (1917-2008) & Chaos theory \\
\hline $\begin{array}{l}\text { René Thom (1923-2002) } \\
\text { Erik Zeeman (1925-2016) }\end{array}$ & Catastrophe theory \\
\hline $\begin{array}{l}\text { Howard Pattee (1926-present) } \\
\text { Herbert Simon (1916-2001) } \\
\text { Timothy Allen (1942-present) }\end{array}$ & Hierarchy theory \\
\hline $\begin{array}{l}\text { C.S. Holling (1920-present) } \\
\text { Lance Gunderson }\end{array}$ & Panarchy/theory of adaptive change \\
\hline Stephen Jay Gould (1941-2002) & Punctuated equilibrium \\
\hline Niklas Luhmann (1927-1998) & Social systems theory \\
\hline C. West Churchman (1913-2004) & Holistic systems thinking \\
\hline Russell Ackoff (1919-2009) & Interactive Planning \\
\hline Peter Checkland (1930-present) & Soft Systems Methodology \\
\hline Ian Mitroff (1938-present) & Strategic Assumption Surfacing and Testing \\
\hline Werner Ulrich (1948-present) & Critical Systems Heuristics \\
\hline Michael C. Jackson (1951-present) & Total Systems Intervention \\
\hline $\begin{array}{l}\text { Fran Ackermann } \\
\text { Colin Eden }\end{array}$ & Strategic Options Development and Analysis \\
\hline \multicolumn{2}{|c|}{ Computational Strand } \\
\hline Anatol Rapoport (1911-2007) & GST co-originator, game theory \\
\hline Gregory Bateson (1904-1980) & Cybernetics and anthropology \\
\hline John von Neumann (1902-1957) & Game theory, cellular automata \\
\hline Robert Axelrod (1943-present) & Theory of cooperation \\
\hline Marvin Minsky (1927-2016) & Artificial intelligence \\
\hline Herbert Simon (1916-2001) & $\begin{array}{l}\text { Artificial intelligence, decision-making and } \\
\text { bounded rationality }\end{array}$ \\
\hline John H. Holland (1929-2015) & Genetic algorithms, complex adaptive systems \\
\hline Melanie Mitchell & Genetic algorithms, cellular automata \\
\hline Stuart Kauffman (1939-present) & Edges of chaos, complex adaptive systems \\
\hline $\begin{array}{l}\text { Joshua Epstein } \\
\text { Robert Axtell }\end{array}$ & Agent-based modeling \\
\hline $\begin{array}{l}\text { Jay Forrester (1918-present) } \\
\text { Donella Meadows (1941-2001) } \\
\text { Dennis Meadows (1942-present) } \\
\text { Jorgen Randers (1945-present) }\end{array}$ & System dynamics \\
\hline Stafford Beer (1926-2002) & Cybernetics, Viable System Model \\
\hline Albert-Lázló Barabási & Scale free networks \\
\hline Lotfi Zadeh (1921-present) & Fuzzy set theory \\
\hline
\end{tabular}

Table 4.2 Primary contributors to the systems programme with an eye towards legacy of impact and relevance to SES 


\section{Systems Theories: Abstract Conceptualizations of Complexity}

An entire book could be written on the multitude of theories that underpin the systems programme. Here, I focus on those that contribute significantly to social-ecological thinking and problem solving.

I suggest that the primary value systems theories bring to the management of SES lies in their strong explanatory power, that is, their ability to convey certain aspects of highly complex phenomena in a simple, accessible way. They illuminate themes and characteristics that are crucial driving forces in many, if not all, SES. Though all of the theories can be applied and tested concretely, understanding them on even a basic, abstract level can go a long way towards reorienting our thinking to make better sense of the confounding interactions amongst scales of space and time in wicked problems.

Notably, I omit several theories that could be related to SES. Lovelock's Gaia hypothesis has been critiqued for being based on group selection rather than the lower level, primary units upon which selection typically acts (Ehrlich 1991, Levin 1998, Levin 2005). Bak's self-organized criticality has been questioned on a variety of levels, namely that it lacks substantial empirical support (Levin 1998, Sole et al. 1999) and that the sandpile simulation upon which it is based is simply not analogous to SES in which heterogeneity, frequency dependent fitness, and novelty for evolutionary change are key features (Levin 2002, Holling 2001). Lastly, the goal of systems biology to understand the structure and dynamics of biological systems (Kitano 2002) is important, but too largely focused on the molecular level and computer simulation. 


\section{Dissipative Structures, or the Thermodynamics of Open Systems}

Open systems can be viewed as the basis of systems thinking. After all, wholeness connotes interconnections. Very few, if any, systems in the real world are actually closed, but the traditional laws of thermodynamics problematically only apply to closed systems. Since thermodynamics are the cardinal laws of science to which all theories must bow, the dissipative structures of open system thermodynamics serve as the theoretical basis for the scientific exploration of wholeness. Bertalanffy and others, such as Erwin Schrödinger and Ilya Prigogine, recognized this at the onset of the systems thinking programme after World War II. Dissipative structures refer to the emergent self-organization that results as living and certain non-living - systems build pathways to dissipate excess energy that would otherwise push the system away from equilibrium.

Living, open systems seem to defy the $2^{\text {nd }}$ Law of Thermodynamics, which states that entropy (disorder) must increase, or be maximized (put another way, systems must reach equilibrium) (Schneider and Kay 1994). Quite the opposite, living systems tend to create order from disorder; entropy seems to decrease rather increase (Hornborg 1998, Schneider and Kay 1994). The theory of dissipative structures offers a work around to this conundrum by showing that open systems exist in dynamic equilibrium maintained by constant energy input from their environments and the subsequent dissipation (or output) of that energy. As high quality energy enters a system, it pushes the system away from equilibrium (Kay et al. 1999). In response, the system builds new internal structures that make use of the energy by dissipating it (Abel and Stepp 2003, Hornborg 1998, Kay et al. 1999, Kay and Schneider 1994). Hence, open systems export entropy in order to maintain internal negentropy, or order (Naveh 2000). The emergent self-organizing structures that dissipate energy often take 
the form of hierarchies (Kay et al. 1999). Moreover, open systems have a state space of overall behavior within which are attractors, or sets of behaviors, that the dissipative structures organize themselves around (Kay et al. 1999). Reorganizations that allow for shifts between attractors are often abrupt, à la punctuated equilibrium (covered later) (Kay et al. 1999). Feedback is also at play: the greater the incoming energy, the more structure the system can build, and the greater the structure, the better the system is at dissipating energy - beyond a threshold, at which point the system becomes overwhelmed and chaotic dynamics can take hold (Abel and Stepp 2003).

Like panarchy, explored below, the thermodynamics of open systems beautifully integrates a whole host of concepts - self-organization, emergence, hierarchies, catastrophe, chaos, and punctuated equilibrium - some of which are rich theories unto themselves. $\underline{\text { The Two Pillars }}$

Hierarchy theory and cooperation theory form the bedrock of theoretical thinking about SES because they explicate precisely what interventions in wicked problems require scalarity and critical pluralism. Hierarchy theory offers two salient points for social-ecological management: 1) high-level constraint is critical for both system functionality and freedom across all system levels, even though the nature of the constraint - and its resulting functionality - can change and adapt, and 2) understanding which hierarchical levels - hence which spatial and temporal scales - are affected by our actions is imperative. Cooperation theory extends the temporal scaling of hierarchy theory, and adds the notion of critical plurality, to show that 1) the temporal perspective we employ (short versus long-term), 2) the probability of direct, long-term future interactions, and 3) context-specific approaches to 
interactions are imperative for cooperation to emerge. Nearly every wicked problem related to SES can be approached using some aspect of these two cardinal theories.

Hierarchy Theory

Oft neglected in the systems programme, hierarchy theory can ironically be viewed as the crowning systems theory. Originally developed by social scientist Herbert Simon and biologists Howard Pattee, Richard Levins, and others in the 1970s, and further refined and expanded by ecologist Timothy F.H. Allen and colleagues in the 1980s and beyond, hierarchy theory is fundamentally about relationships between scales and how observers interact with those scales (Ahl and Allen 1996, Allen and Hoekstra 2015). It has been applied extensively to the study of ecology, resource management, and SES (Norton 1990, Norton 2015, Giampietro 1994, Giampietro and Mayumi 1997, Warren 2005). The richness of hierarchy theory lies in its ability to accessibly illuminate the layered, confounding interactions that exist in many types of complex phenomena. It sets forth that lower-level, faster-changing subsystems are embedded in higher-level, slower changing systems, and that all levels are linked by one or more organizing criteria. Hierarchy theory's crowning achievement is showing that the functionality of a system - achieved through high-level constraint on its subsystems - can be crippled when that constraint is lost. (Note: throughout the literature on hierarchy theory - including the literature on panarchy, which is closely related - it is stressed that the word "hierarchy" should not be confused with its less nuanced colloquial meaning associated with top-down control) (Gunderson and Holling 2002, Pattee et al. 1973).

A hierarchical system is composed of multiple levels, with the lower, stable levels unified by high level constraint (Ahl and Allen 1996). High levels provide the context for 
lower levels. High levels, which are typically large spatially but slow temporally (meaning their behavior is low-frequency), constrain lower levels that are spatially small but temporally fast (meaning their behavior is high-frequency) (Ahl and Allen 1996, Allen and Hoekstra 2015, Simon 1973). High levels can be occupied by spatially small entities, but in doing so they must offer some sort of significant high-level context (Ahl and Allen 1996). Constraint is achieved not through action, but inaction (Ahl and Allen 1996, Allen and Hoekstra 2015). This inaction is the result of different rates at which the levels filter information (Ahl and Allen 1996, Allen and Hoekstra 2015). High levels, by nature of their low-frequency behavior, filter information slowly, whereas low levels filter it rapidly. Even if low levels send information quickly to the high level, it simply cannot respond to the high-frequency input (Ahl and Allen 1996). The optimum amount of constraint depends on the desired function of the system - it can be too tight or too loose, resulting in no function at all (Pattee 1973). Paradoxically, it is constraint that gives rise to greater freedom for individual system parts and the system as a whole (Pattee 1973). Constraint also allows for prediction (Allen and Hoekstra 2015).

Just as hierarchical constraint can be viewed as the interface between structure and function (Pattee 1973), so are holons the interface between the whole and the parts, acting as a kind of skin that interfaces between both worlds (Ahl and Allen 1996, Allen and Giampietro 2014, Kineman and Anand 2015). Surfaces, which often demarcate interactions between levels and types of entities, can be both filters and holons (Ahl and Allen 1996). Since we only observe certain phenomenological signals, our perceptions can be seen as the interface between our observational filters and hierarchical filters (Ahl and Allen 1996). 
There are two types of hierarchies: nested and non-nested. In nested hierarchies, the high level imposes constraint upon lower levels through containment (e.g. a human body contains all of its organs) (Ahl and Allen 1996, Allen and Hoekstra 2015). Containment serves as an organizing principle for the system, even though the ordering criteria that dictate how the lower levels interact can change (Ahl and Allen 1996). In non-nested hierarchies where the lower level entities are not contained (e.g. a food web), the ordering criteria for all the levels must be the same in order to maintain system function and integrity. So, nested hierarchies have both an organizing principle of containment and multiple organizing criteria across levels, whereas non-nested hierarchies have one single organizing criterion across all levels (Ahl and Allen 1996, Allen and Hoekstra 2015). Fractal patterns are an exception to nested hierarchies in which nestedness is both the organizing principle and the ordering criterion across all levels (Ahl and Allen 1996).

Hierarchies can change over time. Successful hierarchies adapt qualities that make them resilient to disturbances. For example, forests adapt to contain plant species that require period burning in order to thrive (Ahl and Allen 1996). When hierarchical systems become unstable, positive feedbacks are amplified since the high level constraint that creates balancing feedback is lost (Ahl and Allen 1996). In the absence of the normal constraint, the amplified positive feedbacks result in vigorous high-frequency behavior that makes the system highly susceptible to external perturbations (Ahl and Allen 1996). The system can either collapse to a lower level of organization or it can "collapse" into an even higher level of organization with new constraints that provide increased resilience (Ahl and Allen 1996).

Hierarchies are pervasive in the world (Ahl and Allen 1996). Indeed, most complex systems in nature are part of a hierarchical sequence (Simon 1973). Highly evolved systems 
must be hierarchies, otherwise failure at a high level would mean the entire system would digress back to a random collection entities. Evolved systems rely on stable lower level subunits in order to modify their structure as high-level organizing criteria fail (Ahl and Allen 1996). Accordingly, the time required for a complex system to evolve is faster if it is a hierarchy than a non-hierarchy (Simon 1973).

I agree with Warren's (2005) suggestion that hierarchy theory can serve as a unifying framework for the study of SES (which stops short of Wilby's (1994) suggestion that it should be developed further into a practicable methodology). Hierarchy theory offers two powerful points for social-ecological management: the crucial importance of constraint and scale. It is constraint that enables a hierarchy to operate so effectively - that frees its entities from existing within pseudo-chaos and gives freedom to the whole to adapt and change because it can count on stable sub-entities to fall back on. Whether a certain level of constraint is good or bad is in the eye of the observer. When the normal level of constraint in a system is violated by its lower levels, the system loses its previous functionality but inevitably adopts a new level of constraint, collapsing up with more constraint or down with less. As Allen and Hoekstra (2015) so aptly describe, the collapse of modern industrial society can be viewed as good for those in third-world nations who are enslaved by industrialism but bad by those in the industrialist system who benefit from is exploitation. The importance of scale means that we ought to be explicitly aware of what spatial and temporal scales of a hierarchical system will be affected by the choices we make or consider. Choices that are made at an individual, small scale have cumulative effects at larger scales. For example, developmental activities happen relatively quickly and occur on small, segmented parcels of land or water. The cumulative spatial effects of those individual actions 
across a landscape - converting rich agricultural land into a subdivision or clear cutting part of a forest - occur at a rate too fast for the larger ecosystem to adapt to. The result can be degraded ecosystem function, a switch to an alternate (possibly less desirable) state, or a loss of ecosystem function altogether. Most people tend to think in small spatial and short temporal scales. We continue to do this at our own peril. Our survival is dependent upon our ability to expand these horizons and be explicit about what hierarchical level(s) will be influenced by the decisions we propose - and what the effect those impacted levels will have on the system's constraint and functionality.

\section{Cooperation Theory}

Having garnered over 30,000 citations, Robert Axelrod's cooperation theory is widely recognized as a robust, well-developed framework (Dugatkin 1997) that accounts for how cooperation can emerge in a world of self-seeking egoists. The conundrum had plagued ecologists for decades ever since Darwin's publication of On the Origin of Species. But in 1981, Axelrod, a political scientist, teamed up with evolutionary biologist W.D. Hamilton to produce the first major breakthrough in the area of cooperation (Dugatkin 1997, Sachs et al. 2004), followed shortly thereafter in 1984 by Axelrod's famous book The Evolution of Cooperation, which will be the focus of the analysis below. Cooperation theory applies the embedded temporal scales from hierarchy theory to the complexities of decision-making and interactions. Axelrod's book explores the theory's sweeping implications for social and biological systems - from bacteria to humans and nations - by showing that the extent to which we cooperate is dependent upon the temporal perspective we employ (short versus long-term), the durability of our interactions, and context-specific interaction strategies. 
These variables are of profound importance for understanding both our past (evolution) and our future (normative prescriptions for society).

Cooperation theory demonstrates mathematically that, in non zero-sum games, what is individually rational may or may not be rational for the greater collective depending on the time scale considered. Unlike zero-sum games in which there can be only one winner and one loser since what I gain becomes unavailable to you, both parties can do well or poorly in a non zero-sum game. If a short-term perspective is taken, the pursuit of self-interest tempts an individual to employ a strategy that results in their highest possible gain now, which is a strategy of non-cooperation. This inevitably leads to a lower gain than what is possible in the long run. If, however, a long-term perspective is taken, the pursuit of self-interest leads an individual to employ a cooperative strategy which will result in lower relative gains in the here-and-now but greater cumulative gains over time.

The likelihood that two entities will interact again in the future is a strong component underlying the temporal perspective. In fact, if the likelihood of future interaction is large enough, a cooperative strategy can be an evolutionarily stable one. Originally defined by Maynard Smith in a biological context, evolutionarily stable strategies (ESS) are life strategies whose utility is greater than any other strategy, resulting in the highest reproductive success and thus immunity from other strategies (Maynard Smith 1974). The proof of a cooperative ESS was a breakthrough in the evolutionary sciences that helped pave the way for a host of theories that account for escape mechanisms from selfish, defectoriented strategies (Nowak 2006, Sachs et al. 2004). The concept can also be described generally in a social context as a process of cultural learning - a strategy that cannot be invaded by an alternate strategy when adopted by a population in a given environment 
("Evolutionarily stable strategies" 2015). While non-cooperative strategies are also evolutionarily stable, nice strategies with a large enough future likelihood of interactions between players can invade non-cooperative strategies, providing they do so in a cluster and that they make exploitation unprofitable by immediate retaliation.

A cardinal rule in the cooperative landscape is that there is no single best strategy. An effective strategy takes the other person's strategy as well as the history of the interaction into consideration. The most successful strategy in Axelrod's famous Prisoner's Dilemma games, Rapoport's TIT FOR TAT strategy, did precisely this. Its four characteristics were: 1) niceness, or never being the first to defect, 2) being retaliatory by immediately defecting after an uncalled for defection, 3) forgiveness, or having a high propensity to cooperate again after the other player's defection, and 4) taking feedbacks into consideration by responding to the other player's actions. TIT FOR TAT offers four rules for how to approach interactions: 1) think strategically (long-term), not tactically (short-term). A short-term approach tempts us to compare our immediate success against that of the other player, which can quickly lead to defections, whereas in a long-term approach we are constantly assessing the success of our strategy relative to the other player's while soliciting cooperative behavior. 2) Be nice. Never be the first to defect and don't defect all the time. Not being nice may at first appear promising, but in the long-term it destroys the very environment needed for your own success. 3) Reciprocate both cooperation and defection. The precise level of forgiveness depends on the environment - if there is a danger of unending defections, be more forgiving; if the danger is from exploitation, be less forgiving. Generally, a one-for-one response to defection works well in a variety of environments. And finally, 4) don't be too clever, which can appear unresponsive and typically doesn't yield good results. 
Cooperation is increasingly proving to be the linchpin in efforts to move towards sustainability. It appears again and again in situations such as global climate change policy, regional nonpoint pollution management, and general tensions surrounding citizengovernment interactions and intergenerational equity. We urgently need rigorously based principles and methodologies that can guide our so-called soft, communicative and interrelational efforts in wicked problems. Cooperation theory offers not only sound strategic tools, but also ways in which we can promote a cooperative landscape: 1) make the future more important relative to the present by making interactions more durable and frequent, 2) change pay-offs by making the long-term incentive for mutual cooperation greater than the short-term incentive to defect, and 3) teach the values, facts, and skills that will promote cooperation. Teach people to care about each other by promoting altruism and punishing selfishness. And teach reciprocity - unconditional cooperation provides an incentive for exploitation, leaving a burden on society to reform toxic individuals. Complexity Theory

There are many references to so-called "complexity theory," which can generate confusion. Rather than being a single theory, complexity theory is a reference to a set of theories that involve nonlinear dynamics, specifically chaos theory, catastrophe theory, complex adaptive systems, the edges of chaos, and self-organized criticality. I include punctuated equilibrium in this category since it clearly deals with nonlinear behavior, but, as discussed earlier, I do not cover self-organized criticality.

\section{Chaos Theory}

Originally developed as dynamical systems theory by French mathematician Henri Poincare in the late $19^{\text {th }}$ century and developed further in the 1980s by Edward Lorenz, 
chaos theory deals with unexpected changes in system states. Crutchfield et al. (1986)

provide an accessible account of this mathematically intensive theory. Whereas unpredictable phenomena were previously thought to be stochastic, chaos theory has shown that many are actually chaotic: they are deterministic, because they follow a chaotic attractor, but they are not predictable due to the unique path of the attractor. Chaotic attractors work on the geometric operation of stretching and folding, like kneading dough. Within an attractor are orbits. The path of the orbits, combined with the shuffling process, results in an infinite number of folds and therefore an infinite number of final possibilities. A central characteristic of chaotic systems is high final state sensitivity to initial state conditions. This means that, while a chaotic system is deterministic via the geometric path of the attractor, the final state is not predictable since microscopic changes in trajectory are amplified exponentially at the macroscopic level. The three common chaotic attractors - named Lorenz, Rössler, and Shaw for the scientists who discovered them - are contrasted against predictable attractors. These include fixed point (e.g. a pendulum subject to friction), limit cycle (e.g. a pendulum clock or a heart beating), and torus (compound oscillations) attractors. The degree of chaos can be measured by entropy of motion or the dimensions of an attractor.

The application of chaos theory to SES was a hot topic in the 1980s and 90s. Chaotic dynamics are pervasive in ecosystems, found most commonly in population dynamics, food webs, and epidemics (Hastings et al. 1993, Pulliam and Haddad 1994). The unpredictability of chaos can be further amplified when chaotic dynamics interact with exogenous forcing functions that can enhance the chaotic nature of the system (Hastings et al. 1993). Some sociologists contend that chaos is common in social contexts, occurring in management succession, organizational decline, crisis behavior, negotiation processes, decision-making, 
and organizational change (Gregersen and Sailer 1993). Understanding where chaotic dynamics exist (or might exist) allows social-ecological managers to build in buffers to deal with its seemingly intractable unpredictability.

\section{Catastrophe Theory}

Conceived of initially by the French mathematician René Thom and developed further by Erik Zeeman in the 1970s, catastrophe theory deals with discontinuous phenomena that jump rapidly and often unpredictably from one stable system state to another. Zeeman (1976) does an excellent treatment of this highly advanced theory. Hailed as describing all possible discontinuous phenomena controlled by no more than four dimensions, one of the seven catastrophes must purportedly describe any continuously changing force that has an abruptly changing effect. The difficult proof for the theory is derived from mathematical topology, which gives rise to the geometric names and shapes of the catastrophes. Of the four cuspoids and three umbilics, the cusp and fold catastrophes are the simplest and most common, particularly in SES. The well-known cusp (Figure 4.3) is the highest dimensional catastrophe that can be drawn (and often conceived of) in its entirety. It is defined by a two-dimensional control surface (with two control parameters, one on each axis) and a third-dimensional behavior surface. Its five properties are 1) bimodality, 2) sudden transitions, 3) hysteresis, or dependence of outputs on inputs, 4) inaccessibility, meaning that the middle portion of the cusp between the two states can never be occupied, and 5) divergence, indicating that a small perturbation in the initial state can make a large difference in the final state. The state space of behavior - and, more importantly, the path of behavior change - is determined by where on the control surface the control parameters lie and thus whether change is smooth and continuous or abruptly discontinuous. The fold 
catastrophe (Figure 4.4) - the simplest of the seven elementary catastrophes - is a simplified version of the cusp. Also containing only two possible behavior states, the fold, however, has only one control parameter, allowing it to be modeled two-dimensionally. Unlike the bifurcation set of the cusp catastrophe, the fold has a single bifurcation point. Similarly to the cusp, there are two possible ways that shifts between system states can happen. Figure 4.4 shows the sudden jump from the top behavior region to the bottom region once the control variable has reached the bifurcation point, $\mathrm{F}_{2}$; the only way to return back to the top region is for the control variable to reduce all the way back to $F_{1}$, at which point the jump back occurs. It also shows that a system may be perturbed close enough to the bifurcation point to induce a premature jump to the alternative state.
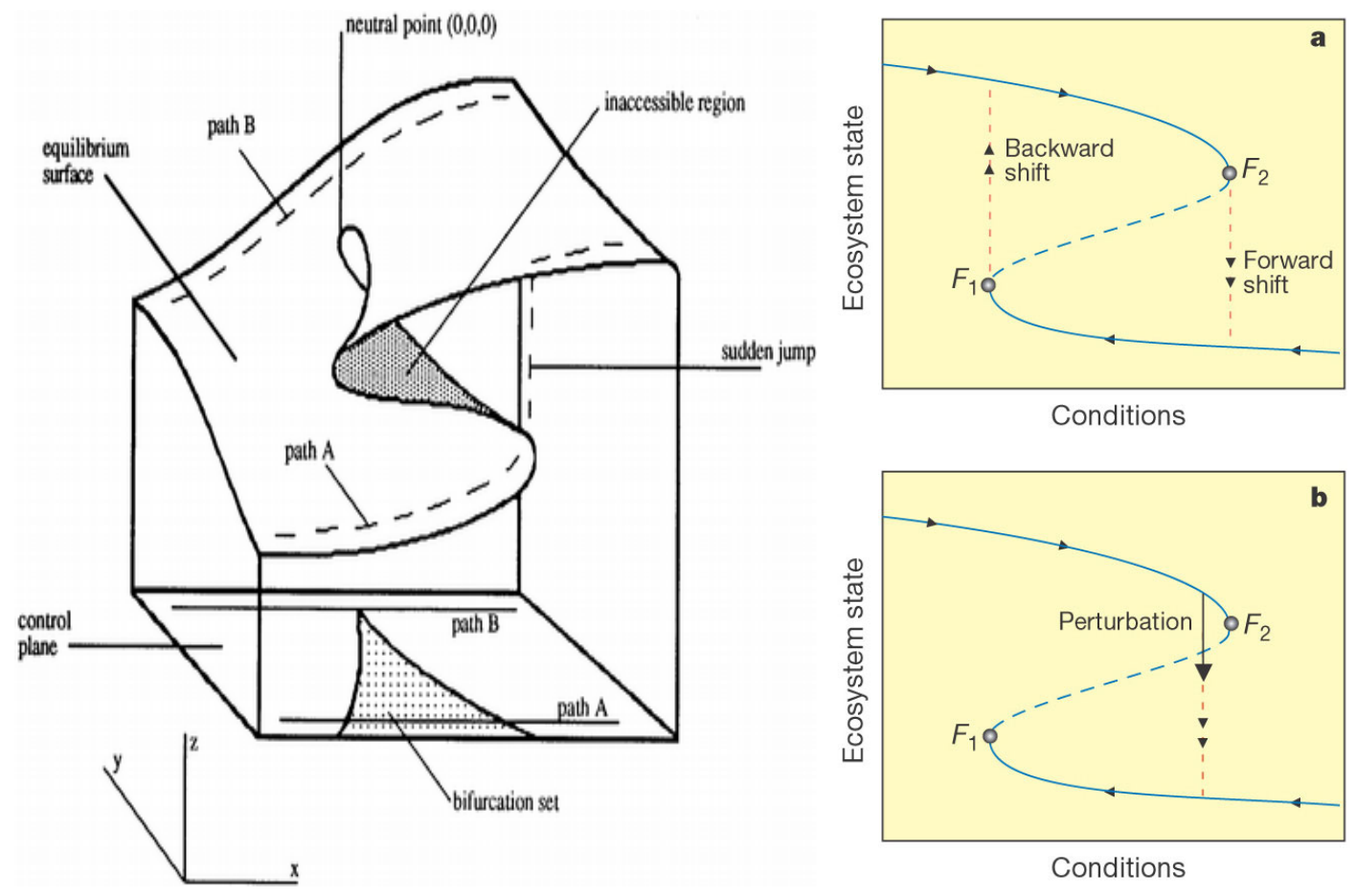

Figure 4.3 The cusp catastrophe (source: http:// Figure 4.4 The fold catastrophe (source: unifiedtao-it.blogspot.com/2012_02_01_archive. Scheffer et al. 2001) Html) 
Catastrophe theory demonstrates that SES are capable of flipping rapidly from one system state to another. The SES resilience literature is replete with examples from catastrophe theory (plus, see Resilience Alliance's http://www.resalliance.org/regime-shifts page and the Regime Shifts Database at http://www.regimeshifts.org/). The literature goes further to show that some system states may be more desirable than others and that some may even be irreversible. Panarchy (2002) implicitly discusses the fold catastrophe in SES using two classic examples from limnology and semiarid ecosystems. Excessive pollution can cause shallow lakes to abruptly and unpredictably shift from clear and vegetated to turbid and unvegetated. And excessive grazing in semiarid ecosystems can shift the landscape from a vegetated to a desert state. Other examples of bifurcations abound: pine bark beetle epidemics in the Rocky Mountains, tipping points in the climate system, and overshoot and collapse of populations. Although detecting catastrophic regime shifts is notoriously difficult, new research suggests that generic early warning signals may exist (Scheffer et al. 2009).

\section{Punctuated Equilibrium}

Stephen J. Gould and colleagues produced several landmark papers in the 1970s that profoundly changed the way we think about evolutionary biology. Punctuated equilibrium, the idea that change is often rapid and episodic rather than slow and incremental, was one of them. I draw from Eldridge and Gould's 1972 classic below.

While punctuated equilibrium applies to much more than just evolution, we must delve briefly into evolutionary biology to understand its origins. Darwin said that new species could arise in two different ways: through phyletic gradualism or speciation. Phyletic gradualism is a gradual, steady transformation of an entire ancestral population to new, 
modified descendants. Allopatric speciation is the rapid development of new species through the geographic, peripheral isolation of a portion of an ancestral population. Since Darwin focused predominantly on phyletic gradualism, it became the prevailing theory held by paleontologists and evolutionary biologists, despite continual difficulties in the fossil records that didn't support it. Eldridge and Gould emphasized the theory of allopatric speciation (which had been developed more rigorously from the 1940s onward) and proposed punctuated equilibrium to describe its features - rapid, episodic events of speciation that punctuate the homeostatic equilibrium that is the stability of a species.

Punctuated equilibrium's significant contribution to the growing body of work on nonlinear change has extended well beyond biology to sociology, ecology, and the history of science (Gersick 1991). It has been suggested that organizations, groups, and adults often change in rapid, episodic ways (Gersick 1991). Punctuated equilibrium is a strong thread in Gunderson and Holling's theory of adaptive change and in Kuhn's classic work on scientific revolutions that preceded the concept by nearly a decade (Gersick 1991). Furthermore, it has been suggested (Hanel et al. 2010) that periods of heightened change might result from the precarious interplay between normal-equilibrium and chaotic-disequilibrium dynamics, linking punctuated equilibrium with the edges of chaos.

Edges of Chaos

Pioneered by the work of Stuart Kauffman in the early 1990s, this theory postulates that complex adaptive systems - specifically, their genomic regulatory systems - evolve towards the edges of chaos (Hanel et al. 2010, Kauffman 1991, Upadhyay 2009), the small transition phase between the extremes of order and chaos that allows for maximum adaptability and computational power. Using computer Boolean network analysis, Kauffman 
(1991) initially concluded that the sweet spot for coordination of behavior is just on the unordered side of ordered; minimal perturbations in the network cause many small and some large "avalanches" whereby nearby sites communicate frequently and distant sites communicate rarely. Unfortunately, much of the work on the edges of chaos has been in the form of computer simulations with limited experimental research (Beggs 2008). Mitchell, Crutchfield, and Hraber (1994) also cite problems with experimental repeatability.

Nonetheless, the theory seems to have promising applications not just to living systems, but to areas such as economics and politics (Jin and Haynes 1997, Ma 2007).

\section{Complex Adaptive Systems}

Complex adaptive systems (CAS) are self-organizing systems in which macroscopic patterns emerge out of the interplay between microscopic interactions and evolutionary processes (Levin 2002, Rammel et al. 2007). As mentioned earlier, CAS can be distinguished from complex systems by the presence of selective pressures - which can take place across a variety of interacting scales - that result in evolution (Levin 2002).

While the development of a theory of CAS is nascent and largely abstract based on computer simulations (Holland 2006, Lansing 2003, Levin 2002, Rammel et al. 2007), the fact that ecosystems and the global biosphere are prime examples (Levin 1998, Levin 2002) suggests that the existing body of work deserves due exploration. A number of different features of CAS have been postulated but can be captured most succinctly as 1) sustained diversity and individuality of components, 2) localized interactions among components, and 3) an autonomous process that selects from the components a subset for replication or enhancement based on the results of localized interaction, (Levin 1998, Levin 2002). CAS 
are based on the interplay between two processes: the emergence of pattern in a system of fixed entities, and the continual appearance of new kinds of entities (Levin 2002).

The essential challenge posed by CAS is to develop a theory of co-evolutionary interactions across time scales (Rammel et al. 2007), beginning at the level of the genome and organism, where evolution operates (Levin 2002).

Panarchy, or the Theory of Adaptive Change

Developed by esteemed ecologists C.S. Holling and Lance Gunderson in the 1990s and 2000s, panarchy offers a rich conceptual framework for the complex dynamics of SES. Panarchy has been widely applied in a metaphorical sense, and many of its core concepts have been tested empirically, though much testing yet remains as long-term ecological data becomes available (Allen at al. 2014). The central idea is that ecosystems, rather than being viewed as simply resilient, are better characterized as nested adaptively changing systems (a panarchy) that undergo alternating periods of growth-connectivity and releasereorganization. Panarchy was born out of a response to the failures of natural resource management under the reductionist-equilibrium paradigm. It sought to conceive of a more nuanced view of SES, how they change, and how they can be better managed. Below, I draw from Gunderson and Holling's seminal book Panarchy: Understanding Transformations in Human and Natural Systems (2002).

The theory of adaptive change proposes that resilience, while a crucial characteristic of ecosystems, is an insufficient caricature of nature. Rather, nature as evolving - through a nested set of adaptive cycles called a panarchy - is a more plausible metaphor. "Ecosystem resilience" is first differentiated from "engineering resilience." Engineering resilience is stability near an equilibrium steady state and focuses on efficiency, control, constancy, and 
predictability related to the system's ability to return to equilibrium after a disturbance. It draws from traditions of deductive mathematical theory. Ecosystem resilience, on the other hand, is about conditions far from equilibrium where instabilities can flip a system into another stability domain, or regime of behavior (e.g. the bifurcations of catastrophe theory). It is measured by the magnitude of a disturbance a system can absorb before changing its structure and behavior. Sustainability, it is emphasized, requires a focus on the latter conception. If, however, ecosystems were merely resilient, dramatic landscape changes over geologic time would not be possible (and could not be explained). For example, the Florida Everglades were a dry savanna 10,000 years ago. The metamorphosis to their current state cannot be explained by resilience alone. Hence the need for a more nuanced theory of ecosystem, and SES, change.

The r-to-K and omega-to-alpha phases are the two opposing states of the adaptive cycle, as depicted in Figure 4.5. "R" and " $\mathrm{K}$ " are borrowed from ecology to represent fastgrowing species that die quickly after reproducing numerously $(\mathrm{r})$ and slower-growing species that live longer and reproduce less $(K)$. The $r-K$ phase represents a transition from low to high connectivity, low to high potential, and high to low resilience. Capital accumulates and the interconnections between resources grow more plentiful and rigid, with increased potentialities as a result of the new connections. The omega-alpha phase (representing release and reorganization, respectively) happens after the rigidity and vulnerability of the $\mathrm{K}$ state leads to broken connections and a release of accumulated resources. It is a rapid, unpredictable recombination process characterized by low connectivity, medium potential, and high resilience. Flips between the opposing $r-\mathrm{K}$ and omega-alpha states are mediated by slow-changing variables that trigger fast-changing 
variable responses. In general, social-ecological change is driven by high-level, slow-changing dynamics. Success brings rigidity, which then leads to the omega-alpha phase. Many SES are now in the far stages of the $\mathrm{r}-\mathrm{K}$ phase - ripe for disconnection and recombination.

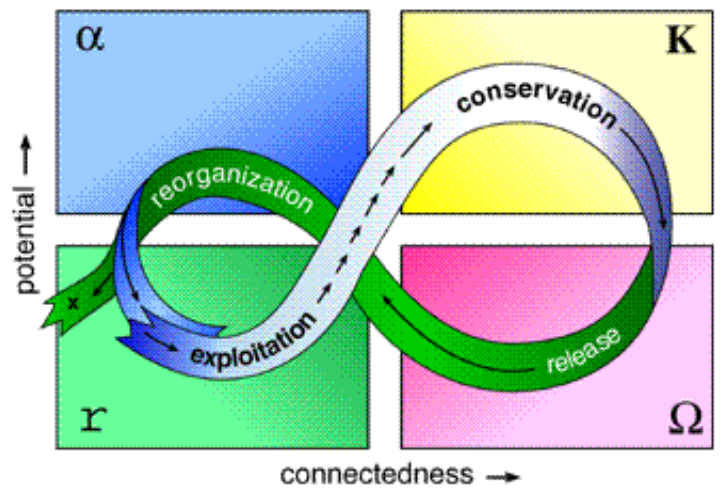

Figure 4.5. The adaptive cycle (source: sustainablescale.org)

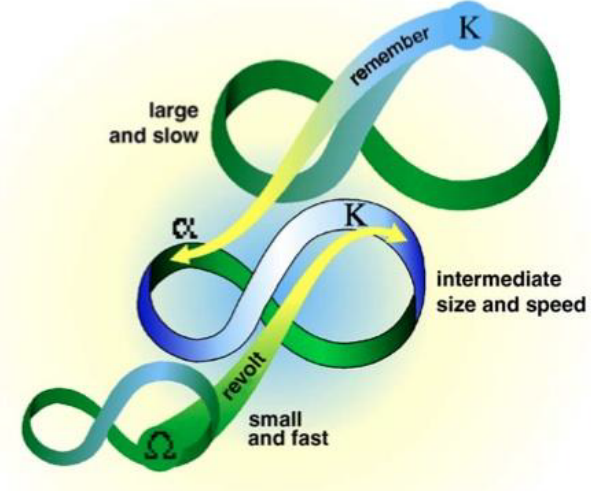

Figure 4.6. A panarchy (source: Folke 2006)

There are cross-scalar relationships between different levels of adaptive cycles within a panarchy. Most notable are the "remember" and "revolt" relationships depicted in Figure 4.6. In the "remember" relationship, the $\mathrm{K}$ (conservation) phase within a higher level adaptive cycle provides the basis for structural and process-oriented constraint in the new reorganization of the omega phase. Conversely, in the "revolt" relationship, the disruptive processes during the alpha (release) phase effect the structures and processes at higher levels.

The sweeping scope of the theory can be credited to Gunderson and Holling's ability to tie together many systems theories - hierarchy theory, catastrophe theory, and the "clumpiness" or "patchiness" of punctuated equilibrium - into one cohesive framework. Indeed, it is admitted that panarchies are strongly based on hierarchy theory. As mentioned earlier, the word "hierarchy" is tremendously burdened by its colloquial meaning of topdown control. Thus, "panarchy" - based on the Greek god of nature, Pan, who invokes 
unpredictable change - was adopted to avoid this confusion and to connote a hierarchy of adaptive cycles. Another key feature that separates a panarchy from a hierarchy is the notion of lumps, or discontinuous breaks in scale. Lumping begins with discontinuous distributions of body mass within species, which results from unevenly dispersed resources. The reverberations of lumpy body mass distributions then cascade up and back down levels of a panarchy, affecting things like phylogeny (evolutionary relationships amongst species), competition, and trophic relationships. Thus, lumps assert that there are breaks between scale levels and that within scales there are clusterings.

The theory of adaptive change emphasizes two critical management implications for SES: the potential for catastrophic regime shifts and the futility of trying sustain one particular state of the adaptive cycle. Flipping from one system state to another can be undesirable and/or irreversible and can be further compounded by unpredictable chaotic dynamics. For example, an ecosystem that that has a low propensity for catastrophic change may be either fragile or resilient. A fragile ecosystem will have a low tolerance for stress while the resilient system will have a higher tolerance. Ecosystems with a high propensity for catastrophic change - for example, lakes or semiarid ecosystems - will have definitive levels of stress they can endure, beyond which point the system will flip into a different state (e.g. turbid and vegetative versus clear with no vegetation, or perennial herbaceous vegetation versus desert). These varying responses to stress have important implications for the social dynamics that underlie management. In collaborative processes and policy decisions, more attention should be given to ecosystem dynamics and the outcomes of those dynamics rather than politically driven compromises. Compromise, while socially applaudable, can be ecologically disastrous if the activities result in exceeding a key threshold for stress. And 
finally, the panarchy metaphor illustrates that natural systems are in a constant state of flux, realizing potential through increasing interconnection, eventually becoming too rigid and collapsing back down into elemental parts so that a new potential can be realized. It is up to us to develop social institutions, infrastructure, and ways of life that can change and adapt harmoniously with our surrounding environments. 


\section{Chapter 5}

A Systems Thinking Framework: Soft Approaches

"The job of the systems practitioner is no longer just to build mathematical models in order to enable key decision-makers to 'predict and prepare'... Rather, it is to assist all the stakeholders to design a desirable future for themselves and to invent the means of realizing it." - Michael C. Jackson in talking about the vision of Russell Ackoff in Systems Thinking: Creative Holism for Managers

As discussed in Chapter 2, I suggest that characterizing the many systems thinking approaches as soft or hard can be a valuable starting point to help understand their broad differences and to provide some semblance of organizational clarity. To this end, I differentiate soft from hard systems thinking on the basis that soft approaches tend to deal with multiple perspectives and normative content, whereas hard approaches tend to make system elements, their relations, and resulting behavior concrete using some sort of computer model or simulation to achieve mathematical exactness. The soft approaches tend to align with the analytical strand of systems thinking while the hard approaches tend to align to with the computational strand. Furthermore, I agree with the position that soft systems approaches are of a uniquely systems thinking orientation, while hard approaches overlap significantly with OR's focus on clear objectives, mathematical models, and optimization.

Based on this characterization, I group the systems approaches in the following way. Soft Systems Approaches (Analytical Strand):

- $\quad$ Soft Systems Methodology

- Interactive Planning

- Strategic Assumption Surfacing and Testing

- Strategic Options Development and Analysis

- Critical Systems Thinking 
○ Critical Systems Heuristics

○ Total Systems Intervention and Critical Systems Practice

Hard Systems Approaches (Computational Strand):

- Viable System Model

- System Dynamics

- Causal Loop Diagrams

- Agent-Based Modeling

- Artificial Intelligence Models

I include, to the best of my knowledge, all known soft systems approaches, including those that are sometimes labeled separately as "critical." The approaches I include are distinguished for their ability to reconcile multiple perspectives - and the assumptions that underpin them - in wicked problem formulation and intervention. Two of the approaches the nearly identical Total Systems Intervention and Critical Systems Practice - can be regarded as meta-methodological frameworks that help to identify which approaches should be used in a particular problem situation.

\section{Soft Systems Approaches}

I begin with soft systems approaches since it is the "soft" aspects of problem situations that plague us the most, yet are the most essential, in our quest for sustainability. The biggest challenges we face in social-ecological management are not massive amounts of data analysis or generating the right algorithm. Moving towards sustainability most importantly forces us to confront ethics (normative, value-laden choices or propositions), differing mental models about the mechanics of a particular problem situation (i.e. spatial and temporal boundary-setting, elements involved and what their interconnections are), and 
conflicts that can arise amongst different groups of people over what constitutes legitimate knowledge and who holds power in assessing knowledge. Soft systems approaches can help to work through these mercurial issues.

It is important to note that many of the soft systems approaches, and discussions about them, revolve around Burrell and Morgan's (1979) classic notion of social reality being viewed through four dominant paradigms: functionalist, interpretive, radical humanist, and radical structuralist. The functionalist paradigm is objective and rooted in positivism. It places importance on equilibrium and stability and seeks to provide rational explanations, bringing about change through social engineering. The interpretive paradigm is subjective and seeks explanations on the basis of individual consciousness and subjectivity through a participant - rather than observer - frame of reference. Radical humanism is also subjective in nature but it views consciousness as dominated by ideological structures that limit human fulfillment. It sees social efforts as continually struggling to be freed from such structures in an attempt to reach full potential. And finally, radical structuralism, which the authors label as objective in nature, views society as being characterized by fundamental conflicts that generate radical change, which brings about emancipation.

For each approach below, I 1) introduce its creator(s) along with the impetus for its development, 2) identify in bullet format its key philosophical underpinnings, core ideas, and broad applications, 3) provide an overview of it, and 4) discuss critiques, both my own and those of others. Italicized items in the philosophy bullets represent areas of Churchman's philosophy that I contend the approach resonates with. 


\section{$\underline{\text { Soft Systems Methodology }}$}

Soft Systems Methodology (SSM), the first of the system programme’s soft approaches, was developed by Peter Checkland in the 1980s at Lancaster University (Jackson 2003). SSM was developed in response to the functionalist limitations of OR in dealing with multiple worldviews in wicked problem situations and as a methodology to conduct scientific research in the social sphere (Checkland and Poulter 2010, Jackson 2003). Its original impetus came from a SE framework developed by Bell Telephone Company (Checkland and Poulter 2010).

- Underpinning theory/philosophy:

- Burrell and Morgan’s interpretive paradigm (Jackson 2003)

- $\quad$ Core idea(s):

- Concept of an organization as navigating values, norms, roles, and relationships as opposed to rational decision-making (Jackson 2003)

○ The systems idea of an adaptive whole - a system that survives by adapting to its changing environment (Checkland and Poulter 2010)

- Iterative, group learning - we must collectively learn our way to improvements in a never-ending process

- Broad application(s):

○ Problem formulation, identifying interventions and their implications

Originally seven phases (Jackson 2003), SSM now has four phases that involve active participation by all members in a continuously iterative group learning process (Checkland and Poulter 2010). The phases are not designed to be followed systematically, per se, but 
wherever the action research requires it, proceeding on as part of a learning cycle (Flood 1999).

\section{Find out about the problem situation.}

In the first step, participants elucidate their perspectives on what the problematical aspects of the situation are. Two initial prompts can be used (Checkland and Poulter 2010):

- What resources are deployed in what operational processes under what planning procedures within what structures, in what environments and wider systems, by whom?

- How is resource deployment monitored and controlled?

Participant input is synthesized in the form of rich pictures - actual pictorial drawings, ranging from formal to cartoon-like (Checkland and Poulter 2010, Jackson 2003). The idea is that a picture, showing how different aspects are interrelated, is more rich and illuminating than linear prose.

Three analyses are performed in the first phase after the generation of rich pictures (Checkland and Poulter 2010):

- Analysis One: Intervention. The client, practitioner, and owners are identified. The client is the person or group of people who initiated the intervention; the practitioner is the person or group of people conducting the SSM investigation; and the owners are those who are concerned about or affected by the situation and the outcome of the intervention.

- Analysis Two: Social. Works through the values, norms, and roles related to the problem situation. Values are the standards by which behavior is judged; norms 
are expected behaviors of each role; and a role is a social position that differentiates members in a group. All three will likely be represented dynamically with feedbacks.

- Analysis Three: Political. Seeks to elucidate the political climate in which the problem is situated. It asks what the "commodities" of power are and how they are obtained, used, protected, defended, passed on, and relinquished.

All analyses can be incorporated into the rich picture and/or stored in their own individual file documents, which should be updated continuously as new information comes to light.

\section{Generate "purposeful activity models" that represent multiple declared}

worldviews (Checkland and Poulter 2010, Jackson 2003).

a) Develop a Root Definition (RD) to describe each model. The idea is to generate a rich description getting at the "what," "how," and "why" in such a way as to generate meaningful conversation about the model's outcome. RDs must specify whether they are Primary Task - keeping within organizational boundaries or officially declared tasks - or Issue-Based - matters of concern that cross organizational boundaries. Creating a RD can be aided by two processes:

- The PQR Formula, which means doing P, by Q, to help achieve R

- The CATWOE mnemonic:

$$
\begin{aligned}
& \text { C - customers (those affected by transforming process) } \\
& \text { A - actors (who would do the transforming activities) } \\
& \text { T - transforming process } \\
& \text { W - worldview that leads to } \mathrm{T}
\end{aligned}
$$




$$
\begin{aligned}
& \text { O - owners (who could stop T) } \\
& \text { E - environmental constraints }
\end{aligned}
$$

b) Develop the model by writing down the minimum number of activities necessary to carry out the RD's transformation (Checkland and Poulter 2010, Jackson 2003).

There should be around seven activities, captured as verb statements, whose interrelations are shown. Activities are typically grouped into "operations" and "monitoring and control" categories. Monitoring and control depends upon defining " $3 \mathrm{E}$ " criteria to tell whether the transformation is efficacious (produced the intended outcome), efficient (minimum use of resources), and effective (achieving higher-level, longer-term aim).

3. Use the models to ask questions about the problem situation and how it can be changed, with an eye towards both desirability and feasibility (Checkland and Poulter 2010, Jackson 2003).

This dialogue can take place in a number of ways. There can be an informal discussion, with the models in plain sight, about how to improve the problem. A more formal discussion using a synthesized matrix of the models is often used. Or, a model scenario can be juxtaposed against a similar situation in the real world that has already happened or is happening.

4. Define the action that will be taken to improve the situation (Checkland and Poulter 2010).

SSM stresses accommodation rather than consensus. It recognizes that consensus rarely happens and that what is more likely is agreeing upon an intervention to 
improve the situation that all participants can live with. During the discussion, it should be kept in mind that change can take place in structure, process, and/or attitude.

SSM emphasizes that it doesn't seek solutions, but rather establishes a continuous process of group learning to improve situations (Checkland and Poulter 2010, Jackson 2003).

While SSM is considered to be well developed (Checkland and Poulter 2010) and remains the most widely used soft systems approach (Mingers and White 2010), it does have criticisms. Along a procedural line, SSM does not specify how participants are to be selected or how many should be involved. Similarly, some critics say it has a limited range of applicability - that it works well in pluralist situations where there is a need to create a shared mental model but that it doesn't apply well to problems of organizational design or where coercion is involved (Jackson 2003). Many other critiques revolve around the theoretical underpinnings of SSM, namely debates about which of Burrell and Morgan's paradigms it most closely aligns with. SSM has been labeled functional, interpretive, and partially radical humanist (Houghton and Ledington 2002, Jackson 2003, Mingers 2004), though Houghton and Ledington (2002) claim that most of the labels are empirically unsubstantiated. Those of a functionalist orientation see it as too subjective to provide insights into the design of systems, while those of an emancipatory persuasion view it as ineffective in coercive situations where securing inclusive discourse is necessary (Flood 1999, Jackson 2003). While a methodology and its techniques ought to align with its purported philosophical foundations, associations with Burrell and Morgan's paradigms are certainly not the beginning and end of the discussions over the merits of that methodology. The debate will surely continue - and hopefully expand - but so likely will the popularity of SSM. 


\section{Interactive Planning}

Interactive Planning (IP) was formulated by Russell Ackoff in the 1980s primarily at the University of Pennsylvania (Ackoff 1999, Jackson 2003). Like other originators of soft system approaches, Ackoff studied under, and was profoundly influenced, by C. West Churchman (Ackoff 1999, Jackson 2003). A reaction against the mathematically oriented models of OR, IP was specifically designed to help with the "messy" situations Ackoff so famously coined (Ackoff 1991, Jackson 2003) - complex systems of strongly interacting problems that are based on how parts interact, juxtaposed against separable problems that can be explained by the parts themselves (Ackoff 1991). As its name implies, IP starts by establishing an ideal system state, then works backwards to get there by identifying gaps between the ideal state and the current state.

- Underpinning philosophy:

○ Churchman's holistic systems thinking (Jackson 2003)

- Comprehensive (multiple perspectives) and critical rationality

- Pragmatism

- Ethics

- Dialectics

- $\quad$ Core idea(s):

○ Objectivity must be value-laden and derived from many worldviews

- Broad application(s):

○ Problem formulation, identifying ideal end systems and how to get there 
Ackoffs process of planning is interactive as opposed to reactive (tactical, bottomup, and piecemeal) or preactive (strategic, top-down, and based on prediction) (Ackoff 2001, Jackson 2003). Ackoff believed there is no such thing as value-free objectivity and that wide participation is needed in planning situations (Jackson 2003).

IP is based on four principles, five phases, and four types of organizational models. The four principles are:

- Participation of all possible stakeholders. Professional planners should merely be facilitators in helping citizens to plan for themselves (Jackson 2003).

- Continuity in the face of constantly changing values and events (Jackson 2003).

- Holism. Planning should be based on the interdependence of parts across levels (Jackson 2003).

- Consensus. Ackoff (1999) claims that IP tends to generate consensus because it focuses on values rather than the means used to pursue them.

IP's five primary phases are:

\section{Formulating the mess.}

In the first phase, participants identify what isn't working, or how the organization would destroy itself if kept on the same path (Ackoff 2001). This is done through four steps.

a) Systems analysis. A detailed description of how the system currently operates (Ackoff 2001), including what it does, who its stakeholders are, and how it relates to its environment (Jackson 2003). This entails four descriptions, all of which except the first can be narrative in form (Ackoff 1999): 
i. Using a flow chart, describe what the organization does, including the flow of orders, information, and finances.

ii. Describe the organization's culture, i.e. its behavior and practices, both stated and actual.

iii. Describe the organization's conflicts, both internal and external.

iv. Describe trends, both internal and external, that could affect the organization's performance. In addition to a practitioner, a group of young professionals who haven't been with the organization for very long should do the bulk of this work, as they are less inhibited and more sensitive to the difference between what is stated and what is actually done in practice.

b) Obstruction analysis. Identifies obstacles to development (Ackoff 2001, Jackson 2003).

c) Reference projections. Futuring based on the organization's current state and current environment (Ackoff 1999, Ackoff 2001, Jackson 2003).

d) Reference scenario. A description of how the system would destroy itself given the above assumptions (Ackoff 1999, Ackoff 2001).

\section{Ends planning.}

This phase involves formulating what the participants would like the system to be like (Ackoff 2001) by identifying ideals, objectives, and goals (Ackoff 1999, Jackson 2003). This is done through five steps (Ackoff 1999, Jackson 2003).

a) Formulation of a mission statement.

b) Specification - identifying desired properties of the system. 
c) Design - creating an idealized design of the organization showing how the specified properties will be realized across all areas of the organization. Two types of design must considered: bounded and unbounded. Bounded design assumes no changes in the environment while unbounded does. Most organizations can realize significant change without environmental changes.

Also, three constraints must be imposed on the design - they must be technologically feasible, operationally viable, and capable of continuous improvement.

d) Identification of the closest attainable approximation to the idealized design.

e) Identification of gaps between the ideal and approximation.

\section{Means planning.}

This phase is about how to close the gaps in order to get to the closest approximation of the ideal design (Ackoff 1999, Jackson 2003). Ackoff (1999) says there are two ways to decide upon the means: dialectical and countermeasures. A dialectical approach (employing thesis and antithesis) hears arguments from two different points of view, then accepts one fully or a position that combines elements of both. Through the use of countermeasures, decisions are made sequentially, each one a response to an action by a competitor (Ackoff 1999). Gaps can be closed by adding, eliminating, or changing parts of an organization, and changes can be made through acts/behavior, policies, procedures, practices, processes, projects, programs, incentives, inducing cooperation, and reducing conflict (Ackoff 1999).

\section{Resource planning.}


This phase tackles what is needed to get to the closest idealized approximation.

Five types of resources ought to be considered (Ackoff 1999, Jackson 2003):

- Money

- Capital goods (buildings, equipment)

- People

- Consumables (materials, supplies)

- Information

Three questions should be asked for each:

- How much will be required, where, and when?

- How much will be available at the required time and place?

- How should each shortage or excess be treated?

\section{Implementation and control.}

The final phase is about doing and learning. It focuses on the what, when, where, and how (Jackson 2003).

Four models of organizations can help with the IP process:

- Democratic hierarchy (Ackoff 1999, Jackson 2003). Focuses on the interactions amongst parts rather than the parts themselves through the development of a "board." The board shows the relationships between a manager, their supervisor, their subordinates, and their external stakeholders, which can in turn help to plan the unit, the unit's policies, coordination, integration, performance improvement, and quality of work life.

- Learning and adaptation support systems (Ackoff 1999, Jackson 2003). Shows feedbacks amongst threats, opportunities, and problems; decision-making; 
implementation; control; and information exchange in order to generate doubleloop learning.

- Internal market economy (Ackoff 1999, Jackson 2003). Takes the view that every unit in an organization must be a profit center.

- Multidimensional organizational structure (Jackson 2003). Takes the view that developing functional, production, and market-oriented units at every level can save time and effort since organizational restructurings often involve shifting from one type to another.

IP has been applied to hundreds of problem situations (Haftor 2011, Jackson 2003) and appears frequently in the soft systems literature, but it does present weaknesses. The various steps that comprise the five phases can be cumbersome and ill-defined. In the first phase, it is unclear how to go about doing the last three analyses, as well as how the reference projection differs from the reference scenario. In the unbounded design of phase two, Ackoff does not discuss to what extent changes in the environmental conditions should be considered (i.e. how realistic they must be). In phase three, who conducts the dialectical process and makes the countermeasure decisions? At what point in the IP process do the four models of organizations come into play? As with SSM, IP does not explain how participants are to be selected. And finally, IP's focus on consensus can ignore the inherent conflict that underpins many social situations as well as the emancipatory mechanisms available to reconcile that conflict (Flood 1999, Jackson 2003).

\section{$\underline{\text { Strategic Assumption Surfacing and Testing }}$}

Developed initially by Richard Mason and Ian Mitroff in the 1980s and then later by Mitroff, Mason, Ralph Kilmann, and Vincent Barabba, Strategic Assumption Surfacing and 
Testing (SAST) was designed to surface the underlying assumptions of a problem and productively work through them (Barabba and Mason 2014, Jackson 2003). It takes the stance that good problem formulation can be of greater of importance than problem solving itself (Jackson 2003), since solving the wrong problem is of no good.

- Underpinning philosophy:

○ Burrell and Morgan's interpretive paradigm (Jackson 2003)

○ Churchman's holistic systems thinking (Jackson 2003)

- Comprehensive (multiple perspectives) and critical rationality

- Pragmatism

- Ethics

- Dialectics

- Core idea(s):

○ Surfacing and productively working through assumptions

- Application(s):

○ Problem formulation

SAST is based on four principles (Barabba and Mitroff 2014, Jackson 2003):

- Participation. Different stakeholders, from within and outside of an organization, should be involved in wicked problems since the relevant knowledge and resources are distributed amongst a group.

- Adversariness. The best way to test the validity of an assumption is to consider the strongest case against it. 
- Integration. Different perspectives must be synthesized to create a unified set of assumptions that can guide action.

- Support. Exposure to different assumptions underpinning wicked problems provides deep insight for moving forward.

Originally designed with four phases (Jackson 2003), SAST has now developed into five (Barabba and Mitroff 2014):

\section{Group formation.}

Groups of six to eight people are formed using one key person from each functional area of an organization (e.g. finance, marketing, operations, HR, etc.). Groups should be composed of individuals who get along well together (to minimize conflict) but who have different perspectives and areas of knowledge (to maximize differences).

\section{Assumption surfacing.}

Each group identifies and writes down the key assumptions of its members. A technique called Stakeholder Analysis can help with this. Here, the group identifies key stakeholders upon whom the success or failure of a preferred strategy would depend. Then, two or three assumptions about each stakeholder are surfaced.

\section{Intra-group debate.}

a. Each group eliminates irrelevant assumptions by asking whether the opposite of the assumption has any bearing on the issue. Those assumptions to which the answer is "no" are dismissed. 
b. Each group then ranks the remaining relevant assumptions by their importance and certainty using a four-quadrant chart:

- Assumptions that are both important and certain are rated the highest.

- Assumptions that are important but uncertain need to be researched.

- Assumptions in the other two quadrants - certain but unimportant and uncertain and unimportant - should be dropped (or researched, if time allows).

\section{Inter-group debate.}

A spokesperson for each group presents their assumptions in the four-quadrant graph, focusing on those that were retained. All retained assumptions are then combined into a single list and opened up to debate. A series of prompting questions can be used:

- How are group assumptions different?

- Which stakeholders feature most prominently in each assumption?

- Do groups rate assumptions differently?

- Which assumptions does each group find the most troubling?

\section{Synthesis.}

a. If agreement on a set of assumptions is not reached, then further investigation is undertaken. If agreement is reached, the set of assumptions is used as a basis for how to proceed forward. 
b. A Planning Book is produced with a prioritized list of critical issues to which SAST can be applied in the future. For each critical issue, it should be stated what the current state of knowledge related to the issue is and what can be done to improve that knowledge.

SAST is considered to be a successful methodology (Jackson 2003) that has been applied to a wide range of organizations and problem types, including large corporations, public health agencies, and most recently the Census Bureau (Barabba and Mitroff 2014). Unlike SSM and IP, it offers a simple, straightforward process. Its main critique, however, is that deals narrowly with problem formulation at the exclusion of how to improve the problem (Jackson 2003). It leaves us with a set of assumptions but does not specify what to do with them.

\section{$\underline{\text { Strategic Options Development and Analysis }}$}

Strategic Options Development and Analysis (SODA) was developed initially in the 1980s by Colin Eden, S. Jones, and D. Sims, then later by Eden and Fran Ackermann at the University of Strathclyde in Glasgow (Ackermann and Eden 2010). It is a subjective approach that collectively explores messy problems using cognitive mapping, specifically Decision Explorer software (Ackermann and Eden 2001, Ackermann and Eden 2010). The idea is to surface and integrate multiple individual perspectives into one shared mental model of the problem situation which the group has ownership of, thereby increasing their sense of commitment to the agreed-upon actions that will be implemented to improve the situation (Ackermann and Eden 2001, Ackermann and Eden 2010). SODA tries to approach consensus as much as possible (Ackermann and Eden 2001). Its success is measured not by 
identifying a rationally optimal solution, but by the degree to which participants feel confident that the action they will take is right (Ackermann and Eden 2001).

SODA is designed to be facilitated by a consultant who uses cognitive mapping as a negotiation tool (Ackermann and Eden 2001). The consultant must be willing to view the participants, rather than the organization, as the client (Ackermann and Eden 2001). SODA is typically used with groups but can also be applied at an individual level to explore management options (Ackermann and Eden 2010).

As SODA has evolved, so has its name. Ackermann and Eden see it being referred to as SODA when it is used in service of messy problems but as JOURNEY Making, which stands for Jointly Understanding, Reflecting, and Negotiating Strategy (Ackermann and Eden 2001), when used in a strategic development context (Eden 2016).

- Underpinning philosophy:

○ Personal construct theory (from cognitive psychology)

Organizations as changing sets of coalitions based on politics and power

- $\quad$ Core idea(s):

- Aggregating individual mental models into one shared collective mental model that is used to identify options for strategic improvement

- Broad application(s):

○ Problem formulation, identifying interventions, developing strategies, facilitating negotiations within and across organizations 
SODA is based on two primary theoretical constructs, one at the individual level and one at the organizational level (Ackermann and Eden 2001, Ackermann and Eden 2010). George Kelly's personal construct theory from cognitive psychology sees individuals as problem solvers who are continually trying to make sense of the world so they can better manage and control it (Ackermann and Eden 2001). This allows individuality to blossom, and it sees problems as constructed rather than as something "out there" that must be grasped at (Ackermann and Eden 2001). SODA takes a view of organizations as consisting of groups of individuals who bring different perspectives, which inherently results in sets of coalitions brought about by political and power struggles. Thus, organizations don't engage in rational decision-making, but instead they negotiate constantly shifting coalitions based on different perspectives (Ackermann and Eden 2001, Ackermann and Eden 2010). Cognitive mapping is an integral part of SODA. It is a subjective pictorial representation of a mental model that includes nodes and relationships between them. As discussed with SSM, graphical representations of mental models have many advantages over linear prose (Ackermann and Eden 2010). SODA's preferred cognitive mapping tool is Decision Explorer, created specifically for SODA. It is a formal mapping technique, therefore it has rules, conventions, and formal modes of analysis (Ackermann and Eden 2001). Even though Decision Explorer is a useful tool, it doesn't have to be used in situations where time constraints prohibit its use or where it doesn't match the style of a group (Ackermann and Eden 2001).

There are some basic guidelines for generating a cognitive map (more specific guidelines can be found in the SODA source material). Essentially, it contains statements that are linked by unidirectional arrows to show causality (Ackermann and Eden 2001, 
Ackermann and Eden 2010). Statements should be short (around six to eight words), actionoriented, and include a verb (Ackermann and Eden 2010). Whenever possible, statements should contain a contrasting idea linked by "rather than" (Ackermann and Eden 2001, Ackermann and Eden 2010). A “-“" sign should be used to denote when the first phrase of a statement is linked to the second phrase of another statement (Ackermann and Eden 2001, Ackermann and Eden 2010). Arrows can be read as "leads to," for example "the ability to attract top talent leads to increased competitive advantage” (Ackermann and Eden 2010). Statements are numbered for ease of reference and to make far-away connections easier (Ackermann and Eden 2010). Similar statements are grouped into clusters (Ackermann and Eden 2010). Cognitive maps can be generated by starting with goals at the top and working down to options at the bottom, or vice versa (Ackermann and Eden 2001). There are three main hierarchical aspects of a cognitive map: goals, key issues, and supporting assertions, or options (Ackermann and Eden 2010).

There are three primary ways to apply the SODA process (Ackermann and Eden 2010):

- The facilitator either conducts individual interviews or analyzes documents, from which he/she generates individual cognitive maps using Decision Explorer. The facilitator then aggregates the individual maps into a collective cognitive map in Decision Explorer, which he/she presents to the group for further clarification and analysis using the software. This is the preferred method so as to avoid group think (Ackermann and Eden 2001).

- The facilitator leads the group in generating a collective cognitive map using the Oval Mapping technique, essentially a manual version of cognitive mapping 
using paper on a board. The facilitator then leads the group through manual map refinement and analysis, which entails:

○ Identifying "busy" statements (with many arrows going in and out) and looking for assertions/options that link to many clusters

○ Checking clusters for possible goals and key issues

- Identifying feedback loops

- The facilitator leads the group in generating a collective cognitive map using Decision Explorer, with the facilitator entering participants' input directly into the software. The facilitator then leads the group through map refinement and analysis using the software.

When aggregating individual cognitive maps into one strategic map, it is important to retain the individual's own language and problem orientation (e.g. whether they pose a problem in a positive or negative light) and include a balanced representation of everyone's input (Ackermann and Eden 2001). Clearly, the aggregation process involves subjective judgment on the part of the consultant (Ackermann and Eden 2001).

There are four ways to analyze the finalized cognitive maps (Ackermann and Eden 2010):

- Domain analysis. Manually (i.e. without the use of the software) calculate the number of links in and out of each statement. Statements with the most number of links are candidates for key issues.

- Central analysis. Uses Decision Explorer to examine statements and their linkages as molecules, with statements showing the most "centrality" being candidates for 
key issues. This provides a more accurate assessment than domain analysis. It can be augmented by two additional software-based analyses:

- Cluster analysis. Uses an algorithm to identify clusters of themes, which can potentially contain key issues.

- Hierarchical set analysis. Takes potential key issues and maps out their supporting statements (generating chains of arguments).

SODA has been applied extensively to organizations of all types and sizes, including different levels within organizations (Ackermann and Eden 2010), and can be used in conjunction with other approaches and models, such as SSM (Georgiou 2012) and system dynamics (Ackermann and Eden 2010). Its main drawback is that it doesn't seem to deal critically with the various perspectives it surfaces; it focuses on allowing individuality to blossom at the expense of critically examining the legitimacy and implications of those perspectives. Finally, it should be noted that, while Eden and Ackermann typically view SODA/JOURNEY as falling within “soft OR” (Jackson 2016, Reynolds 2016), they are also comfortable with it being called a systems approach, which it certainly is based on the rubric used for this framework.

\section{Critical Systems Thinking}

Critical Systems Thinking (CST) concerns the critical application of systems thinking in professional practice. As with the other soft approaches, it was born in response to increasing criticisms that OR was unable to deal with the human and social aspects of the vast major of problem situations in which goals and objectives are not readily apparent and optimization is not possible (Jackson 2003, Jackson 2010). CST has evolved to have two primary strands: Critical Systems Heuristics (CSH) and Total Systems Intervention (TSI) 
(Ulrich 2003), now also developed into a modified version called Critical Systems Practice (CSP) (Jackson 2010). The difference between the two derives primarily from each strand's employment and interpretation of "critical."

\section{Critical Systems Heuristics}

Critical Systems Heuristics (CSH) is a discursive framework for promoting critical reflective and emancipatory - practice (Ulrich 2003). It was developed by Werner Ulrich, who studied under and was deeply influenced by Churchman and renowned philosopher Jurgen Habermas at Berkeley in the 1970s. Ulrich returned to his native Switzerland and spent the remainder of his career developing CSH primarily at the University of Fribourg. $\mathrm{CSH}$ aims to surface the perceived facts and values that comprise a problem situation, which in turn shapes the situation's system boundaries. The dynamic interplay between the facts, values, and system, as well as the ethical implications of that interplay, are then critically examined.

- Underpinning philosophy:

o Kant's two-dimensional normative-instrumental rationality

○ Practical philosophy

- American pragmatism

- Habermas' critical social theory, which relies on discourse theory to work through value conflicts

○ Churchman's holistic systems thinking

- Comprehensive (multiple perspectives) and critical rationality

- Pragmatism

- Ethics 


\section{- Dialectics}

- Core idea(s):

- Boundary critique, emancipation, and deep complementarism

- Broad application(s):

- Stakeholder identification, problem formulation, identifying and evaluating interventions, surfacing ethical implications

CSH is a move towards critical holism (Ulrich 1993). Ulrich contends that calling for systems thinking is good, but not enough. The deeper problem is how to reconcile the concept of rationality. Simply expanding the boundaries of problem situations doesn't make any clearer what is rational or right (Ulrich 1993). Of the two dimensions to reason - the instrumental (or utilitarian) concept and the ethical (or normative) concept - Ulrich believes there is a deficit of the normative concept not only in our awareness, but also in methodology. CSH is an attempt to incorporate the normative aspect of reason into methodology by finding a "third way" between the two classic approaches to methodology and epistemology (Ulrich 1993). The analytical/realist approach espoused by Popper declares normative reason to be impossible (in effect reducing it to instrumental reason), while the dialectical/idealist approach espoused by Habermas insists that normative reason is indeed possible, but the conception is so ideal that it is not operationalizable (Ulrich 1993). CSH attempts to make practical reason operationalizable by grounding methodology in rational argumentation (Ulrich 1993).

Boundary critique is the core idea behind CSH that allows for rational argumentation (Ulrich 2002). Boundary critique is a systematic unfolding of all relevant stakeholders' boundary judgments about the empirical (factual) and normative (ethical) aspects of a 
problem situation, which serve to circumscribe the boundaries of the reference system in question (Ulrich 2002, Ulrich 2003). Ulrich talks about the "eternal triangle" of "systemic triangulation": system boundaries, facts, and values are highly interrelated, with a change in one requiring us to reevaluate how the other two might change (Ulrich 2002, Ulrich 2003). Boundary critique is done through 12 questions which get at the four dimensions of problem situations (Ulrich 1996, Ulrich 2002, Ulrich and Reynolds 2010):

- Sources of motivation/values

- Sources of power

- Sources of knowledge

- Sources of morality/legitimacy

The questions are asked in both "ought" and "is" modes, after which a critique is performed of the two sets of responses. The idea is to initially establish an ideal situation and then compare the actual against the ideal (Ulrich 2002).

An important aspect of $\mathrm{CSH}$ is that it attempts revive the concept of civil society by reframing the basis of knowledge. It offers the philosophical and methodological basis for everyday citizens to engage competently with the "experts" who are typically the sole drivers of social planning.

The versatility and range of CSH's applicability is wide. It can be used to inform the approaches used in an intervention or to evaluate an intervention (Ulrich and Reynolds 2010). It can be used to surface underpinning boundary judgments, collectively question boundary judgments with respect to practical and ethical implications, and/or emancipatorily challenge unqualified claims to knowledge and rationality (Ulrich 2002). It has been used to identify who the relevant stakeholders are in a problem situation (Achterkamp and Vos 
2007). The "ought" mapping can be performed by the researcher while the "is" mapping can be done through interviews with researcher-identified stakeholders (Ulrich and Reynolds 2010). Possibilities for other types of application abound, as practitioners are encouraged to be creative and flexible with the ways in which they employ CSH.

$\mathrm{CSH}$ is unique in that it systematically surfaces and deals with ethical implications, something no other soft systems approach explicitly does. Even though the motivation and legitimacy dimensions tend to deal with normative content and the control and knowledge dimensions tend to deal with empirical content, the normative-empirical associations can change - becoming dualistic rather than just singular in nature - depending on the modes. The "ought" mode is itself one large normative exercise by asking of every dimension - even the empirical ones - "what should this be?" The "is" mode assumes more of an empirical stance by identifying - even for the normative dimensions - "what is this?" The process of critical discourse, then, engages participants in considering the ethical implications of the two modes as well as the ethical implications of changing the content of the four dimensions. The result is a constant interplay between normative and empirical evaluations. This process deals not only with ethics, but it provides a structured, systematic way to critically examine various perspectives - more so than SSM, IP, and SAST. However, some see it as not enough to surface the values that underpin a problem situation - some critics think it is necessary to understand the material, structural conditions that give rise to particular values (i.e. the "why," not just the "how") (Jackson 2003). Others ask under what circumstances those in power would even bother to consider the perspectives of those who are affected by their decisions (Jackson 2003). These criticisms notwithstanding, I contend that CSH is the most philosophically, systematically, and normatively robust of the soft systems approaches. 


\section{Total Systems Intervention and Critical Systems Practice}

TSI and CSP can be described generally as meta-methodological frameworks for facilitating critical - informed - methodology choice (Flood and Carson 2010, Flood and Jackson 1991, Jackson 2003, Ulrich 2003). TSI emerged from the work of Michael C.

Jackson, P. Keys, and Robert L. Flood at Hull University in the UK in the 1980s (Flood and Carson 2010, Ulrich 2003), which Jackson later modified into CSP.

- Underpinning philosophy:

○ Habermas' theory of human interests (Jackson 2003)

- $\quad$ Core idea(s):

- Methodological pluralism and complementarism

- Broad application(s):

○ Methodology choice selection

TSI has three major components: philosophical underpinning, principles, and phases. TSI is based philosophically on CST (Flood and Jackson 1991), which Flood and Jackson say is embodied by five commitments (originally three): critical awareness, social awareness, methodological pluralism, theoretical pluralism, and emancipation (Flood and Jackson 1991, Jackson 2003). Critical awareness uses theory to evaluate the strengths and weaknesses of approaches. Social awareness looks at the societal circumstances that lead some approaches to be used in certain places at certain times. Methodological pluralism addresses the problem of "paradigm incommensurability," which suggests that different systems approaches cannot be used together because, through their associations with a particular paradigm, their theoretical assumptions are irreconcilable. CST claims to resolve the problem of paradigm incommensurability at the theoretical level by creating a meta-paradigmatic meta- 
methodology that addresses Habermas' theory of human interests. This says that all humans have technical, practical, and emancipatory interests. At the technical level, we seek to achieve goals and bring about material well-being through social labor. Practical interests involve securing and expanding possibilities of mutual understanding amongst all involved in a social system. And through emancipation, we seek to be free of power constraints through genuine, participatory, democratic free speech. Flood and Jackson believe that a metamethodological framework that addresses these interests would be transparadigmatic, hence achieving theoretical and methodological pluralism. Finally, while emancipation is a commitment of CST, it is simultaneously recognized as applying to only a small subset of problem situations - those involving coercion. Thus, its status as a core philosophical underpinning is unclear.

TSI is based on seven principles (Flood and Jackson 1991, Jackson 2003):

- Problem situations are too complicated to understand through one perspective and to tackle with quick fixes

- Problem situations should be explored through a variety of perspectives, which can be simplified through metaphors

- Once the issues of a problem situation have been identified through the use of metaphors, a methodology or methodologies to guide intervention can be selected

- Methodology selection should take the strengths and weaknesses of each methodology into consideration

- Different methodologies can be used in complementary ways

- TSI is a systemic cycle of inquiry 
- Facilitators and stakeholders are engaged at all stages of the TSI process

TSI has three phases (Flood and Carson 2010, Flood and Jackson 1991, Jackson 2003):

1. Creativity. Facilitators and stakeholders identify major issues or areas of concern, exploring all perspectives and employing various system metaphors (e.g. machine, organism, brain, culture, coalition, coercive system) from which dominant and dependent concerns emerge.

2. Choice. A methodology or multiple methodologies are selected to guide intervention based on the dominant and dependent metaphors. System of System Methodologies (SOSM) is the traditional tool for methodology choice selection, but any of TSI's outlined choice selection tools can be used (Jackson 2003). SOSM is a matrix of six possible problem types across a range of two dimensions, complexity (simple to complex) and relationships amongst stakeholders (unitary, pluralist, or coercive) (Flood and Carson 2010, Flood and Jackson 1991).

3. Implementation. After a methodology or methodologies are selected, they are implemented to bring about change, revisiting the previous two phases as the situation changes.

After the development of TSI by Flood and Jackson, Jackson branched off to modify TSI into CSP (Jackson 2003). Jackson places CSP under the umbrella of what he calls creative holism - being creative about the systems ideas we use to intervene in problem 
situations. The seven principles remain the same, but the commitments (philosophical basis) and methodological conceptions have evolved.

CSP's philosophical reliance on CST changes, with CST's commitments dwindling from five to three: critical awareness, pluralism, and improvement (Jackson 2003). Critical awareness absorbs social awareness. Pluralism, which absorbs theoretical and methodological pluralism, no longer claims to be transparadigmatic. Rather, CSP seeks to protect paradigm diversity by clearly identifying which approaches operationalize which paradigms. And finally, improvement replaces emancipation. TSI was criticized for making grand claims about universal emancipation. Now, CSP places emancipation within a broader goal of realizing human potential on more local scales.

As part of the pluralistic commitment, CSP shifts away from SOSM as the tool for whole methodology choice to being a multi-paradigm multi-methodology (Jackson 2003). CSP outlines "generic system methodologies" that are derived from a combination of the four paradigms and existing approaches that are implicitly or explicitly oriented towards each paradigm. Hence, there are four generic system methodologies, corresponding to the four paradigms. Rather than dealing in "whole methodologies," CSP's new framework, in certain places, decomposes the methodologies and uses only parts of them.

TSI/CSP are applaudable for their attempt to provide a prescriptive framework for selecting appropriate methodologies. Their strong reliance, however, on Burrell and Morgan's paradigms - and the notion of paradigm incommensurability - seems problematically ideological. Flood and Jackson begin the development of their framework with the a priori assumption that it must cater specifically and only to the paradigms and that it must overcome the notion of paradigm incommensurability. As stated earlier in addressing 
some of the critiques of SSM, Burrell and Morgan's four paradigms need not exclusively frame our epistemological conceptions, as has been argued by others (Schultz and Hatch 1996). Also, CSP claims to be creatively holistic, but is it really? As a self-described metamethodological framework, its intent is to provide a prescriptive, not a creative, approach for methodology selection. The creativity might lie more in the unique combination of paradigms with decomposed parts of methodologies and the ways in which we play with and land on guiding metaphors. Further, exclusive reliance on the four paradigms can hardly engender creativity - quiet the opposite, it would seem to inhibit it.

\section{Critical Holism}

Ulrich (2003) argues that CSH and TSI/CSP depart primarily in their treatment of complementarism and emancipation, which in turn color each framework's approach to the criticality aspect of CST. Complementarism, in the eyes of CSH, is about the Kantian notion of dealing simultaneously with the complementary empirical-normative dimensions of rationality. Recall that for Ulrich, the ultimate call of systems thinking is to help make clear what is rational, or right, in any given problem situation. If CST is to act in service of rational decision-making, complementarism must exist at the level where we handle reason. By examining the dynamic feedbacks between both the instrumental (factual/empirical) and normative (ethical) aspects of reason (and the boundaries those facts and values shape), Ulrich (2003) contends that CSH offers deep complementarism, as opposed to TSI's shallow complementarism that deals simply and more superficially with the complementary aspects (i.e. contextual strengths and weaknesses) of different approaches. For TSI/CSP, which subscribes to Burrell and Morgan's four paradigms, methodological complementarism means overcoming the notion of paradigm incommensurability, which says that approaches that 
adhere to different paradigms can't be complementary or used together since paradigms fundamentally differ in the way they view "knowing." But who is to say that Burrell and Morgan's four paradigms are the only ones through we can view the world; why must we limit our epistemological conceptions to a set of paradigms at all? Numerous researchers have criticized the notion of paradigm incommensurability on the grounds that paradigms and their borders should be challenged and crossed (Schultz and Hatch 1996).

Ulrich (2003) also challenges the conceptualization of emancipation that is pervasive in much of the CST literature and to which TSI/CSP subscribe. TSI/CSP tends to view emancipation as securing discourse only for certain groups that are perceived as existing in coercive situations, whereas CSH says that emancipation isn't about coercive situations per se but rather explicitly surfacing the sources of selectivity in all of our mental models, whether that selectivity comes from structural asymmetry or simply a lack of critical reflection (Ulrich 2003). Furthermore, if coercive situations are those in which structural conditions create an asymmetry of discursive chances, then coercive situations are the norm rather than the exception (Ulrich 2003)! Ulrich views emancipation as securing the possibility of critical discourse for everyone - every ordinary citizen - to ensure their voices are heard across multiple scales of discourse - from ideal speech situations to total closure of debate in a civil society. TSI/CSP are unclear on the issue of emancipation. While it is one of the commitments TSI/CSP aim to serve, it is simultaneously - and contradictorily - viewed as representing only a narrow class of problem situations, therefore representing only a subset of CST. 
Thus, CSH views the "critical" aspect of CST as being critically reflective about factvalue-system judgments and sources of selectivity, whereas TSI/SCP view it as critically examining and selecting systems thinking approaches. 


\section{Chapter 6}

A Systems Thinking Framework: Hard Approaches

"Our most important statements about the likelihood of collapse do not come from blind faith in the curves generated by World3. They result simply from understanding the dynamic patterns of behavior that are produced by three obvious, persistent, and common features of the global system: erodible limits, incessant pursuit of growth, and delays in society's responses to approaching limits." - Donella Meadows, Jorgen

Randers, and Dennis Meadows in Limits to Growth: The 30-Year Update

Recalling that distinctions between soft and hard systems approaches can be a

helpful starting point for understanding major differences between the many "tools in the systems thinking toolbox," but that discussions about these distinctions can be distracting from ultimately understanding what all the tools are and how they can be applied creatively and critically, let us begin with a brief review of how I separate the soft and hard approaches.

Soft Systems Approaches (Analytical Strand):

- Soft Systems Methodology

- Interactive Planning

- Strategic Assumption Surfacing and Testing

- Strategic Options Development and Analysis

- Critical Systems Thinking

○ Critical Systems Heuristics

- Total Systems Intervention and Critical Systems Practice

Hard Systems Approaches (Computational Strand):

- Viable System Model

- System Dynamics

- Causal Loop Diagrams

- Agent-Based Modeling 
- Artificial Intelligence Models

\section{Hard Systems Approaches}

After the work of wicked problem formulation has been done (which, again, may or may not involve using one of the soft systems approaches), hard systems approaches can be useful tools for exploring the dynamics of complex systems. They allow us to explore system design, structure, behavior, and intervention consequences through the use of modeling methods that tend to seek mathematical exactness. In some cases (system dynamics, agentbased modeling, and artificial intelligence), moderate to advanced computer literacy, including coding capability, is required. As mentioned previously, both soft and hard systems approaches can be used together.

\section{$\underline{\text { Viable System Model }}$}

There are differing opinions on whether the Viable Systems Model (VSM) falls under hard or soft systems thinking. Some place it in the hard systems category because of its functional relationship to cybernetics, while others see it as falling within an interpretive paradigm (Hoverstadt 2010, Preece et al. 2013). Though VSM does not use computer modeling or rely on mathematically defined relationships, I place it in the hard category of this framework for the primary reason that its purpose is to design a system irrespective of problem formulation (why are we examining the design of the system in the first place?, what are we trying to achieve?, who should be involved?, how do their perspectives on the nature of the problem differ?, and how should those differences be addressed?). In other words, VSM jumps straight into problem solving without first formulating the problem or attempting to integrate multiple perspectives or normative content. Moreover, its reliance on cybernetic principles also aligns it with the computational strand of systems thinking. 
VSM was developed by Stafford Beer in the 1970s and 80s in an attempt to apply cybernetic principles to organizational theory and science (Hoverstadt 2010). For Beer, the primary challenge of organizations is to maintain viability, i.e. to adapt in the face of a changing environment (Hoverstadt 2010). Cybernetics, which deals with control and communication, seemed to offer a well-suited set of principles to reconcile such a challenge since, after all, organizations are ultimately goal-seeking, adaptive entities (Jackson 2003). VSM is, at its core, a graphical representation of a system showing the relationships between five sub-systems and the system's environment (Hoverstadt 2010, Jackson 2003). It seeks to create models of systems that allow us to better manage them through negative feedback and the engineering of variety (Jackson 2003).

VSM is based on three foundational ideas. The first is Ashby's concept of requisite variety, also known as the Conant-Ashby theorem, which states that "every good regulator of a system must be a good model of that system," i.e. the ability to manage a system depends on how accurate the regulator's model of the system is (Hoverstadt 2010, Jackson 2003). Put another way, variety must matched. Organizations/systems must have a level of complexity that aligns with their external environment as well as their internal management. Requisite variety can be seen abstractly as defining the edge of chaos; VSM shows how a system walks that fine line (Hoverstadt 2010). Second, VSM is centered around two critical tensions: the tension between autonomy of parts and the cohesion of the whole, and the tension between current status quo and future planning (Hoverstadt 2010). The first tension is often discussed in the VSM literature in the form of centralization versus decentralization, or hierarchy versus anarchy (Hoverstadt 2010, Jackson 2003). Organizations typically assume that they must pick one, but Beer believes this is a false dichotomy and that VSM 
demonstrates how to achieve viability through a balance of the two (Hoverstadt 2010). The second tension is what, in Beer's experience, often leads organizations to fail since they tend to focus almost exclusively on maintaining the status quo at the expense of planning and adaptation. Finally, VSM relies heavily on the notion of recursion, (Hoverstadt 2010, Jackson 2003), or hierarchically embedded systems in which sub-systems mirror the organization of the systems in which they are embedded, which draws from the notion of a fractal patterns in hierarchy theory. There are four levels of recursion in VSM: Level 0, the environment; Level 1, the system of interest; Level 2, primary activities; and Level 3, sub-activities (Jackson 2003).

Let us now consider the five systems, keeping in mind that Systems 1 through 3 are called "autonomic management" since they can maintain internal performance without Systems 4 or 5 (Jackson 2003).

System 1: Operations deals with the primary activities or tasks of the organization that deliver value to its customers (Flood 1999, Hoverstadt 2010). Operations must be allowed maximum possible autonomy while still serving the functional integrity of the system (Jackson 2003, Flood 1999). Through a process of “unfolding complexity," primary activities are broken into sub-activities and structured based on four "drivers of complexity": technology, geography, customers, and time (Hoverstadt 2010). Changing the order in which activity complexities are unfolded and structured must be experimented with and can impact the organization's viability (Hoverstadt 2010).

System 2: Coordination is the harmonious coordination amongst operational activities so as to reduce conflict (Hoverstadt 2010, Flood 1999). The need for coordination increases with the number of operational activities, the degree to which they are 
interdependent, and the degree to which they affect the same parts of the environment (Hoverstadt 2010). Symptoms indicating a lack of coordination include oscillations in performance, continual low-level chaos, recurring operational problems, and inter-activity turf wars (Hoversadt 2010). Coordination entails restricting unnecessary complexity that can destabilize operations while retaining genuine differences in organizational activities (Hoverstadt 2010). It can be achieved through mechanisms such as protocols, rules and regulations, legal requirements, common standards and language, scheduling, and mutual adjustment (Hoverstadt 2010, Jackson 2003). A lack of coordination is one of the most common problems in organizations. We tend to praise problem solving but neglect the prevention of problems through better coordination (Hoverstadt 2010).

System 3: Resource Allocation and Performance Management is self-explanatory. Whereas traditional resource management doggedly adheres to annual budget cycles (which can dominate much of managers' time and lead to dysfunctional behavior), VSM espouses a more flexible approach that judiciously balances freedom and constraint - it gives autonomy to managers within agreed upon limits, allowing for flexibility in the face of changing circumstances (Hoverstadt 2010). Likewise, VSM takes an untraditional approach to performance management. It links resource decisions to performance measurement, designs performance metrics that are specific to operational activities, seeks to attribute the right measures to the right processes and activities, and judiciously incorporates monitoring (qualitative and unplanned) so as not to burden staff with over-reporting (Hoverstadt 2010). In System 4: Planning and Development, internal and external information is captured to ensure the organization maintains a good fit with its environment (Flood 1999, Hoverstadt 2010, Jackson 2003). Information can take the form of strengths, weaknesses, 
opportunities, and threats (typically referred to as SWOT analysis) (Flood 1999). Common symptoms of organizations not matching their environments are creating new products without a market for them, failing to adapt to changing markets and technology, and persisting with outdated products and processes (Hoverstadt 2010). As far as managing change, VSM takes a "mosaic" rather than traditional homogenous approach. Since all parts of an organization are different, change is broken into discrete "packets" that are sequentially initiated based on resource availability and where change is most practicable and worthwhile. Hoverstadt (2010) cites the statistic that $80 \%$ of change projects fail. In the area of strategy development, VSM takes a dynamic approach rather than a conventional one in which vision and mission drive core competencies and product/service offerings. VSM views strategy and organizational structure as mutually affecting each other rather than strategy merely dictating structure (Hoverstadt 2010). This is because, oftentimes, we are only open to hearing, seeing, and considering what is already right in front of us - that which the current structure presents. As with change management, Hoverstadt (2010) says that $90 \%$ of strategic plans are never implemented. Not surprisingly, the ability to plan for the future and adapt accordingly is one of the most common problems in organizations due to our obsession with internal efficiency (Hoverstadt 2010).

System 5: Identity and Integrated Management is the governance role of the leadership team (Hoverstadt 2010, Jackson 2003). Identity formulation can happen under two circumstances, in two ways (Hoverstadt 2010). If a new system is being created, purpose can be explicated using the formula "a system to do $x$ by means of $y$ for the purpose of $z$ " and the mnemonic TASCOI:

- $\mathrm{T}-$ transformation of the system 
- A - actor carrying out the transformation

- $\mathrm{S}$ - suppliers to the transformation process

- $\mathrm{C}$ - customers in receipt of the transformed product/service

- $\mathrm{O}$ - owners responsible for the transformation

- I - interveners with an interest in the process

If an existing system is being analyzed, "structural coupling" looks at the dynamic interplay between the parts of the organization and the parts of its environment with which it interacts. Crucially, this system also maintains the balance between Resource Allocation and Performance Management (System 3) and Planning and Development (System 4), while also connecting with lower levels and the environment (Hoverstadt 2010). Balance between Systems 3 and 4 is crucial - when one of them is neglected, organizations are prone to fail, which is why good governance is so important (Hoverstadt 2010).

As VSM is not a methodology, there are no prescribed ways for building and analyzing the model. Though, similar to the two processes for formulating identity in System 5, there are two common modes in which it can be used: design and diagnosis (Hoverstadt 2010, Jackson 2003).

Lastly, Beer advocates for using actuality, capability, and potentiality, rather than money, as a three-pronged indicator of achievement (Jackson 2003). Actuality is what we're actually doing now, under existing resources and constraints. Capability is what we could achieve now under existing conditions and constraints. And potentiality is what we could do by feasibly developing resources and removing constraints.

VSM is a powerful tool that has been used extensively across a wide range of problem situations, from biological to social systems (Flood 1999, Hoverstadt 2010). The 
primary criticism of VSM is that it does not question whether the purposes organizations/systems pursue are ones that ought to be pursued (Jackson 2003). As a work around to this, some researchers have coupled VSM with, for example, SSM J Jackson 2003, Preece et al. 2013). Furthermore, VSM seems to view hierarchies in the sense of their colloquial meaning rather than hierarchy theory. Recall that the term "hierarchy" is often associated with its colloquial meaning of top-down control - which is indeed how VSM uses it - at the expense of its other reference to a set of embedded systems, which is ironically what recursion is. With its use of the concept of recursion, VSM can be viewed, to a certain extent, as operationalizing hierarchy theory. But its focus on the negative colloquialism dampens this linkage. Perhaps VSM would benefit from maintaining its focus on the tension between autonomy of parts and the cohesion of the whole and foregoing the hierarchyanarchy analogy.

\section{$\underline{\text { System Dynamics }}$}

System Dynamics (SD) is the computer simulation of a system's behavior using mathematically defined relationships between the system's stocks, flows, and auxiliary variables. Grounded in control theory and the various theories under the "complexity" umbrella (Sterman 2000), SD was developed by Jay Forrester at MIT in the 1950s and was later made popular by the famous Limits to Growth book (Meadows et al. 1972). SD is primarily a push-back against linear, event-oriented thinking, showing how behavior or results are often generated by the complex interrelations and feedbacks within a system that is, its internal structure rather than exogenous forces (Meadows 2008, Morecroft 2010). Most simply described, SD uses stock and flow diagrams, with mathematically defined relationships between all variables, to create a computer simulation of the system. The 
simulation generates a two-dimensional, static representation of the system behavior on an $\mathrm{x}-\mathrm{y}$ axis over the specified time period. SD is a helpful tool to examine dynamic, complex systems in which nonlinear behavior resulting from feedbacks plays an important role.

John D. Sterman's (2000) Business Dynamics: Systems Thinking and Modeling for a Complex World offers an extensive, robust treatment of SD. A SD diagram consists of stocks, flows, and auxiliary variables (variables other than stocks and flows) that are connected by arrows to denote causal influences. Stocks are capital or resources that can accumulate or decline over time (e.g. the population of a species) and are represented by boxes. Flows are variables that flow into or out of the stock (e.g. births and deaths) and are represented by exaggerated arrows with cloud-like bubbles at the end (see Figure 6.1). Auxiliary variables are all other elements of the system. Arrows are typically labeled as “+” or "-," from which reinforcing and balancing feedbacks can be deduced. SD diagrams are read such that, as one variable increases or decreases, it causes the variable(s) it influences to either increase or decrease above or below what it otherwise would have been. Thus, a SD diagram with variable $\mathrm{x}$ connected to variable y with a " + " can be read, "as x increases, y increases (beyond what it otherwise would have been)," or "as x decreases, y decreases (below what it otherwise would have been)," though the last part can be omitted since it is taken for granted. Replaced with a “-," it would read "as x increases, y decreases" or "as x decreases, y increases." This type of cause-effect relationship is more specific than, say, generic flow charts in which arrows simply mean "influences" or "relates to." Care must be taken to ensure that arrows represent causality, not correlation. The famous example is that an increase in ice cream sales during the summer can be correlated with an increase in the murder rate, even though the former isn't actually a cause of the latter. Additionally, any prominent delays should be labelled with 
a "=" across the middle of the arrow. Lastly, arrows should be rounded to give a softer look, and, while not always possible, criss-crossing of arrows should be avoided.

Feedbacks are either reinforcing (positive) or balancing (negative). A reinforcing feedback involves exponential growth or decline, whereas a balancing feedback is the result of a goal or control mechanism to keep runaway growth and decline in balance. Feedbacks are labeled with an " $\mathrm{R}$ " or "B," respectively, with a circular arrow around them aligning with the direction of the arrows in that particular loop. There are two ways to determine whether a feedback loop is reinforcing or balancing. The first is to simply count the number of "-" signs along the loop. If there are an even number, then the feedback is reinforcing; if there are an odd number, it is balancing. The other more reliable way is to work through the logic of the loop to see what the end effect is. It is useful to label feedback loops with phrases to denote the nature of the loop's impact.

Variable nomenclature is important in SD. Unlike the causal mapping in SODA, variable names in SD should only contain nouns or noun phrases with no verbs; verbs are denoted by arrow polarity. Variable names should also be stated in the positive, that is, no negatives such as "noncompliance" so as to avoid confusion about the polarity of impacts.

Vensim and STELLA are the most commonly used SD software packages. Coding is not required, though intermediate computer skills are helpful, particularly to understand and master the more advanced mathematical options and syntax. 


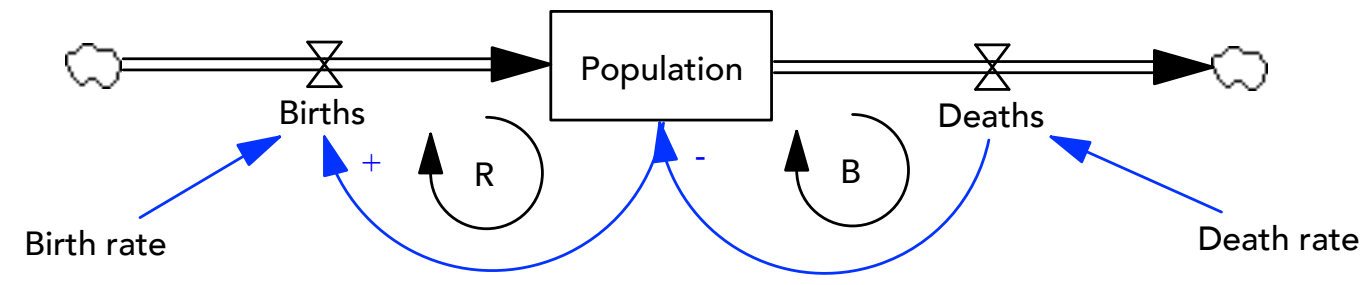

Figure 6.1 System dynamics diagram of population dynamics

SD relies on a straightforward approach to the modeling process, characterized by six main steps:

1. Problem Identification. SD tends to treat this initial phase in a rather straightforward, clear-cut manner, however the results of soft approaches could certainly be used. Key variables and time horizons are identified.

2. Hypothesis Formulation. Hypotheses should be based on behavior resulting from the endogenous interactions within the system rather than exogenous forcing functions.

3. Model Building. This begins with a conceptual model of the system, which can take a number of forms, including Causal Loop Diagrams (covered next). The conceptual model is then translated into the software.

4. Verification. This entails making sure the model actually works and that there are no syntax or logic errors.

5. Validation. Hard systems modeling tends to use a real world "reference" system against which to compare model/simulation results. This can be problematical because it is the less than desirable behavior of the real world system that we are trying to improve - there might be no reference system because that is precisely what we are trying to create. 
6. Conclusions and Policy Recommendations. SD is typically employed in service of a decision maker, so the results should be expressed in terms of both the system dynamics as well as their implications for how to intervene in the problem situation.

$\mathrm{SD}$ is probably the most well known of the hard systems approaches. Its consistency with the clear-cut goals, real world reference systems, and mathematically based models of OR is self-evident. Its common reliance on procedural phases gives it methodological attributes, while the modeling approach itself provides a method within the structured process. As with VSM, SD can be of great benefit when used in conjunction with soft system approaches (Lane and Oliva 1998) to further enhance its ability to explicate nonlinear system dynamics, the behavioral consequences of those dynamics, and how the system can be designed or re-designed to bring about different behaviors.

\section{Causal Loop Diagrams}

Causal Loop Diagrams (CLDs) are simplifications of SD diagrams. In CLDs, stocks and flows are not differentiated from other variables and there are no mathematical relationships between the variables since CLDs are visual diagrams only and not part of a computer simulation. Figure 6.1 shows a CLD of the population SD diagram depicted above. CLDs are a simple yet highly powerful tool to visually represent the elements and interrelations of a system of interest, lending themselves well to mental model explication and identifying places to intervene in problematical situations. 


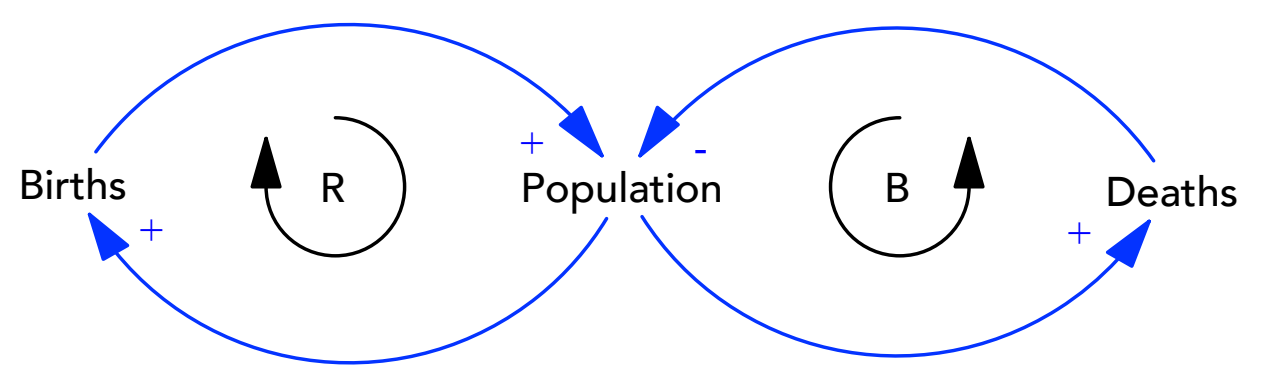

Figure 6.2 CLD of population dynamics

Though CLDs are difficult to categorize as "soft" versus "hard," I identify them as a hard systems approach for the purposes of this framework. CLDs emerged out of the undeniably hard systems approach of SD rather than the soft tradition of dealing subjectively with messy problems. Even though CLDs are purely qualitative in nature, aligning with the tendency of soft approaches, they do not necessarily deal with multiple perspectives or normative content. Based on this analysis, I contend that CLDs most closely align with hard systems approaches. That said, CLDs can be used in group situations to generate multiple individual or collective mental models. And, like SD, CLDs can be used in conjunction with soft systems approaches.

A helpful use of CLDs is to consider where to intervene in a system to bring about a desired outcome. CLDs can be used in conjunction with Donella Meadows' popular list of leverage points, or places to intervene, in a system (Meadows 2008). The larger the number on the list, the more effective the intevention.

1. Constants, parameters, numbers

2. Sizes of buffers \& stabilizing stocks (not applicable in a CLD)

3. Structure of stocks \& flows (not applicable in a CLD)

4. Length of delays 
5. Strength of balancing feedback loops

6. Strength of reinforcing feedback loops

7. Gain from driving positive feedback loops

8. Information flows

9. Rules of the system

10. Structure of the system

11. Goals of the system

12. Paradigm of the system

13. Transcend paradigms

CLDs are an extremely useful tool when nonlinearity and feedbacks exist in a system. It can be excellent visual tool to represent a mental model (shared or individual) of a system and to explicate how to intervene in the system. They are easy to produce, as they can be hand-written or easily captured in a software program, Vensim being the most widely used. Agent-Based Modeling

Agent-based modeling (ABM) is a form of computer simulation that models the emergence of macroscopic patterns from localized, individual behaviors. This may sound strikingly similar to Chapter 4's theory of complex adaptive systems, which ABM indeed has strong roots in (Macal and North 2007). Often contrasted against the top-down nature of VSM and SD, in which systems are designed in a centralized way, ABM seeks to study system behavior that emerges often unexpectedly from the localized interactions of agents at smaller scales (Macal and North 2007). ABM uses computer coding to program agent rules and the environmental landscape, resulting in a dynamic, graphical simulation display over the specified time period (see Figure 6.3). 


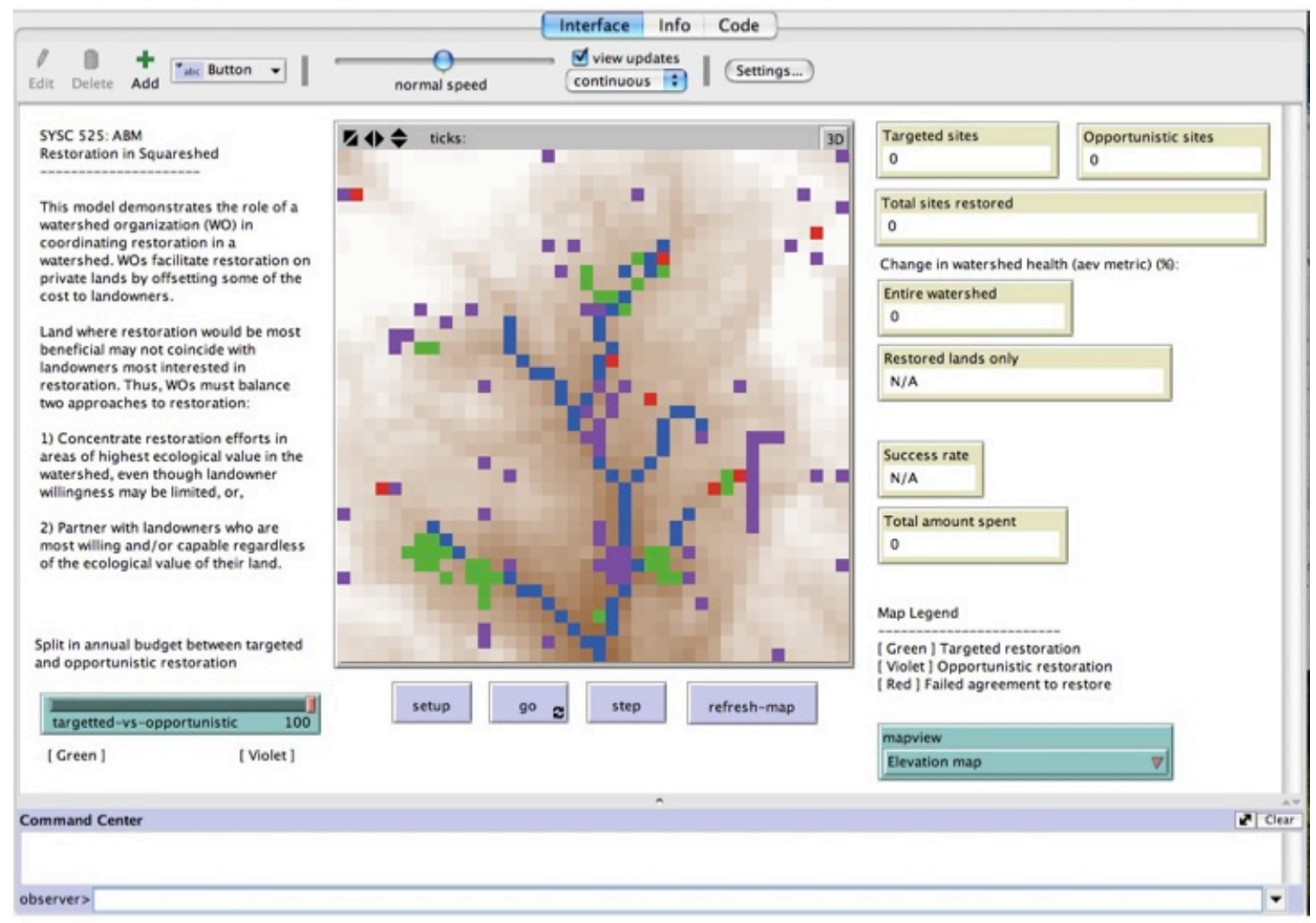

Figure 6.3 Example of an ABM user interface in NetLogo

$\mathrm{ABM}$ is based upon entities that interact with their environment (either conceptually or spatially defined). Entities are discrete and autonomous, possessing attributes and carrying out behaviors based on the rules they are programmed with. Entities can have rules not only for how to interact with each other and their environment, but also for how to learn and adapt over time. Hence, entities are heterogeneous and dynamic (Macal and North 2007). The macroscopic behavior of the system emerges from the localized interactions of entities with each other and their environment based on what can be a simple or sophisticated set of rules. 
ABM has a unique background. It emerged as a modeling technique out of multiagent systems, the robotics of artificial intelligence, and the cellular automata being used to study CAS (Macal and North 2007). Thomas Schelling's model of neighborhood segregation patterns in the 1970s is often credited with being the first use of ABM (Macal and North 2007, Macy and Willer 2002), followed by Craig Reynolds' famous model of bird movement in 1980s (Macy and Willer 2002) and Epstein and Axtell's similarly famous Sugarscape model in the 1990s (Macal and North 2007). From an epistemological standpoint, ABM is widely seen as providing an alternative mechanism to achieving mathematical exactness (Helbing and Balietti 2015, Railsback and Grimm 2012). Macy and Willer (2002) contend that it has roots in Coleman's critical realist epistemology, in which the macro and the micro dynamically influence each other (Macy and Willer 2002).

The modeling process for $\mathrm{ABM}$ is nearly identical to that for $\mathrm{SD}$, involving problem identification, hypothesis formulation, model building, verification and validation, and using results of computer experiments to generate policy recommendations.

The software for ABM can range from all-purpose, such as spreadsheets, to specially designed packages such as NetLogo and StarLogo for intermediate scale modeling, to Swarm and MASON at the larger scale (Macal and North 2007). Some degree of computer coding capability is required. ABMs can incorporate features such as neural networks and genetic algorithms to help facilitate agent learning and adaptation (Bonabeau 2002). Models can range from small, elegant learning tools to large decision-support tools (Bonabeau 2002, Macal and North 2007). Phenomena that ABM has been applied to are immense in their breadth: wealth distribution, trade networks, supply chains, unemployment patterns, organizational behaviors, epidemics, traffic congestion, stock market behavior, voting 
behavior, coalition formation, migration, urban and regional development, social cooperation, the growth and decline of ancient civilizations, and cognitive science (Epstein 1999, Helbing and Balietti 2015, Macal and North 2007).

$\mathrm{ABM}$ is an innovative tool to understand and gain insights into the dynamics of emergent phenomena. It has the potential to be more valuable when used through a process of participatory modeling. Despite grand claims to being a revolutionary new way of doing science (Bonabeau 2002, Helbing and Balietti 2015, Macal and North 2007, Macy and Willer 2002), ABM does have drawbacks. Most importantly is the challenge of encapsulating the full range of human behaviors and responses and then quantifying them into computer code (Bonabeau 2002, Epstein 1999). Different people respond differently in different situations how do we capture that variation? Aggregating or identifying the most likely range of behaviors seems to fly in the face of one of ABM's purposes, which is to provide a natural work around to aggregation. Furthermore, ABM's use is restricted only to those with a strong command of programming and coding.

\section{$\underline{\text { Artificial Intelligence Models }}$}

Artificial intelligence (AI) seeks to incorporate human intelligence into computing. It does this using features such as better computer-user communication and an enhanced ability to deal with language, ideas, uncertainty, and complexity (Stock and Rauscher 1996). While AI's original goal was to create a "general problem solver" of sorts, it quickly became apparent that only domain-specific applications would be possible (Stock and Rauscher 1996). Hence the area of knowledge-based systems (KBS) was born, the goal of which is to encode knowledge into computers so as to act intelligibly upon information (Cortés et al. 2000, Stock and Rauscher 1996). Decision support systems (DSS) are a common type of 
KBS. The goal of DSS is to help mangers make better decisions more quickly in the face of uncertain or complex data (Cortés et al. 2000, Stock and Rauscher 1996). DSS typically integrate several components: geospatial data; AI along with statistical and numerical models; reasoning and integration to help with prediction or planning; and a user interface. Chen et al. (2008) discuss a range of AI techniques that can be used to model environmental systems, including case-based reasoning (CBR), rule-based systems (RBS), fuzzy models, cellular automata, genetic algorithms, artificial neural networks (ANN), multi-agent systems (MAS), swarm intelligence, and reinforcement learning. Each technique has a range of suitable applications as well as benefits and drawbacks.

- Case-based reasoning (CBR). Solves a problem by recalling past problems with similar solutions. It does this using four steps: retrieve, adapt, revise, and retain. Examples of applications include estuarine behavior, air quality monitoring, and wastewater treatment plant management.

- Rule-based reasoning (RBS). RBS solves problems by rules derived from expert knowledge. The rules have condition and action parts, account for uncertainty using a variety of methods, and apply forward (data-driven) or backward (goaldriven) chaining. Does not involve learning (i.e. rules cannot be modified). Applications most commonly include plant and animal identification and pest diagnoses.

- Furay models. Deal with imprecise or incomplete data by assigning values between zero and one to the set members. For example, the five classifications of plant species for wetland delineation would be assigned values between zero (obligate) and one (upland). Fuzzy outputs are transformed into crisp numbers via a fuzzy 
inference machine. Fuzzy models are usually used as part of a hybrid system and can be applied to vegetation dynamics, soil hydraulics, macroinvertebrate habitat suitability, rainfall runoff, soil erosion, and drought prediction.

- Cellular automata (CA). A lattice of cells that interact with their neighbors discretely. The four classes of CA as described by Wolfram are analogous to limit points (homogenous), limit cycles (periodic), chaotic attractors, or have no direct analog due their randomness. Population dynamics, animal migration, landscape changes, and the spread of fire can all be modeled using CA.

- Genetic algorithms. Mimic natural selection by using binary strings to represent chromosomes. It can be used to model species distribution, air and water quality, and soil density.

- Artificial neural networks (ANNs). Strive to model the way human brains process information. There are processing units (similar to neurons) interconnected by links (like synapses) with weights. Information flow can be either feedforward (unidirectional) or feedback (flow goes in both directions), and learning can be either supervised or unsupervised. Applications range from pattern classification (e.g. land classification from satellite imagery) and function approximation (e.g. river sediment yield, catchment water supply, ozone concentration) to prediction and optimization.

- Multi-agent systems (MAS). A network of agents that communicate to achieve a goal. The infrastructure of the network determines how information is communicated: all agents can communicate directly or via a facilitator, or a 
central controller can coordinate all activity. Rangelands, fisheries, dairy, forestry, irrigated farming systems, and urban catchments can all be modeled by MAS.

- Swarm intelligence. Global properties emerge from local interactions without centralized control. Interactions can be either direct or indirect (via the environment). The two main algorithms are Ant Colony Optimization (ACO) and Particle Swarm Optimization (PWO). ACO works via autocatalytic, positive feedback. At each tick in PSO, agents evaluate their fitness relative to the goal, then share memories of the best positions with the swarm and update their positions. ACO has proven most useful for engineering (e.g. water distribution systems) while PSO has been used for applications such as project scheduling and resource allocation.

- Reinforcement learning. Learning through interaction between an agent and its environment. There are three parts - environment, reinforcement function, and value function - in which the reinforcement function specifies immediate desirability while value function specifies long-term desirability. Used mostly in robotics and game playing, reinforcement learning has limited environmental applications; it is used primarily in hybrid systems.

AI technology has a valuable role to play in the management of very specific aspects of SES. Perhaps the specific problem situations themselves may not be of a wicked nature, but they are undoubtedly embedded within a greater wicked context - how to treat wastewater or deal with nonpoint source pollution, for example. The application of AI techniques to social-ecological problem solving necessitates a depth of highly specialized computer knowledge, which only a small group of experts will likely possess. 


\section{Chapter 7}

Case Studies

"...Typical discussions among professionals are characterized by a remarkable lack of clarity... Different voices will be addressing different issues... different speakers will assume different time scales. The resulting confusion will then provide splendid cover for personal and private agendas to be advanced." - Peter

Checkland and John Poulter in Systems Approaches to Managing Change: A Practical Guide

This chapter sets out to apply the Systems Thinking Framework developed in the preceding chapters to actual problem situations faced by the USFS Enterprise Program (EP) and broader agency. Three case studies are included, one each applying theory and a soft and hard systems approach.

\section{Case Study 1: The Enterprise Program Reorganization}

\section{$\underline{\text { Introduction }}$}

As mentioned in Chapter 1, the EP is currently undergoing a reorganization. The preliminary investigations lasted from September 2014 through August 2015. Initial steps towards the re-design began immediately thereafter, with a target date of end-2016 for completion. In April of 2016, I was brought into the fold to take over a contract with an external consultant related to the reorganization. That contract was a hold-over from the previous director who was interested in systems thinking and attempted to integrate it into EP work whenever possible. By the time we received the necessary approvals to move forward, we were left with one month to complete the work outlined in the contract in order to stay within the timeline for the reorganization.

This case study analyzes the original scope of the contract - which attempted to bring a systems approach to the reorganization - against the complementary traditional and systems approaches I recommended.

\section{$\underline{\text { Background }}$}


The original scope of the contract was simple and abstract: develop a "systems map" of how organizations change from one state to another. The idea, presumably, was to apply that abstract model in a concrete way to the reorganization. But some glaring problems quickly emerged. First, what exactly is a "systems map"? In the absence of a clear definition, one could take it to mean nearly anything, ranging from a unique, original diagram to a model with prescriptive rules and conventions (such as a CLD) to even a computer simulation. Second, the deliverable seemed too vague to be of use. Organizations can change in an indefinite number of ways for a multitude of reasons under widely varying circumstances. It seemed unlikely that such huge variation could be captured in a single diagram, and if it could, it would probably be too general to be of use.

I suggested that we modify the scope of work to be more context-specific, concrete, and pluralistic. The contractor would develop several options for the organizational redesign from an organizational development perspective and I would provide input from a systems thinking perspective. My reasoning was three-fold. First, abstract models can be highly useful learning tools, metaphorical devices, or entry points into a particular subject matter, but sometimes they simply cannot deliver deeper level insights into specific problem situations. That certainly seemed to be the case here. Understanding that organizations typically change episodically and rapidly - using punctuated equilibrium as an abstract model, for example - is helpful from a high level contextual perspective (and can perhaps help in walking resistant employees through the nature of change), but it does not actually help with the re-design itself. Second, models of organizational change are ubiquitous - a few minutes on GoogleImages will generate a multitude of organizational change diagrams. Why spend money to reinvent the wheel? Third, critical plurality in systems thinking means that we 
should not only be critical and creative in examining the full range of systems thinking tools, but that there might also be other ways to tackle a wicked problem that are complementary to bona fide systems approaches. As a sub-field within human resources, organizational development typically employs its own well developed, domain specific principles with creativity and expertise. I saw value in bringing both approaches to the table.

$\underline{\text { Process }}$

Is this a wicked problem?

I begin this thesis with the contention that systems thinking offers a valuable toolbox for dealing with wicked problems in the social-ecological domain. So, is this particular problem situation a wicked one? To answer that question, we must look at the goals of the reorganization along with the context of this particular project.

My EP point of contact (POC) for the project was a member of the EP Leadership Team (EPLT). I began the project by asking him for as much background information as possible on the purpose and intent of the reorganization. I acquired information in a number of ways:

- From a SharePoint site about the reorganization that contained documents on the initial program review and its results. The program review involved input from six different stakeholder groups: the EPLT, USFS leadership, current EP clients, potential clients, EP employees, and the USFS union.

- From business plans for each service offering. Each existing EP unit wrote a business evaluation, which the EPLT then used to redesign the service offerings. Business Plans were then written by the EPLT for each new service offering and the general categories under which they fell. 
- From the POC, who provided his personal insights into some of the cultural challenges within EP.

- From both the EP Director and the POC, directly through one-on-one phone calls and indirectly through bi-weekly "office hours" phone calls in which the Director provided updates on the status of the reorganization and answered questions from employees.

I ended up receiving no clear guidance on the goals of the reorganization; it was up to me to synthesize everything I had heard and been given into a concise, coherent set of objectives to share with the consultant. I provided him with the following reasons for, and goals of, the reorganization.

Reasons:

- Unproductive competitiveness. The highly competitive mentality of the Clinton-Gore era National Partnership for Reinventing Government initiative - from which EP was born - had grown counterproductive. The level of competition had bred distrust amongst EP units (leaders and employees alike) and discouraged inter-unit collaboration.

- Redundant service offerings. Many of the EP units offered similar services, creating confusion on the part of USFS clients and unnecessary redundancy from a business operations standpoint.

- Financial failings. Several EP units dissolved between 2013 and 2015 due to financial insolvency. Recall that EP units operate on a full cost recovery business model, meaning they receive no funding from Congress and are solely responsible for income generation and financial viability. 
Goals:

- Collaboration. Transition from a competitive business model to a collaborative one.

- Agility

- Ability to form project teams consisting of people from across EP units.

- Ability to add and dissolve service offerings as needed, given USFS needs.

- Scalability. Ability to quickly flex the USFS workforce up or down through the creative use of permanent, temporary, contract, and associate EP staff (associates are USFS employees who work on a Forest but spend some of their time on a "detail" working for the EP).

- Revenue Accountability. Clearly identify which roles are responsible for business development.

- Employee Development. Provide opportunities for all individuals in the EP to pursue their passions and interests.

- Adaptive Management. Continue to learn and adapt as an organization in the face of changing internal and external factors.

Given this set of reasons and goals, the reorganization can certainly be viewed as a wicked problem. Using Norton's condensed criteria:

- Problems of problem formulation were clearly pervasive. Numerous stakeholders with different perspectives were consulted during the program review. Two years into 
the process, the EP Director and POC still struggled to clearly frame and identify the problem, which seemed to be scattered across a range of documents.

- No computable solution. Redesigning an organization is not something that can be computed or optimized.

- Nonrepeatability (or no one-size-fits-all solution). All organizations are unique, and as such, the problems they face and the nature and shape of their evolutions will be unique.

- Temporal open-endedness. Whether or not organizational leadership explicitly states their intent to be a learning organization (which EP leadership did), organizations continually face internal and external changes. This means that no reorganization effort is ever "done" - the results of the changes should be monitored and continually weighed against the milieu ever-changing variables.

Recognizing this is indeed a wicked problem and that systems thinking could potentially help to improve it, what types of systems approaches might be useful to apply? Which systems approach might be appropriate, and why?

VSM quickly emerged in my mind as a potentially useful systems approach. Identifying and assessing multiple perspectives to help formulate the problem and work through possible interventions was not part of the scope of this project. Stakeholder engagement had already taken place during the program review and during the multiple opportunities for employees to provide feedback on the business evaluations and business plans. The task now was to use that previous input to guide a new, improved design of the EP. The EPLT had attempted to work through the reorganization entirely on its own, but was now seeking outside consultation with little time remaining. Burdened and losing 
creative perspective, the EP Director and POC were seeking swift analysis by myself and the consultant, working together as a small agile team with a fresh set of eyes and ideas, to synthesize the reorganizational intent from two years' worth of work and offer re-design options to support that intent.

These tight, specific constraints created a narrow state space for systems approaches. Soft systems approaches could clearly be ruled out for the reasons outlined above. As discussed earlier, the application of systems theories would be too abstract for the needed level of design detail. From the set of hard systems methods, CLDs and SD could be ruled out since causality and feedbacks were not underlying features of the problem. ABM could be ruled out since bottom-up emergence was not either. Since AI models are typically useful for environmental science DSS, they were also not appropriate. This left VSM as a solid candidate.

The application of VSM (see Figure 7.1) yielded two important high-level insights that helped to inform the design options for the reorganization. Most importantly, the development of the VSM shows quite strikingly that the existing EP was entirely lacking both operational coordination and planning and development (two of the five VSM subsystems). The lack of coordination manifested itself clearly in the classic symptom of interoperational turf wars - the counterproductive level of competition and distrust that existed amongst the service lines. The problem was too much autonomy on the part of the operational activities; some level of coordination was needed to bring harmony (i.e. collaboration) and reduce conflict. Different mechanisms to bring about the necessary level of coordination were used in the various design options, but generally, this involved some sort of project management framework to link and synchronize the right experts within the 
right service lines. The lack of an explicit, bona fide planning function signaled that the EP had no formal, consistent mechanism to assess itself in relation to the broader USFS system that it serves. It is therefore not surprising that the EP hit a "crisis" brick wall that is the classic symptom of this missing sub-system. There are many ways to incorporate planning and development into an organization, but in this case, a Red Cell or Skunk Works of sorts (a small, agile team given the freedom to be creative and innovative) could be promising. It could consist of six to eight individuals from the EP, with a mix of junior and seasoned professionals and those new and old to the Program, that rotate out every two years or so. 


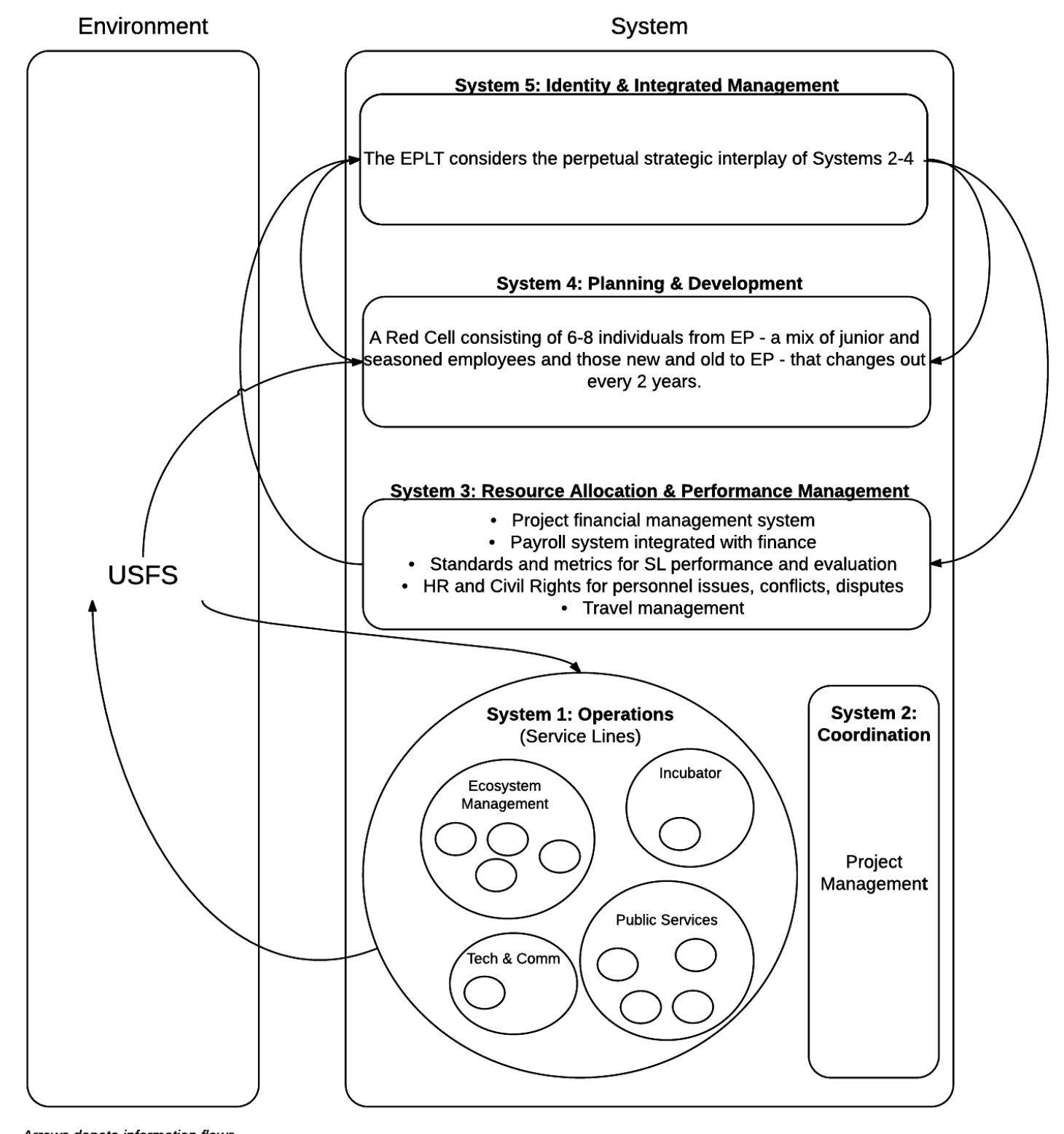

Arrows denote information flows

Figure 7.1. A Viable System Model of the Enterprise Program

Four design options were developed and presented to the EPLT in August of 2016.

Three of the design options were "pure" approaches while one was an example of a hybrid that combined elements from two of them. The high level insights from the VSM were 
discussed before presenting the options, which helped to make clear that certain critical elements were missing and needed to be accounted for in the new design.

\section{Case Study 2: The Recreation Diagnostic}

\section{Introduction}

In August of 2014, the former director of the EP lunched a "Recreation Diagnostic" to examine the expanding role of recreation as part of the USFS mission. A key part of the diagnostic was a "Guiding Team" composed of the EP Director, the Deputy Chief of the National Forest System (NFS), the Director of Recreation, chiefs from Research and Development and Business Operations, and several Regional and Deputy Regional Foresters. The task was to use a "systems map" to identify leverage points that could enhance recreation's role within the USFS. By the time I was brought into the project in early 2016, the map had been developed and leverage points - referred to as "High Fives" had already been identified. I was asked to examine the "systems map" and assist with developing final materials to implement the results as part of a pilot initiative.

\section{Background}

The "systems map" ended up being the focal point of the remainder of my involvement. Figure 7.2 shows this map, which was the Guiding Team's collective mental model that was generated by an external contractor. 


\section{Essential Tension}

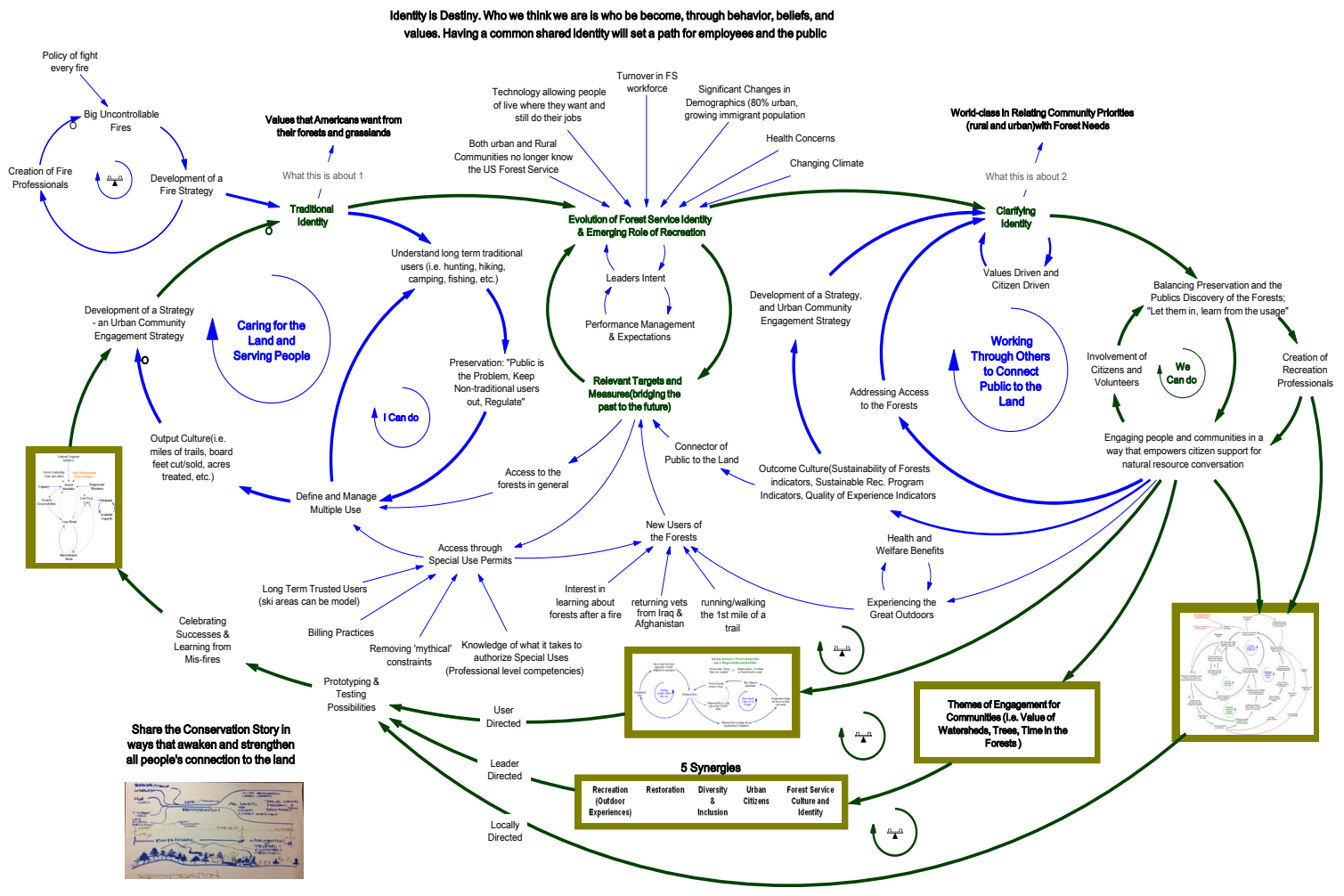

Figure 7.2. Pseudo-CLD of the role of recreation in the USFS

It seemed to me that that the diagram was intended to be a CLD but that it didn't actually adhere to CLD conventions. It used (presumably) causal arrows, but without "+" and "-" signs. It also included circular feedback loop arrows, some with the teeter-totter symbol that can denote a balancing loop and others with no label at all. Variable names did not adhere to rules for CLD nomenclature. Pictures, graphics, and text boxes were interspersed throughout. And, as was part of the tasking, analyses of the diagram made references to leverage points. In essence, the diagram walked and talked like a CLD, but it wasn't a CLD. Furthermore, diagrams are intended to convey complex information or concepts in an accessible, simplified visual form - they should say a lot with a little. This 
particular diagram does the opposite - it is incredibly complicated and doesn't convey very much.

Not only that, but how could leverage points be identified if causality - and the feedbacks that can result from it - were not incorporated into the model? In the absence of a properly developed CLD, leverage points could only have been identified subjectively. I was not able to get an answer on what the rationale for the leverage points were. To make matters worse, it was made clear that the process wasn't about to stop in order to retrace its steps.

Since the ship continued to sail and we had no choice but to keep building it as best as possible en route, I made the recommendation to develop a more linear diagram that could be used in lieu of the pseudo-CLD as a reference visual. This would serve two purposes. First, it removed the potentially faulty foundation upon which the leverage points relied. Since no clear connection could be made between the leverage points and how, precisely, they were derived from the model, it seemed best to remove the model and simply state that the leverage points were subjectively arrived at. Second, I contended that it wasn't possible to fix or modify the pseudo-CLD to make it legitimate. I believed the problem situation called instead for a more linear graphical representation. In looking over the diagram, my interpretation was that it was trying to convey that the USFS is in the process of transitioning from an old paradigm to a new one. The old paradigm was characterized by a narrow, short-term view of multiple-use that focused on extraction and fire suppression, with recreation occupying only a minor role. The new paradigm is characterized by a broadened, long-term view of multiple-use centered around ecosystem integrity and recreation, with recreation now occupying a prominent role because of the recognized 
benefits of getting outdoors and the critical importance of a nature-literate citizenry for stewardship. The current paradigm - where we're actually at right now - is stuck somewhere in the middle, trying to move in the direction of the new one. Causality, feedbacks, and complex structure aren't at play in this narrative. Rather, it is a relatively straightforward progression of paradigms. Figure 7.3 shows this new linear diagram that I developed. It was used in the kick-off meeting for the pilot initiate (which set out to implement the High Fives) to represent the Guiding Team's conception of the situation and, presumably, how they subjectively arrived at the five interventions.

\section{USDA

Forest Service Paradigms

Recreation shifts from a limited role to one of the agency's primary roles

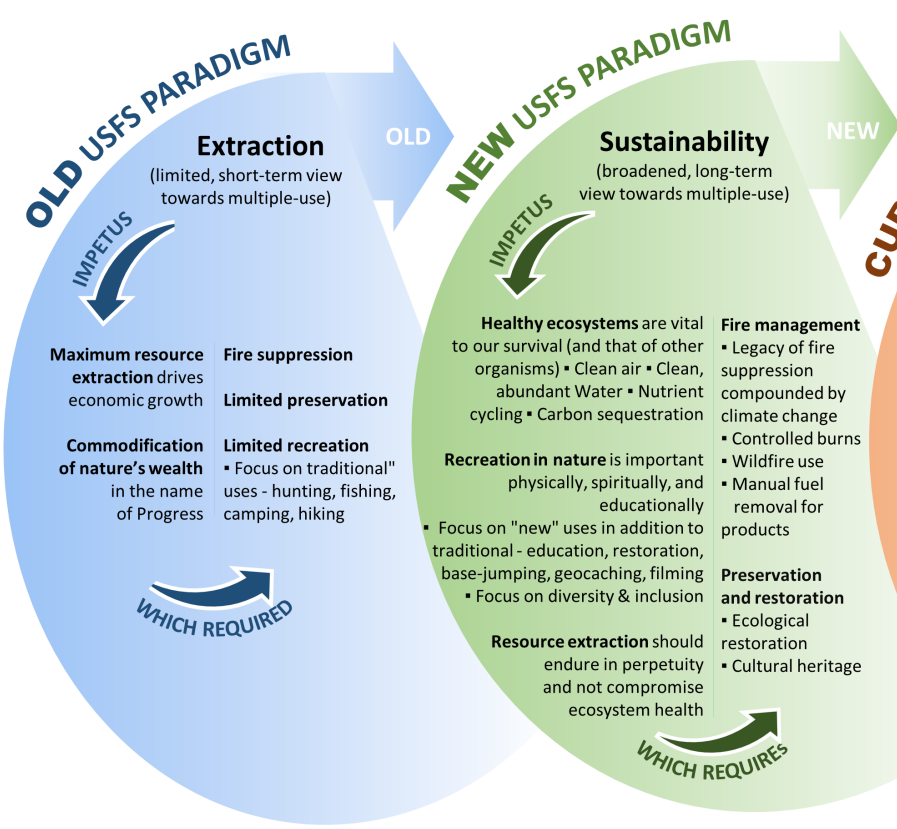

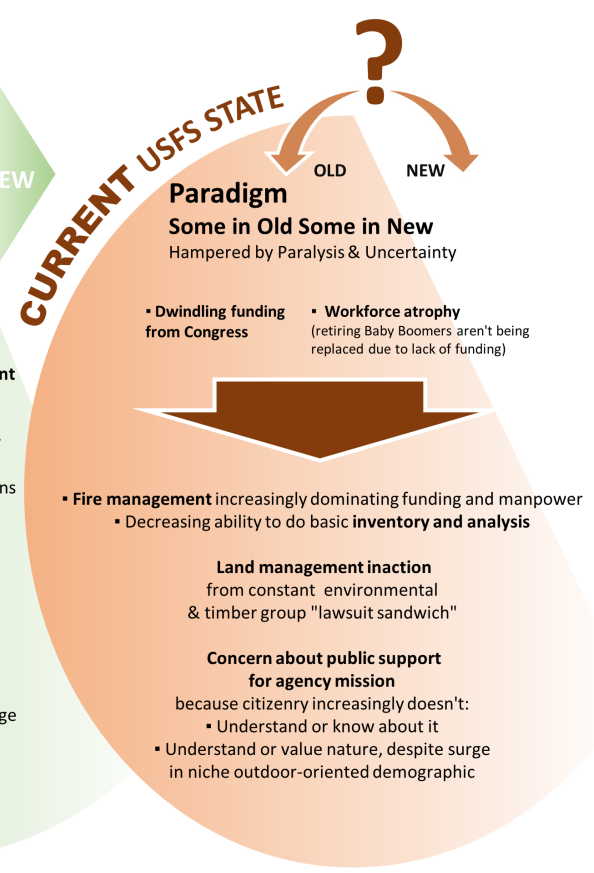

Uuis Forest Service

Figure 7.3. Translation of the pseudo-CLD into a linear progression of paradigms 


\section{$\underline{\text { Process }}$}

Had the ship not already sailed and we were given the opportunity to pause and reevaluate how to best approach the problem situation, the possibility of employing a more suitable systems approach - which was clearly desired by the then EP Director - could have been explored. This is what I do below.

Is this a wicked problem?

Using Norton's criteria again, the Recreation Diagnostic was clearly a wicked problem:

- Problems of problem formulation. The whole intent of the Recreation Diagnostic was to formulate the problem. It took about a year to engage a host of stakeholders, as well as an outside contractor, to formulate what was preventing recreation from realizing its expanded role within the USFS.

- No computable solution. No amount of computation could work through the many perspectives and structural factors at play.

- Nonrepeatability (or no one-size-fits-all solution). While other agencies, such as the National Park Service, may face similar problems of responding to increasing demands for recreation, the challenge of doing it within this particular agency with its particular contextual factors makes it unique.

- Temporal open-endedness. The role of recreation will undoubtedly change over time with changing populations, demographics, and agency missions and resources.

Given that this is a wicked problem, let us re-examine the fundamental nature of the endeavor in order to explore potential systems thinking approaches. 
Which systems approach might be appropriate, and why?

The purpose of the Recreation Diagnostic was to explore ways to get more citizens recreating on USFS lands. This hugely loaded task ought naturally to start with initial questions, such as "who should we engage as stakeholders in this process?" and "whose perspectives and opinions matter or are relevant?" Only by engaging, or at least considering, the perspectives of all relevant stakeholders could the messiness of the problem be fully formulated.

So we can begin by examining which tools in our systems thinking toolbox can aid in this initial stakeholder identification and problem formulation phase. The application of theory would not be helpful since high level abstraction is not needed. Nor are hard methods since it is too early for system design. Participatory CLDs could be considered later, but as stated earlier, causality and feedbacks didn't appear to be problem features - at least not yet. Critical Systems Heuristics (CSH) is particularly useful for identifying stakeholders, especially those voices that might not normally be heard. CSH could also be useful in circumscribing the system boundaries by identifying motivating factors, who is in control, and what information and skills are needed. Strategic Assumption Surfacing and Testing (SAST) could similarly help to identify stakeholders and the assumptions that would underpin their perspectives or preferred approaches. Soft Systems Methodology (SSM) and Strategic Options Development and Analysis (SODA) could then be employed to work through the various perspectives of the identified stakeholders and how those perspectives would inform and shape interventions.

CSH seems to initially offer the most value since it can help give shape and direction to this vast and seemingly loaded problem. In this case, an ideal map would probably have 
been best developed by several USFS individuals who were involved in the problem situation at the onset (for example, the NSF Chief, the Recreation Chief, several foresters, and the EP member). For this exercise, however, I developed an ideal map by myself based on my knowledge and understanding of the situation.

The CSH ideal mapping (see Figure 7.4) forces us to think fully and systematically about the dominant aspects of a problem situation that aren't usually explicitly explored. By focusing on what the sources of motivation, control, knowledge, and legitimacy ought to be, and by exploring questions that prompt us to think fully about all aspects of these areas (for example, unborn future generations, non-human nature, and those whose voices might not be heard), poignant considerations and unique possibilities are brought to light.

\begin{tabular}{|c|c|c|c|}
\hline & $\begin{array}{l}\text { Social Role } \\
\text { (Stakeholders) }\end{array}$ & $\begin{array}{c}\text { Role-Specific Concerns } \\
\text { (Stakes) }\end{array}$ & $\begin{array}{c}\text { Measures/Conditions } \\
\text { of Success }\end{array}$ \\
\hline $\begin{array}{l}\text { Motivation } \\
\text { (What are } \\
\text { the } \\
\text { motivating } \\
\text { factors?) }\end{array}$ & $\begin{array}{l}\text { Beneficiary } \\
\text { (whose interests ought we } \\
\text { serve?) } \\
\text { - The public } \\
\text { - USFS ecosystems } \\
\text { - Future generations }\end{array}$ & $\begin{array}{l}\text { Purpose } \\
\text { (what do we want to achieve?) } \\
\text { - More citizens recreating on } \\
\text { more USFS lands, while } \\
\text { - Sustaining or improving } \\
\text { ecosystem integrity } \\
\text { - More citizens taking part in } \\
\text { stewardship }\end{array}$ & $\begin{array}{l}\text { - Visitor use on USFS } \\
\text { lands } \\
\text { - Condition of the } \\
\text { resource } \\
\text { - Number of citizen } \\
\text { volunteers on USFS } \\
\text { lands } \\
\text { - Amount of completed } \\
\text { maintenance/restoratio } \\
\mathrm{n}\end{array}$ \\
\hline $\begin{array}{l}\text { Control } \\
\text { (Who's in } \\
\text { control?) }\end{array}$ & $\begin{array}{l}\text { Decision Maker } \\
\text { (who ought to decide?) } \\
\text { - USFS personnel } \\
\text { - A Public Representative } \\
\text { group comprised of } \\
\text { individuals from the } \\
\text { general public (spanning } \\
\text { all demographics), } \\
\text { recreation interest groups, } \\
\text { outfitters and guides, and } \\
\text { the scientific community }\end{array}$ & $\begin{array}{l}\text { Resources } \\
\text { (what resources ought to be } \\
\text { available?) } \\
\text { - Forest budgets } \\
\text { - Any additional federal funds } \\
\text { - Pilot project community of } \\
\text { practice } \\
\text { - Interest group knowledge } \\
\text { and manpower } \\
\text { - Outfitter and guide } \\
\text { knowledge and manpower } \\
\text { - Scientific knowledge }\end{array}$ & $\begin{array}{l}\text { Decision Environment } \\
\text { (what conditions ought } \\
\text { to be beyond the reach } \\
\text { of decision-makers?) } \\
\text { None - if decision } \\
\text { makers represent all } \\
\text { sectors of the agency } \\
\text { and public, then there } \\
\text { ought to be no } \\
\text { conditions beyond } \\
\text { their indirect reach }\end{array}$ \\
\hline
\end{tabular}




\begin{tabular}{|c|c|c|c|}
\hline $\begin{array}{l}\text { Knowledge } \\
\text { (What } \\
\text { important } \\
\text { knowledge } \\
\text { and skills are } \\
\text { needed?) }\end{array}$ & $\begin{array}{l}\text { Expert } \\
\text { (whom do we want to } \\
\text { contribute their knowledge } \\
\text { and experience?) } \\
\text { - Relevant USFS personnel } \\
\text { - The public } \\
\text { - Interest groups } \\
\text { - Outfitters and guides }\end{array}$ & $\begin{array}{l}\text { Expertise } \\
\text { (what do we want them to } \\
\text { contribute?) } \\
\text { - Knowledge of the USFS, its } \\
\text { lands (including carrying } \\
\text { capacity (CC)), management } \\
\text { constraints/opportunities, } \\
\text { and budgets } \\
\text { - What types of recreation are } \\
\text { desired and where; } \\
\text { opportunities and challenges } \\
\text { Knowledge of the resource } \\
\text { and various modes of } \\
\text { recreation (including desires, } \\
\text { resource impacts, user } \\
\text { groups, etc.); opportunities } \\
\text { and challenges } \\
\text { - Knowledge of the resource } \\
\text { and various modes of } \\
\text { recreation (including desires, } \\
\text { resource impacts, user } \\
\text { groups, etc.); opportunities } \\
\text { and challenges } \\
\text { Knowledge of the resource, } \\
\text { ecological processes, and CC }\end{array}$ & $\begin{array}{l}\text { Guarantees of Success } \\
\text { (to whom or what should } \\
\text { we look for guarantees } \\
\text { that the plan will work?) } \\
\text { - USFS public outreach } \\
\text { (e.g. face-to-face } \\
\text { interactions, } \\
\text { information } \\
\text { dissemination, new } \\
\text { offerings, marketing) } \\
\text { - Implementation of on- } \\
\text { the-ground programs, } \\
\text { initiatives, and efforts } \\
\text { - Critical discourse and } \\
\text { agreement amongst } \\
\text { those with relevant } \\
\text { knowledge on the } \\
\text { balance between } \\
\text { increased resource use } \\
\text { and protection }\end{array}$ \\
\hline $\begin{array}{l}\text { Legitimacy } \\
\text { (Who is } \\
\text { affected but } \\
\text { not } \\
\text { involved?) }\end{array}$ & $\begin{array}{l}\text { Witness } \\
\text { (who should voice the } \\
\text { concerns of those not } \\
\text { involved?) } \\
\text { - Those with knowledge } \\
\text { (professional or } \\
\text { experiential) of ecological } \\
\text { processes } \\
\text { O USFS lands } \\
\text { - The Public Representative } \\
\text { group } \\
\text { Future generations } \\
\text { The poor who want } \\
\text { to recreate but don't } \\
\text { have the means } \\
\text { The handicapped } \\
\text { who want to } \\
\text { recreate but don't } \\
\text { have the means } \\
\text { Landowners near } \\
\text { USFS lands who } \\
\text { would be impacted } \\
\text { by increased use }\end{array}$ & $\begin{array}{l}\text { Emancipation } \\
\text { (how should we emancipate } \\
\text { them from our premises and } \\
\text { promises?) } \\
\text { - Make ecosystem integrity an } \\
\text { immutable priority } \\
\text { - Inclusion in the decision- } \\
\text { making process (whether } \\
\text { direct or indirect) ensures a } \\
\text { seat at the table }\end{array}$ & $\begin{array}{l}\text { - "Full" worldview - } \\
\text { resources are scarce } \\
\text { and populations are } \\
\text { large, so there must be } \\
\text { a balance between } \\
\text { recreation desires and } \\
\text { resource capacity } \\
\text { - Inclusive worldview - } \\
\text { recreation } \\
\text { opportunities should } \\
\text { be available to all } \\
\text { groups to the fullest } \\
\text { extent possible }\end{array}$ \\
\hline
\end{tabular}

Table 7.4. CSH ideal mapping of the role of recreation in the USFS 
Under sources of motivation, we can see that the purpose of this effort is three-fold: to get more citizens recreating on more USFS lands while sustaining or improving ecosystem integrity, and to get more citizens taking part in resource stewardship. The public, USFS ecosystems, and future generations are the interests that ought to be served in pursuit of these three purposes. Measures of improvement can include the amount of visitor use on USFS lands, the condition of the resource, and the number of citizen volunteers on USFS lands and/or the amount of completed maintenance/restoration.

Identifying what the sources of control ought to be was both challenging and creatively insightful. Relevant USFS personnel - to include the NFS Chief, the Recreation Chief, and foresters - ought clearly to be involved in decision-making. But leaving the extent of decision-making about public activities on a public resource to agency personnel alone didn't seem right. So I include the idea of a Public Representative group comprised of individuals spanning all relevant demographic groups from the general public, recreation interest groups, outfitters and guides, and the scientific community. USFS decision makers would be required to consult this group (with the exact weight of each group's input to be determined). Resources that ought to be available include existing Forest level budgets, additional federal funds if they could be secured, the pilot project community of practice, interest group knowledge and manpower, outfitter and guide knowledge and manpower, and knowledge from the scientific community.

Under sources of knowledge, identified experts ought to be relevant USFS personnel, the general public, recreation interest groups, outfitters and guides, and the scientific community. USFS personnel would contribute knowledge of the USFS and its budgets, resources, management tools, and knowledge of the resource and its carrying 
capacities. The general public would contribute knowledge about what types of recreation are desired and where, including opportunities and challenges. Interest groups and outfitters and guides could contribute knowledge of the resource, various modes of recreation on it (both desired recreation and any impacts), as well as opportunities and challenges. And the scientific community could bring knowledge about ecological processes and carrying capacity. I identified three guarantees of success, or who or what ought to guarantee that the plan will work. The first is USFS outreach with the public, including face-to-face interactions, information dissemination, new products or offerings, and marketing. The second guarantee is implementation of on-the-ground programs, initiatives or efforts. A third guarantee could be critical discourse and agreement amongst those with relevant knowledge on the balance between increased resource use and resource protection.

Sources of legitimacy tie back in with sources of control and surfaced the exciting topic of privileged worldviews. The first step asks us to consider the voices of those who are not involved and who will represent them. I identified two groups with no voice at all: future generations and the USFS lands themselves. Three groups came to mind that are affected by the effort but may not typically have a voice: the poor who want to recreate but don't have the means to, the handicapped who want to recreate but don't have the means to, and landowners near USFS lands who would be impacted by increased recreational use. The latter three groups, in addition to future generations, could all be emancipated via the Public Representative group involved in the decision-making process. The interests of USFS lands could perhaps best be emancipated by anyone with sound knowledge of ecological processes, whether that knowledge is professional/scientific or experiential. Finally, I identified two worldviews that should be privileged: a full worldview and an inclusive 
worldview. A full worldview sees the world as "full" rather than "empty." Resources are scare and populations are large and growing, requiring trade-offs between recreation desires and resource capacity/integrity. An inclusive worldview sees that recreation opportunities should be made available to all groups to the fullest extent possible.

Performing the CSH ideal mapping at the onset of this project could have explicitly surfaced a broad, deep range of normative-empirical system boundaries and content. The insights generated by this individual effort could have shaped three important aspects of the Recreation Diagnostic: the purpose (which was perpetually vague and unspecified), beneficiaries, and measures of improvement; how to emancipate all relevant voices in the decision-making process; and what knowledge and skills were needed. The project could have continued on without further systems approaches after the ideal mapping, using the helpful insights surfaced through the process, or other soft approaches could have been subsequently employed, such as SSM or SODA.

\section{Case Study 3: USFS Wildfire Management}

I take a different approach in this case study as compared with the previous two. Here, I turn my attention to perhaps the most daunting problem facing the USFS: wildfire management. Not only does wildfire consume an enormous amount of the agency's capital, but the EP also has a service line dedicated expressly to fire management.

\section{Background}

It is well understood that fire is a natural disturbance regime that has played an integral role in shaping landscapes across the country. However, the frequency and intensity of wildfires has increased in recent years, consuming ever more of the USFS' annual budget and resources. Referencing Figure 7.3 from the previous case study, two major drivers 
contribute - to varying, context-specific degrees - to the recent escalation of wildfires (Schoennagel et al. 2004, Westerling et al. 2006): climate change and large fuel loads. Anthropogenic climate change is creating conditions that promote both more fires and greater intensity of fires through hotter temperatures and changing hydrologic patterns. Compounded with climate change, forests have accumulated unusually large fuel loads. This is the result of decades of fire suppression as well as management atrophy due to dwindling budgets (consumed increasingly by fire suppression) and management paralysis from a virtually perpetual stream of lawsuits (Keele et al. 2006).

How can we intervene in this seemingly intractable yet massive problem facing the USFS: ever-increasing capital needed to fight fires due to their increasing amplification from the dual anthropogenic drivers of climate change and large fuel loads? More generally, how can we look systematically at the relationship between humans (i.e. the social conditions we create) and fire as an ecological function?

\section{$\underline{\text { Process }}$}

Is this a wicked problem?

Returning again to Norton's criteria:

- Problems of problem formulation. While the above characterization of the problem is likely one held by many people with an understanding of the situation, it would nonetheless be important to ensure all relevant perspectives be included in order to formulate the most inclusive and accurate problem statement possible.

- No computable solution. While computation can offer value to certain aspects of fire management, it simply cannot do so at this level. 
- Nonrepeatability (or no one-size-fits-all solution). Interventions would certainly be scalable but ultimately not "one-size-fits-all"; they, and any subsequent reformulations and re-evaluations, must ultimately be nuanced and contextdependent.

- Temporal open-endedness. There will be no definitive end point at which the USFS and society in general can claim that wildfire management has "been solved." Changing climate, biophysical, and social variables will ensure open-endedness.

Given that wildfire management is a wicked problem, how we can take a systems approach to intervening in this high-level, ubiquitous mess?

Which systems approach might be appropriate, and why?

Systems theory could be a fruitful starting point for such an abstract problem. All of the soft systems approaches could also be applicable but would, aside from the ideal mapping of $\mathrm{CSH}$, require group involvement (which would be a valuable exercise but unfortunately not an option here). The problem is too general and needs initial development before being ready for system design. Cooperation theory seems to offer promise in working through how we can better interact with nature and each other to bring about improvement.

Recognizing the tension between the ecology of fire and the anthropogenic conditions that have amplified it, the following questions arise:

- What, ecologically, is the right amount of fire?

- Can we adapt our societal behaviors/infrastructure to that "right" amount? This forces us to confront the prevalence of permanent human settlements that lead us to fight fire in the first place. Are the amount and types of permanent human 
settlements compatible with natural disturbance regimes such as fire? To what extent is permanence compatible with resilience?

Focusing specifically on the amplifying anthropogenic drivers of fire:

- What can be done to induce Congress to devote more funding to the USFS, whose mission of land stewardship is critical to human well-being and that of the habitats upon which our survival depends?

- What can be done to compel Congress to take action related to climate change?

- What can be done to escape the management atrophy induced by litigation?

By embracing the three central tenets of cooperation - taking a long-term view, engaging in durable interactions, and employing the nice and reciprocal tactics required for a cooperative landscape to take hold - USFS leadership can initiate new dialogues and reframe existing ones.

- What, ecologically, is the right amount of fire?

The management of natural disturbance regimes, such as fire, ultimately rests upon value-laden societal decisions about the character of the SES we want to shape. To this end, there are various conceptual frameworks to draw from that can inform and operationalize fire management decisions, such as emulating natural disturbance regimes (ENDR) (Long 2009, North and Keeton 2008) and historic range and variability (HRV) (Keane et al. 2009).

- Can we adapt our societal behaviors / infrastructure to that "right" amount? To what extent are permanent human settlements compatible with natural disturbance regimes such as fire? To what extent is permanence compatible with resilience? 
We suppress fire (regardless of its frequency or intensity) in order to protect human settlements, many of which are now permanent. We do so despite understanding the important resilience-building role wildfire plays (Long 2009) in shaping landscape structure and function across ecological time. Embracing a longer-term perspective that includes a greater appreciation of natural processes would allow us to achieve greater gains by "cooperating” with nature. By viewing ourselves as separate from nature, and continuing to shelter ourselves from its processes and oftentimes stark realities, we can be seen as avoiding the persistent, one-on-one interactions with the natural world that are necessary to coexist more harmoniously with it. As committed land stewards, the USFS can engage in community-level dialogues - establishing durable interactions with the same communities over the long-run - about what desirable, sustainable futures might look like, starting from the very real, pragmatic lens of our long-term relationship with wildfire. Various approaches could then be experimented with through adaptive management.

- What can be done to induce Congress to devote more funding to the USFS and climate change? USFS leadership could adopt an advocacy role in its relations with Congress. Shaming attention could be brought to the funding of short-term interests at the expense of long-term interests upon which our survival depends, such as basic and, ideally, robust and innovative, public land management. By establishing persistent, face-to-face relationships with relevant individuals and groups, USFS leadership could shift the rules of interaction from relative anonymity to being ever-present - creating precisely the atmosphere of durable one-on-one 
relationships that make escaping cooperation difficult. Finally, USFS leadership could experiment with various strategies and tactics to reciprocate funding and climate change defection on the part of Congress. Perhaps the public could also be motivated to engage in reciprocal behavior with it. Engaging in such reciprocity, while difficult, may very well be what is necessary to make the longterm incentive for mutual cooperation greater than the short-term incentive to defect (defection being the modus operandi of Congress).

- What can be done to escape the management paralysis induced by litigation?

A similar advocacy role could question the efficacy of litigation in bringing about desired land management results. Mechanisms that rely on durable interactions could be explored with interest groups as alternatives to lawsuits. The Navaho Nation, for example, uses conflict resolution processes that force disputing parties to sit down, face-to-face, to work through issues until a mutually amicable resolution has been reached.

The application of cooperation theory to the complex problem of USFS wildfire management thus leads to two important conclusions: 1) it is not necessarily sophisticated, impressive models or analyses that yields insightful results. Sometimes, it is simple, basic premises that can help to find sanity in the face of complexity, and 2) advocacy and valueoriented positions are needed now more than ever in order to intervene productively in what is perhaps the agency's most pressing challenge. 


\section{Chapter 8}

\section{Conclusion}

Systems thinking offers a rich, diverse toolbox of theory and soft and hard approaches that can be employed critically and creatively to help intervene in wicked problem situations. Specifically, the framework developed here is the first of its kind to provide the strategic context - an overview and deep history of systems thinking - and tactical landscape - theories and hard and soft approaches - for applying systems thinking in a land management agency.

I make five key points about the general nature of systems thinking.

- First, I describe systems thinking as the trandisciplinary study of complex phenomena from a holistic, rather than reductionist, perspective. As human constructs that attempt to make sense of the complexities of the world, systems contain elements whose relationships create nonlinear behavior characterized by disproportionate cause-effect dynamics across space and time. The world can be viewed as a massive set of embedded systems, each system of interest containing many sub-systems and also functioning as a sub-system within a larger suprasystem. This makes the role of the observer particularly important, as we must be careful to identify which spatial and temporal scales we are assuming in our analyses and how interventions at those scales affect other levels and aspects of the system.

- Second, the deep history of holistic thinking offers rich context as well as focused entry points into its modern scientific study. Holism is not a new 
vantage point. It is one of the oldest ways of looking at the world, having persisted for millennia despite its continual diminishment in favor of mechanistic and dark mystical approaches. Holism has been foundational to the philosophies of many Eastern cultures for thousands of years, which suggests that the West's newfound scientific approach to studying systems thinking could benefit greatly from exploring the East's long-standing cultural and spiritual approaches to pursuing cognitive unity and oneness with nature and mankind.

- Third, the "soft" and "hard" labels we place on systems thinking approaches are of secondary importance to understanding what the different approaches are and how they can be used. While it is helpful to broadly categorize and subsequently organize the various tools in the systems thinking toolbox, discussions about soft and hard labels can distract us from the more important task at hand, which is to be critical and creative about how we apply systems approaches to make a meaningful difference in the world.

- Fourth, it is important to highlight the relationship between systems thinking and its close cousin, OR. I agree with the viewpoint that sees soft systems approaches as having a distinct systems thinking orientation, whereas hard systems approaches overlap substantially with OR given their focus on clear objectives and the use of models to achieve mathematical exactness.

- Lastly, I outline a sort of complexity spectrum, contending that systems thinking tends to be concerned with complex systems and complex adaptive systems. Simple systems - such as buildings, equipment, infrastructure, and even certain aspects of organisms - can be studied using more linear or mechanistic 
approaches. Complex systems can be either what I call subjectively or computationally complex. Subjective complexity arises from the numerous perspectives that shape a system of interest, whose elements and relations often defy mathematical description. Computational complexity lends itself to modeling and simulation to make concrete - oftentimes through mathematical exactness - the system elements, their relations, and the resulting behavior. Complex adaptive systems are those systems in which both emergence and evolutionary processes are at play.

To this end, I emphasize that is the soft systems approaches and several systems theories - notably the two pillars of hierarchy theory and cooperation theory - that offer the most value to wicked problem solving in the USFS. While incredibly useful tools for working through systems design, hard systems approaches simply cannot work through the difficult and oftentimes value-laden aspects of problem formulation that are inherent in the types of wicked problems increasingly faced by the agency - and, indeed, other organizations and governments working to move towards sustainability. Soft approaches and the conceptual constructs offered by much of the systems theory repertoire stand out for their ability to surface and work through differing mental models about a problem situation and how the problem can or ought to be framed from spatial, temporal, and ethical vantage points. CSH does this particularly well by offering the most robust philosophical, systematic, and normative approach. Once this initial work has been done, hard systems approaches can step in to help further explicate how the system is designed - whether from the top-down or bottom-up - and how the design can inform interventions and their consequences. 
I test the usefulness of the framework through a series of three case studies within the EP. Here, I substantiate key claims contained within this thesis about the pervasiveness of wicked problems in SES management, how the framework can be applied critically and creatively given specific contexts, unique insights that can be gained from taking a systems approach, and the primal role of soft approaches and theory. In the EP reorganization case study, the difficult work of problem formulation and integrating multiple perspectives had already been done - albeit informally and unclearly - leaving a hard method, VSM, as a wise choice to help guide, in a short period of time, the organizational design options. The application of VSM revealed that two of the VSM's five sub-systems - coordination and planning and development - were missing altogether in the current Enterprise organization, paving the way for restructurings that would take those functions into account. The Recreation Diagnostic case study demonstrated that a preconceived systems approach was improperly applied and not appropriate for the context. While using a more linear approach was a quick fix that "kept the ship sailing," I explored how CSH could have been applied to help frame the problem and identify stakeholders at the onset. This yielded unique, normative insights about how to give voice to relevant non-agency stakeholders, including the voiceless entities of nature and future generations. Finally, I surface value-laden insights into the perennial problem of wildfire management through the application of cooperation theory. Normative questions about permanent human settlements and the dual drivers of climate and fuel loads were explored using the theory to show that the USFS could take a more active role in promoting the long-term outlook, durable interactions, and reciprocal behaviors that are required for cooperation - and thus improvement - to take place. 
This framework will continue on as the starting point for the development of a new systems thinking service line in the EP. As a living, breathing document that can and should change along with developments in systems thinking and its application within the agency, it is my hope that this framework will be the seed for what will one day be a thriving, rigorous approach to improving wicked problems in the USFS as it attempts to help shape a sustainable future. 
Works Cited

Abel, Thomas, and John Richard Stepp. (2003). A New Ecosystems Ecology for Anthropology. Conservation Ecology, 7(3).

Achterkamp, Marjolein C., and Janita F. J. Vos. (2007). Critically Identifying Stakeholders: Evaluating Boundary Critique as a Vehicle for Stakeholder Identification. Systems Research and Behavioral Science, 24, 3-14.

Ackermann, Fran, and Colin Edin. "SODA - The Principles." Rational Analysis for a Problematic World Revisited: Problem Structuring Methods for Complexity, Uncertainty, and Conflict. Ed. Jonathan Rosenhead and John Mingers. London: John Wiley and Sons, Inc., 2001. 21-42.

Ackermann, Fran, and Colin Edin. "Strategic Options Development and Analysis." Systems Approaches to Managing Change: A Practical Guide. Ed. Martin Reynolds and Sue Holwell. London: Springer, 2010. 135-190.

Ackoff, Russell L. (2001). A Brief Guide to Interactive Planning and Idealized Design.

Ackoff, Russell L. (1999). Re-Creating the Corporation: A Design of Organizations for the $21^{\text {st }}$ Century. New York and Oxford: Oxford University Press.

Ahl, Valerie, and T. F. H. Allen. (1996). Hierarchy Theory: A Vision, A Vocabulary, and Epistemology. New York: Columbia University Press.

Allen, Craig R., David G. Angeler, Ahjond S. Garmestani, et al. (2014). Panarchy: Theory and Application. Ecosystems, 17, 578-589.

Allen, Timothy F.H., and Thomas W. Hoekstra. (2015). Toward a Unified Ecology, $2^{\text {nd }}$ Edition. New York: Columbia University Press. 
Ashby, William Ross. (1956). An Introduction to Cybernetics. New York: John Wiley and Sons Inc.

Axelrod, Robert. (1984). The Evolution of Cooperation. New York: Basic Books.

Barabba, Vincent P., and Ian I. Mitroff. (2014). Business Strategies for a Messy World. New York: Palgrave Macmillian.

Beggs, John M. (2008). The Criticality Hypothesis: How Local Cortical Networks Might Optimize Information Processing. Philosophical Transactions: Mathematical, Physical, and Engineering Sciences, 366, 329-343.

Bennett, Jonathan. (2001). Learning from Six Philosophers: Descartes, Spinoza, Leibniz, Locke, Berkeley, Hume. Volume 1. Oxford: Clarendon Press.

Berghaus, Günter. (1992). Neoplatonic and Pythagorean Notions of World Harmony and Unity and Their Influence on Renaissance Dance Theory. Journal of the Society for Dance Research, 10(2), 43-70.

Bertalanffy, Ludwig. (1950). An Outline of General System Theory. The British Journal for the Philosophy of Science, 1(2), 134-165.

Bertalanffy, Ludwig. (1972). The History and Status of General Systems Theory. The Academy of Management Journal, 15(4), 407-426.

Bonabeau, Eric. (2002). Agent-Based Modeling: Methods and Techniques for Simulating Human Systems. Proceedings of the National Academy of Sciences of the United States of America, 99(10), 7280-7287.

Boyer, Robert W. "Consciousness: From Reductive Physicalism to Ultimate Holism.” Consciousness-Based Education: A Foundation for Teaching and Learning in the Academic 
Disciplines. Ed. Dara Llewellyn and Craig Pearson. Fairfield, Iowa: Maharishi

University Management, 2011. 151-160.

Burrell, Gibson, and Gareth Morgan. (1979). Sociological Paradigms and Organizational Analysis.

Heinemann Educational Books.

Cabrera, Derek, Laura Cabrera, and Erin Powers. (2015). A Unifying Theory of Systems

Thinking with Psychosocial Applications. Systems Research and Behavioral Science, 32(5), $534-545$.

Cabrera, Derek, Laura Colosi, and Claire Lobdell. (2008). Systems Thinking. Evaluation and Program Planning, 31, 299-310.

Carhart-Harris, Robin L., Robert Leech, Peter J. Hellyer, et al. (2014). The Entropic Brain: A Theory of Conscious States Informed by Neuroimaging Research with Psychedelic Drugs. Frontiers in Human Neuroscience, B(20).

Castellani, Brian, and Frederic William Hafferty. (2009). Sociology and Complexity Science: A New Field of Inquiry. Verlag: Springer.

Checkland, Peter, and John Poulter. "Soft Systems Methodology." Systems Approaches to Managing Change: A Practical Guide. Ed. Martin Reynolds and Sue Holwell. London: Springer, 2010. 191-242.

Chen, Serena H., Anthony J. Jakeman, and John P. Norton. (2008). Artificial Intelligence Techniques: An Introduction to their Use for Modelling Environmental Systems. Mathematics and Computers in Simulation, 78, 379-400.

Cortés, U., M. Sànchez-Marrè, and L. Ceccaroni. (2000). Artificial Intelligence and Environmental Decision Support Systems. Applied Intelligence, 13, 77-91. 
Crutchfield, James P., J. Doyne Farmer, Norman H. Packard, and Robert S. Shaw. (1986). Chaos. Scientific American, 254(12), 46-57.

Dugatkin, Lee Alan. (1997). The Evolution of Cooperation: Four Paths to the Evolution and Maintenance of Cooperative Behavior. Bioscience, 47(6), 355-362.

Ehrlich, Paul. "Coevolution and Its Applicability to the Gaia Hypothesis." Scientists on Gaia. Ed. S.S. Schneider and P.J. Boston. Cambridge: MIT Press, 1991. 19-22.

Eldredge, Niles, and Stephen Jay Gould. (1972). "Punctuated Equilibria: An Alternative to Phyletic Gradualism.” Models in Paleobiology. Ed. Schopf, Thomas J.M. San Francisco: Freeman, Cooper and Company, 1972. 82-115.

Epstein, Joshua. (1999). Agent-Based Computational Models and Generative Social Science. Complexity, 4(5), 41-60.

Esfeld, Michael. (1999). Holism in Cartesianism and in Today's Philosophy of Physics. Journal for the General Philosophy of Science, 30(1), 17-36.

"Evolutionarily stable states." Wikipedia: The Free Encyclopedia. Wikimedia Foundation, Inc. 9 April 2015. Web. 15 September 2015.

Flood, Robert Louis. (1999). Rethinking the Fifth Discipline: Learning with the Unknowable. London and New York: Routledge.

Flood, Robert L., and Ewart R. Carson. (2010). Dealing with Complexity: An Introduction to the Theory and Application of Systems Science. New York and London: Plenum Press.

Folke, Carl. (2006). Resilience: The Emergence of a Perspective for Social-Ecological Systems Analysis. Global Environmental Change, 16, 253-267. 
Folke, Carl, Steve Carpenter, Thomas Elmqvist, et al. (2002). Resilience and Sustainable Development: Building Adaptive Capacity in a World of Transformations. Ambio, 31(5), 437-440.

Furtado, Bernardo Alves, and Patricia Alessandra Morita Sakoski. (2015). Complexity: A Review of the Classics. Journal on Policy and Complex Systems, 1(2), 3-18.

Georgiou, Ion. (2012). Messing About in Transformations: Structured Systemic Planning for Systemic Solutions to Systemic Problems. European Journal of Operational Research, 233, 392-406.

Gersick, Connie J.G. (1991). Revolutionary Change Theories: A Multilevel Exploration of the Punctuated Equilibrium Paradigm. The Academy Management of Review, 16(1), 10-36.

Giampietro, Mario, and Kozo Mayumi. (1997). A Dynamic Model of Socioeconomic Systems Based on Hierarchy Theory and Its Application to Sustainability. Structural Change and Economic Dynamics, 8, 453-469.

Giampietro, Mario. (1994). Using Hierarchy Theory to Explore the Concept of Sustainable Development. Futures, 26(6), 616-625.

Gregersen, Hal, and Lee Sailer. (1993). Chaos Theory and Its Implications for Social Science Research. Human Relations, 46(7), 777-802.

Gunderson, Lance H., and C.S. Holling. (2002). Panarchy: Understanding Transformations in Human and Natural Systems. Washington DC: Island Press.

Haftor, Darek M. (2011). An Evaluation of R.L. Ackoff's Interactive Planning: A Case-based Approach. Systemic Practice and Action Research, 24(4), 355-377. 
Hanel, Rudolf, Manfred Pöchacker, and Stefan Thurner. (2010). Living on the Edge of Chaos: Minimally Nonlinear Models of Genetic Regulatory Dynamics. Philosophical Transaction: Mathematical, Physical, and Engineering Sciences, 368, 5583-5596.

Hansson, Daniel. (2012). Unpacking Spinoza: Sustainability Education Outside the Cartesian Box. Journal of Sustainability Education, 3.

Hastings, Alan, Carole L. Hom, Stephen Ellner, Peter Turchin, and H. Charles J. Godfray. (1993). Chaos in Ecology: Is Mother Nature a Strange Attractor? Annual Review of Ecology and Systematics, 24, 1-33.

Helbing, Dirk, and Stefano Balietti. "How to Do Agent-Based Simulations in the Future: From Modeling Social Mechanisms to Emergent Phenomena and Interactive Systems Design.” Sante Fe Institute, 27 Jul. 2016.

Ho, David Y.F. (1995). Selfhood and Identity in Confucianism, Taoism, Buddhism, and Hinduism: Contrasts With the West. Journal for the Theory of Social Behavior, 25(2), 115139.

Holland, John H. (2006). Studying Complex Adaptive Systems. Journal of Systems Science and Complexity, 19, 1-8.

Holling, C.S. (2001). Understanding the Complexity of Economic, Ecological, and Social Systems. Ecosystems, 4, 390-405.

Hornborg, Alf. (1998). Towards an Ecological Theory of Unequal Exchange: Articulating World System Theory and Ecological Economics. Ecological Economics, 25, 127-136. Houghton, L., and P. W. J. Ledington. (2002). The Evolution of Confusion: Soft Systems Methodology and Social Theory Revisited. Australasion Journal of Information Systems, $9(2), 75-83$. 
Hoverstadt, Patrick. “The Viable System Model.” Systems Approaches to Managing Change: A Practical Guide. Ed. Martin Reynolds and Sue Holwell. London: Springer, 2010. 87133.

Jackson, Michael C. (2003). Systems Thinking: Creative Holism for Managers. West Sussex, England: John Wiley and Sons, Ltd.

Jackson, Michael C. (2010). Reflections on the Development and Contribution of Critical Systems Thinking and Practice. Systems Research and Behavioral Science, 27, 133-139.

Jackson, Mike C. “Question on SODA.” Message to the author. 26 Jul. 2016. Email. Jin, Dengjian, and Kingsley E. Haynes. (1997). Economic Transition at the Edge of Order and Chaos: China’s Dualist and Leading Sectoral Approach. Journal of Economic Issues, 31(1), 79-101.

Jonas, Hans. (1965). Spinoza and the Theory of Organism. Journal of the History of Philosophy, 3(1), 43-57.

Karcanias, N., and S. Vasileiadou. (2007). Systems and their Origins in Ancient Greece. Proceedings of the European Control Conference 2007 - Kos, Greece.

Kauffman, Stuart A. (1991). Antichaos and Adaptation. Scientific American, 265(2), 78-84.

Kay, James K., Henry A. Regier, Michelle Boyle, and George Francis. (1999). An Ecosystem Approach for Sustainability: Addressing the Challenge of Complexity. Futures, 31, $721-742$.

Keane, Robert E., Paul F. Hessburg, Peter B. Landres, et al. (2009). The Use of Historical Range and Variability (HRV) in Landscape Management. Forest Ecology and Management, 258, 1025-1037. 
Keele, Denise M., Robert W. Malmsheimer, Donald W. Floyd, et al. (2006). Forest Service Land Management Litigation. Journal of Forestry, June, 196-202.

Kim, Jihyun, Tae-Seop Lim, Kathryn Dindia, and Nancy Burrell. (2010). Reframing the Cultural Differences between the East and the West. Communication Studies, 61(5), 543-566.

Kineman, John J., and Deepak Anand. (2015). Roots of Sustainability in Ancient India. Proceedings of the $58^{\text {th }}$ Annual Meeting of the ISS - 2014 United States.

Kineman, John J., and Anil Kumar. (2007). Primary Natural Relationship: Bateson, Rosen, and the Vedas. Kybernetes, 36(7/8), 1055-1069.

Kitano, Hiroaki. (2002). Systems Biology: A Brief Overview. Science, 295, 1662-1664.

Kornstein, Martin. Systems Explication Framework: A Case Study in Paper Recycling. Diss. University of Pennsylvania, 1996. Ann Arbor: UMI.

Lane, David C., and Rogelio Oliva. (1998). The Greater Whole: Towards a Synthesis of System Dynamics and Soft Systems Methodology. European Journal of Operational Research, 107, 214-235.

Lansing, J. Stephen. (2003). Complex Adaptive Systems. Annual Review of Anthropology, 32, 183-204.

Levin, Simon A. (1998). Ecosystems and the Biosphere as Complex Adaptive Systems. Ecosystems, 1, 431-436.

Levin, Simon A. (2002). Complex Adaptive Systems: Exploring the Known, the Unknown and the Unknowable. Bulletin of the American Mathematical Society, 40(1), 3-19.

Levin, Simon A. (2005). Self-Organization and the Emergence of Complexity in Ecological Systems. BioScience, 55(12), 1075-1079. 
Lim, Tae-Seop, Sang-Yeon Kim, and Jihyun Kim. (2011). Holism: A Missing Link in Individualism-Collectivism Research. Journal of Intercultural Communication Research, 40(1), 21-38.

Liu, Jianguo, Thomas Dietz, Stephen R. Carpenter, et al. (2007). Complexity of Coupled Human and Natural Systems. Science, 317(5844), 1513-1516.

Liu, Jianguo, Harold Mooney, Vanessa Hull, et al. (2015). Systems Integration for Global Sustainability. Science, 347(6225).

Long, James N. (2009). Emulating Natural Disturbance Regimes as a Basis for Forest Management: A North American View. Forest Ecology and Management, 257, 18681873.

Ma, Shu-Yun. (2007). Political Science at the Edge of Chaos? Paradigmatic Implications of Historical Institutionalism. International Political Science Review, 28(1), 57-78.

Macal, Charles M., and Michael J. North. (2007). Agent-Based Modeling and Simulation: Desktop ABMS. Proceedings of the 2007 Winter Simulation Conference.

Macy, Michael W., and Robert Willer. (2002). From Factors to Actors: Computational Sociology and Agent-Based Modeling. Annual Review of Sociology, 28, 143-166.

Maynard Smith, J. (1974). The Theory of Games and Evolution of Animal Conflicts. Journal of Theoretical Biology, 47, 209-221.

Melamed, Yitzhak K. (2013). Spinoza's Metaphysics: Substance and Thought. New York: Oxford University Press.

Midgley, Gerald, Robert Y. Cavana, John Brocklesby, et al. (2013). Towards a New Framework for Evaluating Systemic Problem Structuring Methods. European Journal of Operational Research, 229, 143-154. 
Mitchell, Melanie, James P. Crutchfield, and Peter T. Hraber. "Dynamics, Computation, and the 'Edges of Chaos': A Re-Examination.” Complexity: Metaphors, Models, and Reality. Ed. Cowan, G., D. Pines and D. Melzner. Reading, MA: Addison-Wesley, 1994.

Meadows, Donella H. (2008). Thinking in Systems: A Primer. Ed. Diana Wright. London and Sterling, VA: Earthscan.

Meadows, Donella H., Dennis L. Meadows, Jorgen Randers, and William W. Behrens III. (1972). Limits to Growth. New York: Universe Books.

Miller, John P. (2008). The Holistic Curriculum, $2^{\text {nd }}$ Edition. Toronto: University of Toronto Press.

Mingers, J. (2004). Real-izing Information Systems: Critical Realism as an Underpinning Philosophy for Information Systems. Information and Organization, 14, 87-103.

Mingers, John, and Leroy White. (2010). A Review of the Recent Contribution of Systems Thinking to Operational Research and Management Science. European Journal of Operational Research, 207, 1147-1161.

Mobus, George E., and Michael C. Kalton. (2015). Principles of Systems Science. New York: Springer.

Morecroft, John. “System Dynamics.” Systems Approaches to Managing Change: A Practical Guide. Ed. Martin Reynolds and Sue Holwell. London: Springer, 2010. 243-292.

Naveh, Zev. (2000). What is Holistic Landscape Ecology? A Conceptual Introduction. Landscape and Urban Planning, 50, 7-26.

North, Malcolm P., and William S. Keeton. (2008). Emulating Natural Disturbance Regimes: an Emerging Approach for Sustainable Forest Management. Patterns and Processes in Forest Landscapes, 341-372. 
Norton, Bryan G. (2015). Sustainable Values, Sustainable Change: A Guide to Environmental Decision Making. Chicago and London: The University of Chicago Press.

Norton, Bryan G. (2005). Sustainability: A Philosophy of Adaptive Ecosystem Management. Chicago: The University of Chicago Press.

Norton, Bryan G. (1990). Context and Hierarchy in Aldo Leopold's Theory of Environmental Management. Ecological Economics, 2, 119-127.

Nowak, Martin A. (2006). Five Rules for the Evolution of Cooperation. Science, 314(5805), $1560-1563$

Pattee, Howard H. "The Physical Basis and Origin of Hierarchical Control." Hierarchy Theory: the Challenge of Complex Systems. Ed. Howard H. Pattee. New York: George Braziller, Inc., 1973. 71-108.

Pattee, Howard H, Herbert A. Simon, Clifford Grobstein, et al. Hierarchy Theory: the Challenge of Complex Systems. Ed. Howard H. Pattee. New York: George Braziller, Inc., 1973. $71-108$.

"Petrarch.” Wikipedia: The Free Encyclopedia. Wikimedia Foundation, Inc. 25 June 2016. Web. 22 June 2016.

Pickering, Andrew. (2002). Cybernetics and the Mangle: Ashby, Beer, and Pask. Social Studies of Science, 32(3), 413-437.

Preece, Gary, Dyuncan Shaw, and Haruo Hayashi. (2013). Using the Viable System Model (VSM) to Structure Information Processing Complexity in Disaster Response. European Journal of Operational Research, 224, 209-218. 
Pullium, Ronald, and Nick M. Haddad. (1994). Address of the Past President: Human Population Growth and the Carrying Capacity Concept. Bulletin of the Ecological Society of America, 75(3), 141-157.

Railsback, Steven F., and Volker Grimm. (2012). Agent-Based and Individual-Based Modeling: A Practical Introduction. Princeton: Princeton University Press.

Rammel, Christian, Sigrid Stagl, and Harald Wilfing. (2007). Managing Complex Adaptive Systems - A Co-Evolutionary Perspective on Natural Resource Management. Ecological Economics, 63, 9-21.

Reynolds, Martin. "IP and SAST.” Message to the author. 2 Aug. 2016. Email.

Reynolds, Martin, and Sue Holwell. (2010). Systems Approaches to Managing Change: A Practical Guide. London: Springer.

Rhee, Yong Pil. (1997). Synthetic Systems Theory: Linkage between Western Theory of Physics and Eastern Thought. Journal of Systems Research and Behavioral Science, 14(3), 211-219.

Rittel, Horst W. J., and Melvin M. Webber. (1973). Dilemmas in a General Theory of Planning. Policy Sciences, 4, 155-169.

Sachs, Joel L., Ulrich G. Mueller, Thomas P. Wilcox, and James J. Bull. (2004). The Evolution of Cooperation. The Quarterly Review of Biology, 79 (2), 135-160.

Scheffer, Marten, Jordi Bascompte, William A. Brock, et al. (2009). Early Warning Signals for Critical Transitions. Nature, 461, 53-59.

Schneider, Eric D., and James J. Kay. (1994). Complexity and Thermodynamics: Towards a New Ecology. Futures, 26(6), 626-647. 
Schoennagel, Tania, Thomas T. Veblen, and William H. Romme. (2004). The Interaction of Fire, Fuels, and Climate Across Rocky Mountain Forests. BioScience, 54(7), 661-676. Schultz, Majken, and Mary Jo Hatch. (1996). Living with Multiple Paradigms: The Case of Paradigm Interplay in Organizational Culture Studies. The Academy of Management Review, 21(2), 529-557.

Simon, Herbert A. "The Organization of Complex Systems." Hierarchy Theory: the Challenge of Complex Systems. Ed. Howard H. Pattee. New York: George Braziller, Inc., 1973. 128.

Solé, Ricard V., Susanna C. Manrubia, Michael Benton, et al. (1999). Criticality and Scaling in Evolutionary Ecology. Trends in Ecology and Evolution, 14(4), 156-160.

Sterman, John D. (2000). Business Dynamics: Systems Thinking and Modeling for a Complex World. Boston: Irwin McGraw-Hill.

Stock, Barbara. (2000). Spinoza on the Immortality of the Mind. History of Philosophy Quarterly, 17(4), 381-403.

Stock, Molly W., and H. Michael Rauscher. (1996). Artificial Intelligence and Decision Support in Natural Resource Management. New Zealand Journal of Forestry Science, 26(1/2), 145-157.

Tao, Julia, and Andrew Brennan. (2003). Confucian and Liberal Ethics for Public Policy: Holistic or Atomistic? Journal of Social Philosophy, 34(4), 572-589.

Tucker, Mary Evelyn. (1991). The Relevance of Chinese Neo-Confucianism for the Reverence of Nature. Environmental History Review, 15(2), 55-69.

Ulrich, W. (2003). Beyond Methodology Choice: Critical Systems Thinking as Critically Systemic Discourse. The Journal of Operational Research Society, 4, 325-342. 
Ulrich, W. (1996). A Primer to Critical System Heuristics for Action Researchers. Hull, UK: University of Hull, Centre for Systems Studies.

Ulrich, Werner. "Boundary Critique.” The Informed Student Guide to Management Science. Ed. H. G. Daellenback and R. L. Flood. London: Thompson Learning, 2002.

Ulrich, Werner, and Martin Reynolds. "Critical Systems Heuristics.” Systems Approaches to Managing Change: A Practical Guide. Ed. Martin Reynolds and Sue Holwell. London: Springer, 2010. 243-292.

Umpleby, Stuart A. (2009). Ross Ashby’s General Theory of Adaptive Systems. International Journal of General Systems, 38(2), 231-238.

Upadhyay, Ranjit Kumar. (2009). Dynamics of an Ecological Model Living on the Edge of Chaos. Applied Mathematics and Computation, 210, 455-464.

Warren, William A. (2005). Hierarchy Theory in Sociology, Ecology, and Resource Management: A Conceptual Model for Natural Resource or Environmental Sociology and Socioecological Systems. Society and Natural Resources, 18, 447-466.

Westerling, A.L., H.G. Hidalgo, D.R. Cayan, et al. (2006). Warming and Earlier Spring Increase Western U.S. Forest Wildfire Activity. Science, 313, 940-943.

White, Morton. (2002). A Philosophy of Culture: The Scope of Holistic Pragmatism. Princeton: Princeton University Press.

Wilby, Jennifer. (1994). A Critique of Hierarchy Theory. Systems Practice, 7(6), 653-670.

Williams, Bob, and Iraj Imam. (2006). Systems Concepts in Evaluation: An Expert Anthology. American Evaluation Assocation.

Zeeman, E.C. (1976). Catastrophe Theory. Scientific American, 234(4), 65-82.

Zwick, Martin. (2014). Elements and Relations. Portland: Portland State University. 